\title{
Suplemento
}

\section{Diretrizes da Federação Mundial das Sociedades de Psiquiatria Biológica para o Tratamento}

Biológico da Esquizofrenia Parte 1: Tratamento agudo

World Federation of Societies of Biological Psychiatry (WFSBP) Guidelines for Biological Treatment of Schizophrenia

Part 1: Acute treatment

\author{
Peter FALKai ${ }^{1}$ \\ ThOMAS WOBROCK ${ }^{1}$ \\ JEFFREY LIEBERMAN ${ }^{2}$ \\ BirTe GLENTHOJ ${ }^{3}$ \\ WAGNER F. GATTAZ ${ }^{4}$ \\ HANS-JÜRGEN MÖLLER ${ }^{5}$ \\ E ForÇa-TAREFA DA WFSBP PARA \\ DIRETRIZES PARA O TRATAMENTO \\ BIOLÓGICO DA ESQUIZOFRENIA*
}

\begin{abstract}
Resumo
Estas diretrizes para o tratamento biológico da esquizofrenia foram desenvolvidas pela Força-Tarefa da Federação Mundial das Sociedades de Psiquiatria Biológica (World Federation of Societies of Biological Psychiatry, WFSBP). A meta fixada durante o desenvolvimento destas diretrizes foi rever sistematicamente todas as evidências disponíveis referentes ao tratamento da esquizofrenia, tanto no âmbito clínico como científico, e chegar a um consenso sobre as principais recomendações para a prática psiquiátrica. Estas diretrizes são destinadas a todos os médicos que atendem e tratam de pacientes portadores de esquizofrenia. Os dados usados para desenvolver estas diretrizes foram extraídos primariamente de vários painéis e diretrizes nacionais de tratamento para esquizofrenia, assim como de metanálises, revisões e estudos clínicos randomizados sobre a eficácia do tratamento farmacológico e de outras intervenções terapêuticas biológicas, identificadas por uma busca nas bases de dados MedLine e Biblioteca Cochrane. A literatura identificada foi avaliada no que diz respeito à solidez das evidências a favor da eficácia de uma dada intervenção e,
\end{abstract}

1 Departamento de Psiquiatria e Psicoterapia, Universidade de Saarland, Homburg/Saar, Alemanha. 2 Departamento de Psiquiatria, College of Physicians and Surgeons, Universidade de Columbia, New York State Psychiatric Institute, Lieber Center for Schizophrenia Research, Nova York, Estados Unidos.

3 Departamento de Psiquiatria, Universidade de Copenhagen, Bispebjerg Hospital, Dinamarca. 4 Departamento de Psiquiatria, Universidade de São Paulo, Brasil.

5 Departamento de Psiquiatria e Psicoterapia, Universidade Ludwig-Maximilians, Munique, Alemanha.

* A. Carlo Altamura (Itália), Nancy Andreasen (Estados Unidos), Thomas R. E. Barnes (Reino Unido), Helmut Beckmann (Alemanha), Jorge Ciprian-Ollivier (Argentina), Tim Crow (Reino Unido), Anthony David (Reino Unido), Michael Davidson (Israel), Bill Deakin (Reino Unido), Helio Elkis (Brasil), Lars Farde (Suécia), Wolfgang Gaebel (Alemanha), Bernd Gallhofer (Alemanha), Jes Gerlach (Dinamarca), Steven Richard Hirsch (Reino Unido), Carlos R. Hojaij (Austrália), Assen Jablensky (Austrália), John Kane (Estados Unidos), Takuja Kojima (Japão), Lars von Knorring (Suécia), Patrick McGorry (Austrália), Herbert Meltzer (Estados Unidos), Driss Moussaoui (Marrocos), Franz Müller-Spahn (Suíça), Jean-Pierre Olie (Franca), A. Pacheco Palha (Portugal), Mitsumoto Sato (Japão), Heinrich Sauer (Alemanha), Nina Schooler (Estados Unidos), Daniel Weinberger (Estados Unidos), Shigeto Yamawaki (Japão).

Endereço para correspondência: Dr. Thomas Wobrock, Department of Psychiatry and Psychotherapy, University of Saarland, Kirrberger Strasse, D-66421 Homburg/Saar, Germany. Tel.: 49-6841-1624216.

Fax: 49-6841-1624270. E-mail: thomas.wobrock@unikliniksaarland.de 
então, categorizada em quatro níveis de evidências (de A a D). A primeira parte das diretrizes abrange a definição da doença, sua classificação, a epidemiologia e o curso da esquizofrenia, assim como o manejo terapêutico de fase aguda. Estas diretrizes são primariamente relacionadas ao tratamento biológico de adultos esquizofrênicos, incluindo medicação antipsicótica, outras opções de tratamento farmacológico, terapia eletroconvulsiva, estratégias terapêuticas recentes e complementares.

Palavras-chave: Esquizofrenia, Tratamento da fase aguda, Medicina baseada em evidências, Diretrizes práticas, Tratamento biológico, Antipsicóticos.

\section{Abstract}

These guidelines for the biological treatment of schizophrenia were developed by an international Task Force of the World Federation of Societies of Biological Psychiatry (WFSBP). The goal during the development of these guidelines was to review systematically all available evidence pertaining to the treatment of schizophrenia, and to reach a consensus on a series of practice

\section{Resumo das recomendações}

\section{Recomendações gerais}

O tratamento específico está indicado para pacientes que preenchem critérios diagnósticos para esquizofrenia, episódio esquizofrênico ou sintomas psicóticos relacionados ao transtorno esquizofrênico. Deve-se realizar regularmente uma avaliação da saúde física e mental para estabelecer as condições comórbidas relevantes (médicas e psiquiátricas), as circunstâncias psicossociais e os aspectos da qualidade de vida. Quando uma pessoa apresenta sintomas psicóticos pela primeira vez, uma avaliação diagnóstica cuidadosa deve ser realizada, incluindo investigação laboratorial e técnicas de imagem (tomografia computadorizada ou ressonância magnética de crânio) a fim de se excluir doença cerebral orgânica. Após a formulação diagnóstica inicial e o estabelecimento de uma aliança terapêutica, um plano de tratamento deve ser formulado e implementado. Essa formulação envolve a seleção das modalidades terapêuticas, do(s) tipo(s) específico(s) de tratamento e do contexto de tratamento. A reavaliação periódica do diagnóstico e do plano de tratamento é essencial. Recomenda-se o envolvimento da família e de outras pessoas importantes no suporte ao paciente, desde que com a permissão deste.

As metas e estratégias de tratamento variam de acordo com a fase e a severidade da doença. A fase aguda do tratamento, que dura de algumas semanas a poucos meses, é definida pela ocorrência de um episódio psicótico agudo. As metas principais são: desenvolver recommendations that are clinically and scientifically meaningful based on the available evidence. These guidelines are intended for use by all physicians seeing and treating people with schizophrenia. The data used for developing these guidelines have been extracted primarily from various national treatment guidelines and panels for schizophrenia, as well as from meta-analyses, reviews and randomised clinical trials on the efficacy of pharmacological and other biological treatment interventions identified by a search of the MEDLINE database and Cochrane Library. The identified literature was evaluated with respect to the strength of evidence for its efficacy and then categorised into four levels of evidence (A/D). This first part of the guidelines covers disease definition, classification, epidemiology and course of schizophrenia, as well as the management of the acute phase treatment. These guidelines are primarily concerned with the biological treatment (including antipsychotic medication, other pharmacological treatment options, electroconvulsive therapy, adjunctive and novel therapeutic strategies) of adults suffering from schizophrenia.

Key-words: Schizophrenia, Acute phase treatment, Evidencebased medicine, Practice guidelines, Biological treatment, Antipsychotics.

um acordo com o paciente e sua família, prevenir danos, controlar o comportamento anormal, reduzir a gravidade da psicose e dos sintomas associados (agitação, agressão, sintomas negativos, sintomas afetivos), determinar e dar atenção aos fatores que levaram à ocorrência do episódio agudo e proporcionar um retorno rápido ao melhor nível de funcionamento pré-mórbido. Atenção especial deve ser dada à presença de ideação, intenção ou planejamento suicida e à presença de alucinações imperativas. $\mathrm{O}$ paciente deve receber informação sobre a natureza e o manejo terapêutico da doença, inclusive sobre os benefícios e efeitos colaterais dos medicamentos, considerando a capacidade do próprio paciente de assimilar a informação. Na fase aguda do tratamento, são enfatizadas principalmente as intervenções farmacológicas (e outras somáticas). Portanto, terapia antipsicótica deve ser iniciada como parte necessária de um pacote abrangente de cuidados que atende a necessidades clínicas, emocionais e sociais do indivíduo.

\section{Recomendações específicas de tratamento}

Num primeiro episódio psicótico, o tratamento farmacológico deve ser introduzido com cautela pelo maior risco de desenvolvimento de sintomas extrapiramidais (SEP). Recomenda-se a introdução da medicação antipsicótica em baixas doses, seguida de ajuste gradual, sempre com cuidadosa explicação ao paciente. Como primeira escolha, devem ser utilizados preferencialmente os antipsicóticas de segunda geração (ASGs). Alternativamente, recomenda-se o uso de antipsicóticos de primeira geração (APGs) no limite inferior da faixa terapêutica. Essa recomendação é baseada principalmente na melhor tolerabilidade e no risco reduzido de discinesia tardia 
dos antipsicóticos atípicos. Durante o período de latência para o efeito antipsicótico das medicações, deve-se disponibilizar atendimento de enfermagem especializado e ambiente seguro e suportivo, além de possibilitar a administração de doses flexíveis de benzodiazepínicos. Essas medidas complementares são necessárias para aliviar o sofrimento, a insônia e os distúrbios comportamentais secundários à psicose.

Nos casos de esquizofrenia que cursam com episódios múltiplos, os fatores contribuintes mais comuns para recidiva dos sintomas são: a não-aderência ao uso da medicação antipsicótica, o abuso de substâncias e os eventos estressantes da vida. Todavia, as recidivas também podem ocorrer no curso natural da doença, mesmo com o tratamento contínuo. Se houver suspeita de não-aderência, recomenda-se avaliar os seus motivos e incluí-los no plano de tratamento. O tratamento farmacológico deve ser iniciado prontamente, pois as exacerbações psicóticas agudas estão associadas ao grande sofrimento emocional e à possibilidade substancial de comportamentos de risco. Em razão das vantagens dos ASGs, esses antipsicóticos geralmente são preferíveis, embora, em princípio, todos os antipsicóticos possam ser indicados no tratamento da esquizofrenia aguda. A seleção de uma medicação antipsicótica é guiada pela experiência prévia, considerando a resposta terapêutica em relação aos efeitos colaterais relatados pelo paciente. Devem-se considerar ainda: a via de administração planejada, as preferências do paciente por determinada medicação, a presença de condições médicas comórbidas e o potencial de interações com outras medicações prescritas. A dose do antipsicótico pode ser titulada de acordo com sua tolerabilidade, objetivando alcançar rapidamente a faixa terapêutica (por exemplo, para os APGs, entre 300 e $1.000 \mathrm{mg}$ em equivalentes de clorpromazina). Nesse ínterim, deve-se monitorizar o estado clínico do paciente. Para reduzir o risco de efeitos colaterais extrapiramidais, recomenda-se o emprego de doses tão baixas quanto possível, especialmente quando se optar pelo uso de APGs. O uso de doses altas de ataque, bem como a elevação rápida da dosagem e o tratamento com doses supraterapêuticas, não tem demonstrado eficácia superior às doses terapêuticas baixas, mas tem sido associado à maior incidência e intensidade de efeitos adversos. Em situações de emergência, como nos casos de pacientes gravemente agitados, há evidências a favor da combinação de benzodiazepínicos e antipsicóticos.

$\mathrm{Na}$ avaliação de esquizofrenia resistente ao tratamento (ERT), ou nos casos de resposta parcial, a avaliação multidimensional deve considerar a persistência de sintomas positivos e negativos, a gravidade da disfunção cognitiva, assim como os comportamentos bizarros, os sintomas afetivos recorrentes, os déficits funcionais vocacionais e sociais e a má qualidade de vida. Os sintomas-alvo devem ser definidos precisamente. Deve-se estabelecer se a resposta terapêutica foi insuficiente a despeito de um tratamento adequado, isto é, com base no emprego alternativo de pelo menos dois antipsicóticos (um dos quais deve ser atípico), administrados nas doses recomendadas por pelo menos 6 a 8 semanas. A aderência ao tratamento deve ser verificada, se necessário, pela determinação das concentrações dos medicamentos.

Em indivíduos com ERT bem definida, a clozapina é o antipsicótico de escolha, uma vez que há evidências de sua superioridade em relação aos demais antipsicóti$\cos$. Em caso de não-resposta à clozapina, recomendamse como alternativas terapêuticas: a substituição por outro ASG, a adoção de estratégias de potencialização com antidepressivos ou estabilizadores do humor, a combinação de antipsicóticos (há evidências limitadas para a associação de risperidona ou sulpirida à clozapina) e, como última opção de tratamento, eletroconvulsoterapia (ECT). Para os pacientes que se apresentam com manifestações catatônicas, a opção pela ECT pode ser feita mais precocemente, na ausência de resposta aos benzodiazepínicos.

A abordagem dos sintomas negativos começa com uma avaliação das condições capazes de provocar uma síndrome negativa secundária. $\mathrm{O}$ tratamento de tais sintomas negativos secundários baseia-se na remoção de sua causa (como os próprios antipsicóticos utilizados para tratar os sintomas positivos primários ou os antidepressivos e ansiolíticos utilizados no tratamento dos estados depressivos e ansiosos comórbidos), no emprego de agentes antiparkinsonianos, na redução da dose do antipsicótico ou na troca de um APG para um ASG. Para o tratamento de sintomas negativos primários, o emprego de um ASG é recomendado. Nessa estratégia, o maior nível de evidências aponta para a amisulpirida, mas ainda não foi claramente provado que essa medicação tenha maior eficácia.

Para pacientes que fazem uso de substâncias psicoativas, recomenda-se um tratamento abrangente integrado, no qual o mesmo clínico (ou equipe clínica) deve prestar assistência a ambas as condições. Há evidências limitadas de que os ASGs, especialmente a clozapina, mas também a risperidona e a olanzapina, sejam benéficos para pacientes com esse duplo diagnóstico, o que pode ser devido à menor incidência de SEP ou à diminuição do desejo pelas drogas de abuso.

Sintomas depressivos que ocorrem durante um episódio psicótico agudo usualmente melhoram à medida que os pacientes se recuperam da psicose. Há também evidências de que os sintomas depressivos melhoram em decorrência do tratamento antipsicótico, com estudos comparativos sugerindo maior eficácia dos ASGs em comparação aos APGs. Os antidepressivos podem ser adicionados como tratamento complementar aos antipsicóticos quando o paciente preencher adicionalmente os critérios diagnósticos para um episódio depressivo maior.

Há evidências de que tanto as medicações antipsicóticas de primeira como as de segunda geração podem reduzir o risco de suicídio. Em vários estudos, a clozapina se mostrou associada a uma redução mais consistente das 
taxas de suicídio e de comportamentos suicidas persistentes. Estratégias terapêuticas adicionais para condições comórbidas médicas e psiquiátricas são amplamente discutidas no texto integral destas diretrizes.

\section{Esquizofrenia}

INTRODUÇÃ̃o

A esquizofrenia é um transtorno psicótico maior (ou um grupo de transtornos) que usualmente aparece na fase mais tardia da adolescência ou no início da idade adulta. Apesar das técnicas modernas de tratamento, a esquizofrenia ainda representa uma enorme sobrecarga para os pacientes e seus familiares. Na maioria dos casos, há prejuízo das funções ocupacionais ou sociais, caracterizado por afastamento social, perda de interesse ou capacidade de agir na escola ou no trabalho, mudança nos hábitos de higiene pessoal ou comportamento incomum ainda na fase prodrômica (Loebel et al., 1992; Häfner e Van der Heiden, 2003).

A esquizofrenia apresenta sintomas diferentes em múltiplos domínios, de forma muito heterogênea em diferentes indivíduos e também variabilidade nos mesmos indivíduos ao longo do tempo. Pela observação sistemática da psicopatologia, fenômenos positivos e negativos podem ser separados (Andreasen, 1982; Crow, 1985). Os sintomas positivos, de maneira abrangente, incluem delírios e ideação delirante, alucinações, distúrbios das associações, sintomas catatônicos, agitação, vivências de influência externa e desconfiança. Os sintomas negativos referem-se ao estreitamento e à redução das expressões emocionais, com diminuição da produtividade do pensamento e da fala, retraimento social e diminuição dos comportamentos direcionados a metas. Portanto, os componentes negativos poderiam ser definidos como monotonia afetiva, alogia, anedonia e avolição. Como uma terceira categoria, os sintomas desorganizados incluem desorganização do pensamento e do comportamento associada ao comprometimento da atenção.

Os critérios diagnósticos atualmente utilizados para classificação da esquizofrenia (DSM-IV e CID-10) a definem como uma categoria distinta. $O$ diagnóstico de esquizofrenia depende da exclusão de doença cerebral orgânica e da ocorrência de um conjunto de sintomas característicos (ou pelo menos um sintoma nuclear), que devem estar presentes durante a maior parte do tempo no último mês ou por um período menor se o quadro foi tratado com sucesso, de acordo com a CID-10, ou por pelo menos 6 meses, segundo os critérios do DSM-IV (Quadro 1).

De acordo com o DSM-IV ou a CID-10, os subtipos de esquizofrenia são definidos por seus sintomas predominantes. Esses subtipos incluem: (1) o subtipo hebefrênico, no qual afeto embotado ou inapropriado é proeminente; (2) o subtipo catatônico, no qual auto-sintomas característicos (catatonia) são permanentes; (3) o subtipo desorganizado, no qual predominam discurso e comportamento desorganizados; (4) o subtipo paranóide, no qual estão presentes predominantemente ilusões ou alucinações auditivas; (5) o subtipo indiferenciado, que é uma categoria não-específica; (6) esquizofrenia simples, assim chamada por seu curso e sintomas negativos permanentes da doença. Os subtipos de esquizofrenia são listados no quadro 2.

Estas diretrizes e recomendações aplicam-se à esquizofrenia aguda e às fases de continuação e manutenção a partir do tratamento de fase aguda. As diretrizes podem ajudar os clínicos, os usuários do serviço e os provedores de cuidados a estar atentos para os diferentes tratamentos que se encontram disponíveis, podendo ainda ser úteis na tomada de decisão em relação a que tratamento deve ser aplicado visto já incluem os níveis de evidências disponíveis para cada tratamento. A primeira parte destas diretrizes abrange a epidemiologia, o curso e a etiologia da esquizofrenia, as propriedades farmacológicas, a classificação e os efeitos colaterais de agentes antipsicóticos e associações, além da avaliação antes do tratamento e durante ele e do manuseio do tratamento na fase aguda.

\section{EPIDEMIOLOGIA E CURSO DA ESOUIZOFRENIA}

Esquizofrenia é uma doença relativamente comum. Sua prevalência ao longo da vida é de aproximadamente 1 caso a cada 100 pessoas (1\%) na população geral, mas essa estimativa pode variar de acordo com a metodologia utilizada nos diferentes estudos. Utilizando critérios diagnósticos mais abrangentes ou restritivos, a incidência média da esquizofrenia relatada em estudos epidemiológicos pode variar entre 0,11 e 0,24 por 1.000 indivíduos (Jablensky et al., 1992). As taxas médias para homens e mulheres são aproximadamente similares, mas a idade média de início é cerca de 5 anos maior para as mulheres do que para os homens (Häfner e Van der Heiden, 2003).

$\mathrm{Na}$ maioria dos casos, o início dos sintomas esquizofrênicos, de acordo com os critérios diagnósticos, é precedido por um período prodrômico caracterizado por sinais iniciais de deficiência nas funções pessoais e sociais. A duração média da fase prodrômica é de 2 a 5 anos (Beiser et al., 1993; Häfner et al., 1993) e, frequientemente, não é reconhecida ou tratada, sendo, portanto, chamada de "duração da doença não-tratada" (duration of untreated illness, DUI). A fase prodrômica é seguida pelo início da esquizofrenia aguda, marcada por sintomas positivos característicos, como alucinações, delírios e distúrbios comportamentais. Na maior parte dos países industrializados, 1 a 2 anos se passam antes que um tratamento adequado seja iniciado (Johnstone et al., 1986; Häfner et al., 1993). O tempo desde a primeira ocorrência de sintomas psicóticos até o início do tratamento é definido como "duração de psicose não-tratada" (duration of untreated psychosis, DUP) (McGlashan e Johanessen, 1996). Pesquisas indicam que a demora para o acesso aos serviços de saúde e ao tratamento propriamente dito está associada 
Quadro 1. Critérios diagnósticos para esquizofrenia ou episódio esquizofrênico

CID-10

Sintomatologia característica:

1. Um mês ou mais, no qual uma parcela significativa do tempo é dominada por um sintoma inequívoco, ou dois sintomas menos

consistentes, tais como:

A. Eco de pensamento, inserção ou retirada de pensamento e transmissão de pensamento;

B. Delírios de controle, influência, ou passividade claramente referida a movimentos do corpo ou membros, ou pensamentos, ações ou sensações específicas; percepção delirante;

C. Alucinações auditivas que comentam o comportamento do paciente ou discutem com ele, ou outros tipos de alucinações auditivas que provêm de alguma parte do corpo;

D. Delírios persistentes de outros tipos, que são culturalmente inapropriados e completamente impossíveis, tais como identidade religiosa ou política, ou poderes e habilidades super-humanas (como ser capaz de controlar o tempo ou estar em comunicação com alienígenas provenientes de um outro mundo);

Ou

2. Pelo menos dois dos seguintes:

E. Alucinações persistentes em qualquer modalidade quando acompanhadas por delírios fugazes ou pouco estruturados, sem conteúdo afetivo claro, ou por idéias supervalorizadas e persistentes, ou quando ocorrem todos os dias por semanas ou meses no final;

F. Interrupções ou interpolações no curso do pensamento, resultando em incoerência ou discurso irrelevante, ou neologismos;

G. Comportamento catatônico, tal como excitação, postura ou flexibilidade cerácea, negativismo, mutismo e estupor;

H. Sintomas "negativos" (tais como acentuada apatia, discurso exíguo e embotamento ou incongruência de respostas emocionais), usualmente resultando em afastamento social e redução do desempenho social; deve ficar claro que esses não são devidos à depressão ou ao uso de medicação neuroléptica;

$\mathrm{Ou}$

3.I. Uma alteração significativa e consistente na qualidade global de alguns aspectos do comportamento pessoal, manifestação de perda de interesse, falta de metas, indolência, atitude auto-absortiva e afastamento social.

Duração: Um sintoma de A-D ou dois de E-H presentes por 1 mês, ou I presente por mais de 1 ano (esquizofrenia simples).

\section{DSM-IV}

A. Sintomas característicos: Dois (ou mais) dos seguintes, cada um presente por um período significativo de tempo durante 1 mês (ou menos, se tratado de forma bem-sucedida):

1. Delírios;

2. Alucinações;

3. Discurso desorganizado (desagregação freqüente ou incoerência);

4. Comportamento muito grosseiramente desorganizado ou catatônico;

5. Sintomas negativos, isto é, monotonia afetiva, alogia ou avolição.

Nota: Apenas um sintoma do critério A é necessário se os delírios forem bizarros ou as alucinações consistirem de voz fazendo comentários simultâneos sobre o comportamento ou os pensamentos da pessoa, ou duas ou mais vozes conversando uma com a outra.

B. Funções sociais/ocupacionais:

Por uma parte significativa do tempo, desde o início do distúrbio, uma ou mais áreas funcionais maiores (tais como trabalho, relações interpessoais ou autocuidado) se encontram acentuadamente abaixo do nível atingido antes do início (ou, quando o início ocorre na infância ou na adolescência, incapacidade para alcançar o nível esperado de realização interpessoal, acadêmica ou ocupacional).

C. Sinais contínuos do distúrbio persistem por pelo menos 6 meses, período que deve incluir pelo menos 1 mês de sintomas (ou menos, se tratado de forma bem-sucedida) que preenchem o critério A (isto é, sintomas de fase ativa) e podem incluir períodos de sintomas prodrômicos ou residuais. Durante esses períodos prodrômicos ou residuais, os sinais do distúrbio podem ser manifestados apenas por sintomas negativos ou "reboque" ou mais sintomas listados no critério A presente de forma atenuada (como crenças estranhas, experiências perceptivas incomuns).

Exclusão: 0 diagnóstico não é estabelecido na presença de sintomas depressivos ou maníacos intensos a menos que esteja claro que os sintomas esquizofrênicos antecederam o distúrbio afetivo. 0 distúrbio não se deve a intoxicação por drogas, dependência ou retirada de drogas ou doença cerebral manifesta.

D. Exclusão de distúrbio esquizoafetivo e do humor: distúrbio esquizoafetivo e distúrbio do humor com características psicóticas foram afastados porque (1) nenhum episódio maior depressivo, maníaco, ou misto ocorreu simultaneamente aos sintomas da fase ativa ou, (2) se episódios referentes ao humor ocorreram durante os sintomas da fase ativa, sua duração total será breve em relação à duração dos períodos ativos e residuais.

E. Exclusão de condição médica geral ou relacionada a drogas: o distúrbio não é devido a efeitos fisiológicos diretos de uma droga (como uma droga de abuso, uma medicação) ou uma condição médica geral.

F. Relação com um distúrbio de desenvolvimento penetrante: se há uma história de autismo ou outro transtorno grave do desenvolvimento, o diagnóstico adicional de esquizofrenia é feito apenas se delírios proeminentes ou alucinações também estiverem presentes por pelo menos um mês (ou menos, se tratada de forma bem-sucedida). 


\begin{tabular}{l}
\hline Quadro 2. Subtipos de esquizofrenia \\
\hline CID-10 \\
F 20.0 Esquizofrenia paranóide \\
F 20.1 Esquizofrenia hebefrênica \\
F 20.2 Esquizofrenia catatônica \\
F 20.3 Esquizofrenia indiferenciada \\
F 20.4 Depressão pós-esquizofrênica \\
F 20.5 Esquizofrenia residual \\
F 20.6 Esquizofrenia simples \\
F 20.8 Outras esquizofrenias \\
F 20.9 Esquizofrenia não-especificada \\
DSM-IV \\
Esquizofrenia tipo paranóide \\
Esquizofrenia tipo catatônica \\
Esquizofrenia tipo desorganizada \\
Esquizofrenia tipo indiferenciada \\
Esquizofrenia tipo residual \\
\hline
\end{tabular}

à recuperação mais lenta ou incompleta (Loebel et al., 1992) e com risco aumentado de recidiva nos 2 anos subsequientes (Johnstone et al., 1996). A fase aguda se refere à presença de sintomas psicóticos floridos. Num certo número de casos, após a atenuação dos sintomas positivos, sintomas negativos similares aos manifestos no período prodrômico permanecem.

O curso e o padrão da esquizofrenia variam consideravelmente. Durante a fase de estabilização ou recuperação, os sintomas psicóticos diminuem de intensidade. O período de estabilização dura cerca de 6 meses, sendo seguido de uma fase estável. Na fase estável, sintomas negativos e residuais positivos que podem estar presentes são relativamente consistentes em gravidade e magnitude. Certo número de pacientes (aproximadamente 20\% a 30\%) não apresenta sintomas proeminentes após o primeiro episódio (Häfner e Van der Heiden, 2003). As exacerbações agudas podem interromper a fase estável e requerer tratamento adicional ou intervenções.

A avaliação neuropsicológica longitudinal mostrou que os pacientes com esquizofrenia têm disfunção cognitiva considerável nos primeiros 4 a 5 anos da doença. Após esse período, há poucas evidências de deterioração (Hoff et al., 1999). Aproximadamente 50\% dos pacientes com esquizofrenia tratados em serviços convencionais irão recidivar e necessitarão de readmissão nos primeiros 2 anos, chegando a até $80 \%$ de recidivas num período de 5 anos (Robinson et al., 1999); cerca de 10\% a $25 \%$ não terão admissões posteriores (Fenton $e t$ al., 1987; Hegarty et al., 1994). Anteriormente às recidivas, sinais de aviso freqüentemente aparecem, os quais usualmente consistem em sintomas não-psicóticos seguidos por distúrbios emocionais e sintomas psicóticos leves ao longo de um período de 4 a 12 semanas (Birchwood et al., 1989; Gaebel et al., 1993). Existem algumas evidências de que os sintomas negativos podem se tornar mais proeminentes em alguns indivíduos durante $o$ curso da doença (McGlashan e Fenton, 1993; Möller et al., 2002).

Fatores preditivos associados em geral à melhor evolução são: início mais tardio em relação às faixas etárias usuais, gênero feminino, estado marital correspondente a indivíduo casado, personalidade pré-mórbida sociável, bom ajuste e bom funcionamento pré-mórbido, quociente intelectual (QI) mais elevado, presença de um desencadeante na esfera emocional quando do início, início agudo, sintomas predominantemente afetivos ou sintomas positivos e ausência de desorganização ou sintomas negativos quando do início, menor número de episódios prévios, padrão por fases de episódios e remissões, ausência de história familiar de esquizofrenia e baixo nível de emoções expressas na família (Hegarty et al., 1994; Davidson e McGlashan, 1997; Bottlender et al., 2000, 2002 e 2003; Häfner e Van der Heiden, 2003).

Outros transtornos mentais comórbidos e condições médicas gerais são freqüentemente encontrados em pacientes com esquizofrenia. A elevada taxa de mortalidade observada em pacientes esquizofrênicos se devem principalmente ao elevado risco de suicídio, aos distúrbios cardiovasculares, às doenças respiratórias e infecciosas, aos acidentes e às injúrias traumáticas (Brown et al., 2000). Uma das condições comórbidas mais freqüentes é o abuso de drogas, que ocorre em $15 \%$ a $71 \%$ dos pacientes com esquizofrenia (Soyka et al., 1993; Kovasznay et al., 1997; Bersani et al., 2002). Fatores que influenciam o risco de abuso de substâncias estão associados ao meio ambiente social (pregresso e atual) e à personalidade pré-mórbida (Arndt et al., 1992) . Condições comórbidas podem piorar o curso e complicar o tratamento (Linszen et al., 1994).

ETIOLOGIA

Esquizofrenia é uma doença de etiologia complexa. Pesquisas têm procurado determinar o papel de variáveis biológicas específicas, tais como os fatores genéticos e bioquímicos e as alterações sutis na morfologia cerebral. De acordo com a hipótese do neurodesenvolvimento, a esquizofrenia aparece como resultado de um distúrbio do desenvolvimento cerebral durante os períodos pré e perinatal. Porém, a natureza precisa dessa alteração cerebral, bem como de sua patogênese, ainda não foi totalmente definida (Marenco e Weinberger, 2000). Os componentes genéticos poderiam explicar apenas metade do risco de desenvolver esquizofrenia, e as complicações pré ou perinatais são responsáveis por $1 \%$ a $2 \%$ desse risco (Gottesman e Bertelsen, 1989).

Portanto, o modelo mais bem-aceito da doença é o da "vulnerabilidade-estresse-superação" (Nuechterlein e Dawson, 1984). Esse conceito propõe que a vulnerabilidade resultará no desenvolvimento de sintomas quando estressores ambientais estiverem presentes e os mecanismos para lidar com eles falharem. Os fatores de vulnerabilidade, baseados em um componente biológico que inclui a predisposição genética, interagem com fatores complexos físicos, ambientais e psicológicos de 
vulnerabilidade. As teorias bioquímicas colocam em foco principalmente a "hipótese dopaminérgica".

A hipótese dopaminérgica sustenta a existência de uma produção aumentada desse neurotransmissor, ou uma hipersensibilidade dos receptores de dopamina, numa certa região cerebral (sistema mesolímbico), resultando em hiperexcitabilidade e aparecimento de sintomas positivos, e de um estado hipodopaminérgico em regiões cerebrais frontais, associado aos sintomas negativos (Sedvall e Farde, 1995). Essa hipótese tem como suporte o tratamento bem-sucedido dos sintomas psicóticos por agentes bloqueadores dos receptores D2 no sistema mesolímbico. Além da dopamina, outros neurotransmissores (como a serotonina e o glutamato) parecem estar envolvidos na fisiopatologia da esquizofrenia. Há ainda a hipótese de que o bloqueio dos receptores de serotonina 5-HT2A e o bloqueio preferencial de subtipos específicos de receptores da dopamina se constituem como um importante mecanismo para a eficácia dos antipsicóticos atípicos (ou de segunda geração) no tratamento dos sintomas negativos (Möller, 2003).

\section{Avaliação ANTES E DURANTE 0 TRATAMENTO}

Uma avaliação completa de saúde e das necessidades de cuidados sociais deve ser realizada regularmente, incluindo a avaliação do funcionamento social e da qualidade de vida. Cada paciente deve ter uma avaliação inicial cuidadosa, incluindo as histórias médicas psiquiátrica e geral completas. Além do exame físico e do estado mental, o exame neurológico deve ser realizado a fim de se excluir certas condições médicas gerais que podem contribuir para o aparecimento de sintomas psicóticos. Testes laboratoriais básicos devem ser realizados, incluindo hemograma, determinação dos eletrólitos, lípidios e glicose sangüíneos, testes das funções hepática, renal e tireoideana, além de sorologias para HIV, hepatite e sífilis, quando indicadas. O exame de triagem toxicológica na urina deve ser feito para avaliar o uso recente de drogas. Além de estabelecer os valores basais para a administração das medicações psicotrópicas, os exames laboratoriais contribuem para o rastreamento do diagnóstico de doenças que podem mimetizar a esquizofrenia, bem como de doenças comórbidas que podem requerer modificações no plano de tratamento. Também podem ser úteis para avaliar os níveis sangüíneos dos medicamentos antipsicóticos e estabelecer se o paciente vem usando sua medicação. Testes para avaliar outras necessidades médicas gerais dos pacientes devem ser considerados, como, por exemplo, a determinação da fração beta da gonadotrofina coriônica (beta-HCG) em mulheres em idade fértil.

Ressonância magnética (RM) ou tomografia computadorizada (TC) e eletroencefalograma (EEG) devem ser realizados em pacientes com um primeiro episódio esquizofrênico, ou na vigência de um quadro clínico atípico, ou ainda quando forem identificados achados anormais nos exames de rotina. Pacientes com doença cardíaca preexistente necessitam de monitoramento cuidadoso em relação às anormalidades do eletrocardiograma (ECG), levando em conta que certas medicações antipsicóticas podem ser cardiotóxicas, conhecimento que influencia na escolha da medicação. Testes neuropsicológicos, em geral, não são úteis para fazer um diagnóstico de esquizofrenia durante a fase aguda, mas são úteis após estabilização clínica para avaliar os déficits cognitivos associados, que podem afetar o plano de tratamento. Em situações especiais (como antes e após aplicação de ECT), a avaliação neuropsicológica pode ser necessária.

Deve-se prestar especial atenção à presença de ideação, intenção ou planejamento suicida, bem como à presença de alucinações de comando. Precauções devem ser tomadas quando houver qualquer dúvida a respeito da intenção do paciente de cometer suicídio, já que a ideação suicida é o melhor fator preditivo de tentativa subseqüente em pacientes esquizofrênicos (Meltzer et al., 2003). Avaliações similares são necessárias quando se considera a possibilidade de determinado paciente provocar dano a alguém ou se envolver em outras formas de violência (Buckley et al., 2003).

\section{CONSEQÜÊNCIAS ECONÔMICAS, SERVIÇOS DE SAÚDE E ESTIGMA}

A esquizofrenia representa uma sobrecarga enorme para os pacientes e seus familiares, além de reduzir a qualidade de vida, especialmente devido ao prejuízo acumulado. Estima-se que a esquizofrenia seja uma das trinta principais condições de incapacidade mais freqüentes em todo o mundo (Murray e Lopez, 1997). De $4 \%$ a $15 \%$ das pessoas que sofrem de esquizofrenia cometem suicídio, e o aumento da mortalidade entre esquizofrênicos está aproximadamente $50 \%$ acima daquela da população geral (Brown et al., 2000). O custo cumulativo do atendimento aos adultos com esquizofrenia é alto: cerca de $5 \%$ a $6 \%$ dos custos com pacientes internados no Serviço Nacional de Saúde na Inglaterra foram atribuídos à esquizofrenia (Knapp, 1997). Estima-se que a esquizofrenia seja responsável por 2,5\% dos gastos com atendimento anual à saúde nos Estados Unidos (Rupp e Keith, 1993). Após um segundo episódio psicótico, a taxa de desemprego entre pacientes com esquizofrenia é superior a $65 \%$, contribuindo para o alto custo indireto da doença (Guest e Cookson, 1999).

As pessoas com esquizofrenia são vítimas de estigmatização, e uma das principais metas das atividades das redes e das associações de saúde envolvidas com esquizofrenia é dar suporte aos programas contra estigmas (Gaebel e Baumann, 2003). Assim, é de grande importância desenvolver estratégias efetivas de tratamento, incluindo abordagens multidimensionais para reduzir a sobrecarga imposta pela doença.

\section{Meta e PÚBLICO-ALVO dAS DIRETRIZES dA WFSBP}

Estas diretrizes são destinadas ao uso na prática clínica por todos os médicos que investigam, diagnosticam e tratam de pacientes com esquizofrenia. Portanto, é aqui disponibilizada uma atualização do conhecimento 
contemporâneo de vários aspectos da esquizofrenia, com ênfase às opções de tratamento. $\mathrm{O}$ objetivo destas diretrizes é melhorar os padrões de cuidados, diminuir variações inaceitáveis no fornecimento de cuidados de saúde e na sua qualidade e dar suporte aos médicos nas decisões clínicas. Embora estas diretrizes favoreçam os tratamentos que tenham bases nas evidências disponíveis, o médico que trata permanece responsável por sua opção de avaliação e tratamento. Estas diretrizes são primariamente referentes ao tratamento biológico (somático) de adultos e dizem respeito a recomendações neste contexto. O objetivo específico destas diretrizes é avaliar o papel de agentes farmacológicos no tratamento e no manuseio da esquizofrenia, enquanto o papel das intervenções psicológicas específicas e dos sistemas de fornecimento de serviços específicos é abordado apenas brevemente. A efetividade do tratamento somático é considerada. As diretrizes foram desenvolvidas pelos autores, que a elas chegaram por meio de um consenso com a Força-Tarefa de Esquizofrenia da WFSBP, constituída por 37 especialistas internacionais nesta área.

\section{Métodos de pesquisa da literatura e extração de dados}

No desenvolvimento deste trabalho, foram consideradas as seguintes diretrizes, relatos de consenso e fontes:

- American Psychiatric Association. Practice guideline for the treatment of patients with schizophrenia (APA, 1997). American Psychiatric Association. Practice guideline for the treatment of patients with schizophrenia, 2.ed. (APA, 2004);

- Deutsche Gesellschaft für Psychiatrie, Psychotherapie und Nervenheilkunde. Praxisleitlinien Psychiatrie und Psychotherapie: Schizophrenie (DGPPN, 1998). Guidelines for Neuroleptic Relapse Prevention in Schizophrenia (Kissling, 1991);

- National Institute for Clinical Excellence. Core Interventions in the Treatment of Schizophrenia London (NICE, 2003). National Institute for Clinical Excellence. Guidance on the use of newer (atypical) antipsychotic drugs for the treatment of schizophrenia (NICE, 2002);

- Royal Australian and New Zealand College of Psychiatrists. Australian and New Zealand clinical practice guideline for the treatment of schizophrenia, Draft only (RANZCP, 2003). Summary Australian and New Zealand clinical practice guideline for the treatment of schizophrenia (McGorry et al., 2003);

- Scottish Intercollegiate Guidelines Network. Psychosocial Interventions in the Management of Schizophrenia (SIGN, 1998);

- Task Force of the World Psychiatric Association. The Usefulness and Use of Second-Generation Antipsychotic Medications an Update (Sartorius et al., 2002);

- The Expert Consensus Guideline Series. Optimizing Pharmacologic Treatment of Psychotic Disorders (Kane et al., 2003);
- The Mount Sinai conference on the pharmacotherapy of schizophrenia (Marder et al., 2002);

- $\quad$ The Texas Medication Algorithm Project (TMAP) schizophrenia algorithms (Miller et al., 1999);

- Translating research into practice: the Schizophrenia Patient Outcomes Research Team (PORT) treatment recommendations (Lehman et al., 1998);

- World Health Organization. WHO Guide to Mental Health in Primary Care (WHO, 2000);

- The Cochrane Library. Meta-analyses on the efficacy of different drugs and interventions used in schizophrenia.

Revisões, metanálises e estudos clínicos randomizados sobre intervenções em pacientes esquizofrênicos foram identificados por busca na base de dados do MedLine (até fevereiro de 2004) e por meio da experiência clínica individual dos autores e dos membros da Força-Tarefa da WFSBP sobre esquizofrenia.

ClasSIFICAÇõES DAS RECOMENDAÇÕES BASEADAS EM EVIDÊNCIAS

As evidências encontradas por meio de busca na literatura e da extração de dados foram resumidas e categorizadas a fim de refletir sua suscetibilidade a vieses (Shekelle, 1999). Os custos do tratamento diário não foram levados em consideração em razão da variabilidade dos custos da medicação em todo o mundo. Cada recomendação de tratamento foi avaliada e discutida quanto à força das evidências em relação à sua eficácia, segurança, tolerabilidade e exeqüibilidade. Deve-se ter em mente que a força da recomendação é decorrente do nível de eficácia e não necessariamente de sua importância. Quatro categorias foram usadas para determinar a hierarquia das recomendações (relacionadas ao nível descrito de evidências):

- Nivel A. Há boas evidências baseadas em pesquisa que dão suporte a esta recomendação. As evidências foram obtidas a partir de pelo menos três estudos controlados, randomizados e duplocegos (ECRs), razoavelmente amplos e positivos. Além disso, pelo menos um desses três estudos precisa ser um estudo controlado por placebo e bem conduzido;

- $\quad$ Nivel B. Existem evidências claras, baseadas em pesquisa, para dar suporte a esta recomendação. As evidências foram obtidas a partir de pelo menos dois estudos razoavelmente amplos, positivos, randomizados, duplo-cegos (que podem corresponder, alternativamente, a dois ou mais estudos de comparação entre drogas, ou um estudo comparativo e um estudo placebo-controlado) ou são provenientes de um estudo razoavelmente amplo, positivo, randomizado e duplo-cego (controlado por droga comparativa ou placebo) e de pelo menos um estudo prospectivo moderadamente grande (tamanho da amostra superior ou igual a 50 participantes), aberto e naturalístico; 
- $\quad$ Nivel C. Existe um mínimo de evidências baseadas em pesquisa para dar suporte a esta recomendação. As evidências foram obtidas a partir de pelo menos um estudo randomizado, duplo-cego com tratamento comparativo e de um estudo prospectivo, aberto (ou série de casos) com tamanho de amostra superior ou igual a 10 participantes, que mostraram eficácia, ou pelo menos dois estudos prospectivos, abertos (série de casos) com um tamanho de amostra superior ou igual a 10 participantes, que mostraram eficácia;

- Nível D. Evidências foram obtidas a partir de opiniões de especialistas (de autores e membros da Força-Tarefa da WFSBP sobre esquizofrenia) com o suporte de pelo menos um estudo prospectivo, aberto ou série de casos, com tamanho da amostra superior ou igual a 10 participantes.

Ausência de eVIdências de qualouer nível ou Boas Práticas Clínicas (Good Clinical Practice, GCP)

Esta categoria inclui as afirmações baseadas na opinião de especialistas para procedimentos e princípios gerais de tratamento.

INDICAÇÃO E METAS DO TRATAMENTO DA ESQUIZOFRENIA

A esquizofrenia é uma condição heterogênea que tem curso e desfecho variados e afeta muitos aspectos da vida do paciente. $\mathrm{O}$ atendimento da maior parte dos pacientes que sofrem deste transtorno envolve esforços múltiplos e a abordagem de uma equipe multidisciplinar para: reduzir a frequiência, a duração e a gravidade dos episódios; reduzir a morbidade e a mortalidade globais por tal distúrbio; melhorar a função psicossocial, a independência e a qualidade de vida. $\mathrm{O}$ tratamento da esquizofrenia requer a plena compreensão do paciente quanto a suas necessidades e metas, conflitos e defesas, mecanismos de superação e recursos disponíveis. Portanto, todos aqueles envolvidos no tratamento precisam entender os fatores biológicos, interpessoais, sociais e culturais que exercem influência na recuperação do paciente. As principais metas do tratamento devem ser a participação do paciente e de todos aqueles envolvidos no processo de tratamento, a cooperação dos familiares, a coordenação e a cooperação das instituições de tratamento em termos de atendimento integrado e a inclusão de ajuda não-profissional e de sistemas de auto-ajuda. Facilitação do acesso para o sistema de cuidados com a saúde para pacientes que sofrem de esquizofrenia é uma meta adicional importante do trabalho profissional. Após a definição inicial do diagnóstico do paciente e das circunstâncias clínicas e psicossociais, um plano de tratamento deve ser formulado e implementado. Essa formulação envolve a seleção das modalidades de tratamento, o tipo específico de tratamento e o contexto do tratamento. As metas e estratégias de tratamento variam de acordo com a fase e a gravidade da doença.

$\mathrm{Na}$ fase aguda do tratamento (com duração de semanas a meses), definida por um episódio psicótico agudo, as principais metas são estabelecer um acordo com o paciente e a família para prevenir dano, controlar o comportamento anormal, reduzir a intensidade da psicose e dos sintomas associados (agitação, agressão, sintomas negativos, sintomas afetivos), dar atenção aos fatores que levaram à ocorrência do episódio agudo e realizar um rápido retorno ao melhor nível de funcionamento. Um psiquiatra pode avaliar o risco de um paciente agudamente psicótico se tornar perigoso para si próprio ou para os outros. Nessas circunstâncias, pode ser impossível fazer uma avaliação adequada no momento inicial. Considerando-se a relativa segurança da maior parte das medicações antipsicóticas, o psiquiatra pode começar o tratamento com a medicação que julgar apropriada, mesmo sem o consentimento do paciente. Nessas situações, o uso involuntário da medicação deve ser aprovado por uma corte judicial, e as avaliações necessárias devem ser realizadas à medida que se tornam possíveis.

Durante a fase de estabilização (usualmente com duração de 3 a 6 meses), as metas de tratamento são: reduzir o estresse sobre o paciente e dar suporte para minimizar a probabilidade de recidiva; aumentar a adaptação do paciente à vida na comunidade; buscar a redução progressiva dos sintomas consolidando a remissão; promover o processo de reabilitação. Se o paciente apresenta melhora com determinado esquema medicamentoso, recomenda-se sua manutenção por pelo menos 6 meses (APA, 2004). Também é fundamental avaliar a persistência de efeitos colaterais e ajustar a farmacoterapia de forma adequada para minimizá-los, uma vez que os efeitos adversos contribuem para a nãoaderência à medicação e, portanto, para a ocorrência de recidivas.

As metas do tratamento durante a fase manutenção (que dura de meses a anos) são: garantir que a remissão ou o controle dos sintomas seja sustentado; que o paciente mantenha ou melhore seu nível de funcionamento e sua qualidade de vida; que as exacerbações de sintomas ou as recidivas sejam efetivamente tratadas; que a monitorização dos efeitos adversos seja feita continuamente. Para a maioria das pessoas com esquizofrenia e quadro clínico estabilizado, as intervenções psicossociais são recomendadas como um tratamento complementar, que também é útil para a efetividade do tratamento farmacológico, podendo melhorar a evolução. O principal objetivo da intervenção farmacológica nesta fase é prevenir recidivas e ajudar a manter o paciente suficientemente estável para viver uma vida tão normal quanto possível (terapia de manutenção e prevenção da recidiva).

\section{Tratamento da fase aguda da esquizofrenia}

$\mathrm{Na}$ fase aguda, as metas do tratamento específico são: prevenir danos, controlar distúrbios de comportamento, suprimir sintomas, realizar um retorno rápido ao melhor nível de funcionamento prévio, desenvolver um acordo com o paciente e a família, formular planos de tratamento 
de curto e longo prazos e conectar o paciente com um sistema de atendimento posterior na comunidade (APA, 2004). Independentemente do tipo de tratamento oferecido, é essencial engajar o paciente, desde o início, numa relação de trabalho colaborativo, de confiança e de cuidado (NICE, 2002). As intervenções psicossociais nesta fase objetivam atenuar relações, situações e eventos estressantes ou superestimulantes e tranqüilizar o paciente por meio da comunicação e do estabelecimento de expectativas simples, claras e coerentes, num ambiente estruturado, previsível e pouco exigente, com relacionamentos tolerantes, incentivadores e de baixa demanda (DGPPN, 1998; APA, 2004). Deve-se fornecer ao paciente informações sobre a natureza e o manuseio da doença apropriadas para sua capacidade de assimilação. O paciente tem de ser informado a respeito dos benefícios e dos efeitos colaterais da medicação (NICE 2002). O psiquiatra deve ter consciência de que o grau de aceitação da medicação e das informações a respeito dela variam de acordo com a capacidade cognitiva do paciente, o grau de negação da doença pelo paciente e os esforços feitos pelo psiquiatra para envolver o paciente e a família num relacionamento que colabore com $o$ tratamento (APA, 2004).

Indicações para hospitalização incluem considerar se o paciente representa uma séria ameaça de dano para si próprio ou para os outros, se é incapaz de cuidar dele próprio ou se necessita de supervisão constante, além de verificar a existência de problemas médicos gerais ou psiquiátricos que tornem o tratamento ambulatorial inseguro ou pouco efetivo. Hospitalizações involuntárias são indicadas se os pacientes recusam a internação e se eles preenchem os critérios estabelecidos pela jurisdição local.

Contextos alternativos de tratamento, tais como hospitalização parcial, home care, terapia familiar, atendimento residencial na crise e tratamento assertivo na comunidade, devem ser considerados para pacientes que não necessitam de hospitalização formal para seus episódios agudos (APA, 2004). Na fase aguda do tratamento, são enfatizadas principalmente as intervenções farmacoterapêuticas (e outras somáticas). Portanto, a terapia antipsicótica deve ser iniciada tão precocemente quanto possível como parte necessária de um conjunto abrangente de medidas que engloba as necessidades clínicas, emocionais e sociais do indivíduo. O clínico responsável pelo tratamento e o chefe da equipe devem monitorizar tanto o progresso terapêutico quanto a tolerabilidade da droga no curso do acompanhamento. A monitorização é particularmente importante quando os indivíduos acabaram de mudar de um antipsicótico para outro (NICE, 2002).

Antipsicóticos

Os antipsicóticos têm sido a base do tratamento da esquizofrenia nos últimos cinquienta anos. Em termos de estrutura química, os antipsicóticos, freqüentemente conhecidos como neurolépticos, são um grupo heterogê- neo de drogas psicoativas (como fenotiazina, tioxantina, butirofenona, difenilbutilpiperidina, benzamida, benzisoxazol e dibenzepina) geralemente utilizado na fase aguda do tratamento, na terapia de manutenção e na prevenção da recidiva da esquizofrenia em longo prazo.

\section{Classificação e eficácia}

Os antipsicóticos convencionais ou de primeira geração podem ser classificados como medicações de alta e baixa potências. A dose efetiva de uma medicação antipsicótica de primeira geração está intimamente relacionada à sua afinidade por receptores de dopamina (particularmente D2) e sua tendência de causar efeitos colaterais extrapiramidais (Creese et al., 1976). Os antipsicóticos de alta potência têm maior afinidade por receptores D2 do que as medicações de baixa potência, e a dose efetiva requerida para tratar sintomas antipsicóticos (como delírios e alucinações) é muito mais baixa quando comparada à de antipsicóticos de baixa potência.

Essa relação de dose pode ser expressa em termos de dose-equivalência (por exemplo, $100 \mathrm{mg}$ de clorpromazina (CPZ), um antipsicótico de baixa potência, têm efeito antipsicótico comparável a $2 \mathrm{mg}$ de haloperidol, um antipsicótico de alta potência). A dose-equivalência não corresponde à equivalência da tolerabilidade $\mathrm{e}$ deve ser considerada como um conceito geral, mais do que um guia clínico preciso. Os efeitos colaterais dos agentes de alta potência (como, por exemplo, sintomas extrapiramidais) são mais fáceis de manusear do que a sedação e a hipotensão ortostática, efeitos associados aos agentes de baixa potência. Por essa razão, é difícil atingir doses antipsicóticas efetivas com medicações de baixa potência.

$\mathrm{O}$ advento da clozapina inaugurou uma nova classe de antipsicóticos, denominados de "atípicos" por se tratar de um agente antipsicótico efetivo que não induz catalepsia e não exerce antagonismo à apomorfina. Como vários antipsicóticos podem ser encontrados num espectro contínuo do típico ao atípico, hoje preferem-se os termos "antipsicóticos de segunda geração" (ASG) ou "antipsicóticos de nova geração" (ANG) para descrever esses novos agentes, que induzem consideravelmente menos SEP numa faixa de dose terapêutica quando comparados aos neurolépticos convencionais (Fleischhacker, 2002).

\section{Antipsicóticos de primeira geração}

Estudos demonstrando a eficácia dos APGs (como as fenotiazinas) em reduzir sintomas psicóticos em esquizofrenia aguda foram em sua maioria realizados nos anos 1960 e 1970, comparando uma ou mais medicações antipsicóticas com placebo ou um agente sedativo. Quase todos esses estudos constataram que a medicação antipsicótica foi superior para o tratamento da esquizofrenia (NIH Psychopharmacology Service Center Collaborative Study Group, 1964). Uma revisão de mais de cem estudos concluiu que a grande maioria dos estudos duplo-cegos encontrou eficácia superior para os APGs comparados ao placebo e, com exceção 
da mepazina e da promazina, todos esses agentes foram igualmente efetivos, embora tenham sido observadas diferenças de dose, potência e efeitos colaterais das diferentes drogas (Davis et al., 1989). A superioridade das APGs sobre o placebo foi confirmada por outras revisões que avaliaram estudos randomizados e duplocegos (Baldessarini et al., 1990; Kane e Marder, 1993; Dixon et al., 1995).

Revisões da Biblioteca Cochrane e do NICE, incluindo ECRs de alta qualidade, verificaram que a maioria dos APGs (como a clorpromazina, a tioridazina e a trifluopirazina) tem eficácia comparável entre si e é superior ao placebo, com apenas pequena superioridade em favor da pimozida e da sulpirida, à exceção do benperidol (Leucht e Hartung, 2004a). Foram identificados estudos com CPZ (Thornley et al., 2004), flupentixol (Centre for Outcomes Research and Effectiveness, Systematic Review Flupenthixol, 2002), flufenazina (Centre for Outcomes Research and Effectiveness, Systematic Review Fluphenazine, 2002), pirazina (Leucht e Hartung, 2004b), perfenazina (Centre for Outcomes Research and Effectiveness, Systematic Review Perphenazine 2002), pimozida (Sultana e McMonagle, 2004), sulpirida (Soares et al., 2004), tioridazina (Sultana et al., 2004), trifluopirazina (Marques et al., 2004) e zuclopentixol (Fenton et al., 2004). Além disso, os APGs (assim como as fenotiazinas nesta revisão) demonstraram eficácia na diminuição de sintomas psicóticos no tratamento em longo prazo e redução das taxas de recaída quando comparados ao placebo (Davis, 1975).

Os agentes antipsicóticos de primeira geração e alta potência estão associados a alto risco de efeitos colaterais extrapiramidais, risco moderado de sedação, baixo risco de hipotensão ortostática e taquicardia e baixo risco de efeitos anticolinérgicas e de bloqueio adrenérgico. Uma revisão dos efeitos clínicos de haloperidol, considerado como exemplo de APG de alta potência, demonstrou eficácia no tratamento da esquizofrenia, tanto no curto como no longo prazos, quando comparado ao placebo, mas também alta propensão de causar distúrbios de movimento (Nível A) (Joy et al., 2004).

APGs de baixa potência estão associados a menor risco de efeitos extrapiramidais, porém maior risco de sedação, hipotensão ortostática e taquicardia, além de alto risco de efeitos anticolinérgicos e antiadrenérgicos. Especialmente pela sedação e pela hipotensão ortostática, a dose deve ser aumentada gradualmente. Uma revisão sobre a eficácia da clorpromazina como exemplo de APG de baixa potência sustenta, com base em dados evolutivos, a existência de melhora discretamente superior da terapia com clorpromazina em relação ao placebo, porém à custa de mais efeitos colaterais, como sedação (Nivel A) (Thornley et al., 2004).

\section{Antipsicóticos de segunda geração}

Embora a eficácia dos APGs na redução de sintomas positivos e na prevenção de recidivas seja inquestionável, as limitações dessa intervenção decorrem do alcance limitado sobre os sintomas negativos e a disfunção cognitiva, que contribuem para a baixa qualidade de vida e os déficits funcionais. Além do mais, os APGs acarretam efeitos adversos importantes em muitos pacientes, mais notoriamente SEP e queixas subjetivas de disforia, comprometendo a tolerabilidade e a aderência ao tratamento. Esses fatos estimularam o desenvolvimento de ASGs, cuja maior vantagem é a baixa propensão para SEP, especialmente discinesia tardia. Além disso, os ASGs demonstraram maior eficácia no tratamento dos sintomas negativos, dos distúrbios cognitivos e dos sintomas depressivos, num perfil clínico que é freqüentemente descrito como um espectro mais amplo de eficácia clínica (Möller, 2000a e 2000b). Os ASGs relacionam-se a alguns riscos, como distúrbios de utilização da glicose, do metabolismo de lipídios e de ganho de peso, que já são conhecidos em relação a alguns dos antipsicóticos convencionais, mas que podem ser ainda mais pronunciados com alguns ASGs.

No momento do desenvolvimento destas diretrizes, os seguintes ASGs estavam disponíveis na maioria dos países europeus ou nos mercados australiano e norteamericano: amisulprida, aripiprazol, clozapina, olanzapina, quetiapina, risperidona, ziprasidona e zotepina. As formulações disponíveis desses ASGs são diferentes. Todas essas medicações podem ser administradas em formulações orais como pílulas ou comprimidos. A amisulprida e a risperidona estão disponíveis como concentrados orais. A olanzapina e a risperidona, em comprimidos de dissolução rápida. A olanzapina e a ziprasidona, como preparações para uso parenteral (intramuscular) de curta duração de ação. A risperidona, como uma preparação injetável de longa ação.

Uma metanálise avaliando a eficácia dos ASGs comparados a placebo, incluindo três ECRs com risperidona, dois ECRs com olanzapina e quatro ECRs com quetiapina, calculou o tamanho do efeito para a taxa de resposta categorial em cerca de 0,67 , e maior que 0,82 para a medida contínua em favor dos ASGs, concluindo que existe uma superioridade estatística de um ASGs em dose terapêutica quando comparado ao placebo (Woods et al., 2001). As taxas de resposta ao placebo variaram de $8 \%$ a $58 \%$ ao longo dos estudos, em parte explicados pelas definições de resposta usadas nos estudos. Além disso, a revisão sugeriu a superioridade da ziprasidona (não comercializada por ocasião da análise) quando comparada ao placebo, sendo similar aos outros ASGs mencionados.

\section{Comparação entre a eficácia de APGs e ASGs}

Ainda há controvérsias se os ASGs, como um grupo, são superiores aos APGs em sua eficácia e efetividade no tratamento da esquizofrenia. Uma metanálise recente relatou pontos cruciais de estudos randomizados controlados (Sartorius et al., 2002). Numa revisão sistemática e com análise de meta-regressão de estudos randomizados controlados, uma heterogeneidade substancial foi observada nos resultados do estudo comparando 
ASGs a APGs, sendo parcialmente relacionada à dose de APGs usada. Quando a dose era de cerca de $12 \mathrm{mg} /$ dia de haloperidol (ou equivalente), constatou-se que os antipsicóticos atípicos não tinham qualquer benefício em termos de eficácia ou tolerabilidade global, mas proporcionavam menos efeitos colaterais extrapiramidais (Geddes et al., 2000).

Numa metanálise de estudos de eficácia randomizados comparando ASGs e APGs e comparando diferentes ASGs. O tamanho dos efeitos da clozapina, da amisulpirida, da risperidona e da olanzapina foram maiores do que aqueles de APGs, e o efeito da zotepina foi marginalmente maior, enquanto outros ASGs não revelaram superioridade evidente (Davis et al., 2003). Nenhuma diferença em eficácia foi detectada entre a amisulpirida, a risperidona e a olanzapina quando diretamente comparadas uma com a outra. Não foram encontradas evidências de que a dose de haloperidol (ou de todos os APGs de comparação convertidos para doses equivalentes de haloperidol) afetasse esses resultados. Numa revisão de estudos que avaliaram a eficácia e a tolerabilidade da olanzapina, da risperidona, da quetiapina e do sertindol, foi relatada a superioridade do placebo (Leucht et al., 1999). Constatou-se que a quetiapina e o sertindol eram comparáveis ao haloperidol, enquanto a olanzapina e a risperidona mostraram eficácia discretamente superior no tratamento de sintomas globais de esquizofrenia. Além disso, demonstrou-se que a olanza- pina e a risperidona apresentaram discreta superioridade no sentido de melhorar os sintomas negativos.

Observou-se que, em comparação ao haloperidol, todos os ASGs estavam associados à menor incidência de SEP, o que foi verificado pelo uso de medicações antiparkinsonianas. A metanálise de todos os estudos clínicos randomizados controlados nos quais os ASGs têm sido comparados a APGs de baixa potência (equivalentes à clorpromazina ou menos potentes que ela) constatou que, como um grupo, os ASGs foram moderadamente mais eficazes que os antipsicóticos de baixa potência, amplamente independentes das doses da droga para a comparação utilizada (Leucht et al., 2003). Além disso, há uma observação de que os APGs de baixa potência em doses mais baixas que $600 \mathrm{mg} /$ dia em equivalentes de $\mathrm{CPZ}$ poderiam não induzir mais SEP que os ASGs.

A monoterapia antipsicótica deve ser preferida, e a dose mínima efetiva deve ser empregada. A dose ótima para cada paciente tem de ser encontrada por julgamento clínico. As dosagens de tratamento recomendadas na fase aguda para os antipsicóticos comumente usados podem ser encontradas na tabela 1.

\section{Farmacocinética e farmacogenética}

Medicações antipsicóticas de primeira geração podem ser administradas em sua forma oral, com aplicações intravenosas (como preparações intramusculares de curta duração) ou com preparações injetáveis de longa ação. Medicações intramusculares de curta duração

Tabela 1. Dosagem recomendada (via oral) de antipsicóticos selecionados no tratamento da fase aguda

\begin{tabular}{|c|c|c|c|c|c|}
\hline Antipsicótico & $\begin{array}{l}\text { Dose inicial de } \\
\text { antipsicótico } \\
\text { (mg/dia) }\end{array}$ & ID' $^{1}$ & $\begin{array}{c}\text { Dose-alvo para } \\
\text { primeiro episódio } \\
\text { (mg/dia) }\end{array}$ & $\begin{array}{c}\text { Dose-alvo } \\
\text { para múltiplos } \\
\text { episódios } \\
\text { (mg/dia) }\end{array}$ & $\begin{array}{c}\text { Dosagem máxima } \\
\text { (mg/dia) }\end{array}$ \\
\hline \multicolumn{6}{|c|}{ Antipsicóticos de segunda geração } \\
\hline $\begin{array}{l}\text { Amisulpirida } \\
\text { Aripiprazol } \\
\text { Clozapina }^{3} \\
\text { Olanzapina } \\
\text { Ouetiapina } \\
\text { Risperidona } \\
\text { Ziprasidona } \\
\text { Zotepina }\end{array}$ & $\begin{array}{c}200 \\
(10)-15 \\
25 \\
5-10 \\
50 \\
2 \\
40 \\
25-50\end{array}$ & $\begin{array}{c}(1)-2 \\
1 \\
2-(4) \\
1 \\
2 \\
1-2 \\
2 \\
2-(4)\end{array}$ & $\begin{array}{c}100-300 \\
15-(30) \\
100-250 \\
5-15 \\
300-600 \\
1-4 \\
40-80 \\
50-150\end{array}$ & $\begin{array}{c}400-800 \\
15-30 \\
200-450 \\
5-20 \\
400-750 \\
3-6-(10) \\
80-160 \\
100-250\end{array}$ & $\begin{array}{c}1.200 \\
30 \\
900 \\
20 \\
750 \\
16 \\
160 \\
450\end{array}$ \\
\hline \multicolumn{6}{|c|}{ Antipsicóticos de primeira geração } \\
\hline $\begin{array}{l}\text { Clorpromazina } \\
\text { Flufenazina } \\
\text { Flupentixol } \\
\text { Haloperidol } \\
\text { Perazina } \\
\text { Perfenazina } \\
\text { Pimozida } \\
\text { Zuclopentixol }\end{array}$ & $\begin{array}{c}50-150 \\
0,4-10 \\
2-10 \\
1-10 \\
50-150 \\
4-24 \\
1-4 \\
2-50\end{array}$ & $\begin{array}{c}2-4 \\
2-3 \\
1-3 \\
(1)-2 \\
1-2 \\
1-3 \\
2 \\
1-3\end{array}$ & $\begin{array}{c}300-500 \\
2,4-10 \\
2-10 \\
1-4 \\
100-300 \\
6-36 \\
1-4 \\
2-10\end{array}$ & $\begin{array}{c}300-1.000 \\
10-20 \\
10-20 \\
3-15 \\
200-600 \\
12-42 \\
2-12 \\
25-50\end{array}$ & $\begin{array}{c}1.000 \\
20-(40) \\
60 \\
100 \\
1.000 \\
56 \\
16 \\
75\end{array}$ \\
\hline
\end{tabular}

'ID: intervalos de dose. Distribuição recomendada da dose diária: uma vez (1), duas vezes (2), etc.

${ }^{2}$ Dosagem máxima aprovada em muitos países. Na prática clínica, para alguns ASGs, são utilizadas até mesmo doses mais elevadas.

${ }^{3} \mathrm{~A}$ clozapina não é usualmente introduzida nos casos de pacientes de primeiro episódio. 
atingem um pico de concentração 30 a 60 minutos após a medicação ser administrada, enquanto as medicações orais atingem um pico após 2 ou 3 horas (Dahl, 1990). Como resultado, o efeito tranqüilizante dos antipsicóticos de primeira geração pode começar mais rapidamente quando a medicação é administrada por via parenteral. No entanto, esse efeito tranquuilizante, que é útil no tratamento da agitação, se mostra diferente do efeito antipsicótico, que pode requerer vários dias ou semanas. Os concentrados para uso oral são mais rapidamente absorvidos que as preparações em pílulas, e frequientemente se aproximam da administração intramuscular quanto ao tempo de serem atingidas as concentrações séricas de pico. As fenotiazinas são inibidores potentes da enzima CYP2D6 do citocromo P450 e podem, portanto, prejudicar a eliminação dos substratos para esta isoforma. $\mathrm{O}$ zuclopentixol é metabolizado pela CYP2D6, e o haloperidol, pelo CYP2D6, pelo CYP1A4 e pelo CYP3A4 (Spina et al., 2003).

Antipsicóticos de segunda geração têm farmacocinética similar àquela dos APGs. Os ASGs são rápida e completamente absorvidos após administração oral, mas freqüentemente passam por extenso metabolismo hepático de primeira passagem (Burns, 2001). O tempo para alcançar as concentrações plasmáticas de pico varia de 1 a 10 horas. Agentes atípicos são altamente lipofílicos, altamente ligados a proteínas, e tendem a se acumular no cérebro e em outros tecidos. O fígado metaboliza amplamente os ASGs, predominantemente por meio de enzimas do citocromo P450. Os ASGs são apenas inibidores fracos de isoenzimas da CYP em concentrações terapêuticas in vitro. Portanto, não se espera que interfiram na eliminação de medicações coadministradas (Spina et al., 2003). Em razão das grandes variações interindividuais na biotransformação e na presença de metabólitos ativos (que não são prontamente medidos), há freqüientemente pouca correlação entre dose, concentração sérica e efeitos clínicos (Burns, 2001).

Certo número de interações medicamentosas pode ter efeitos clinicamente importantes para pacientes tratados com APGs e ASGs (APA, 2004). A coadministração de drogas que inibem as enzimas do citocromo P450 ou interferem nelas (antidepressivos heterocíclicos, alguns betabloqueadores, cimetidina, cafeína, eritromicina, fluvoxamina, fluoxetina, paroxetina, sertralina) pode ocasionar aumento significativo nos níveis plasmáticos e aumento dos efeitos colaterais, como sedação, hipotensão e SEP. Substâncias indutoras das enzimas do CYP450 (fenitoína, nicotina, rifampicina) podem reduzir de forma significativa os níveis de antipsicóticos. Barbituratos e carbamazepina diminuem os níveis plasmáticos por meio de seus efeitos sobre as enzimas da citocromo P450, reduzindo o efeito antipsicótico. Em particular, as mudanças do hábito tabagista podem afetar especialmente os níveis de clozapina. Informação adicional a respeito das propriedades farmacocinéticas dos ASGs (Prior e Baker, 2003; Raggi et al., 2004) são apresentadas na tabela 2 .

Aspectos farmacogenéticos enfocam principalmente diferentes genótipos das enzimas do citocromo P450, responsáveis por variações no metabolismo da droga. Em particular, a atividade do CYP2D6 pode variar até mil vezes na população por causa de setenta ou mais polimorfismos genéticos que podem lhe conferir atividade enzimática diminuída, normal ou aumentada (Albers e Ozdemir, 2004). Em 5\% a 8\% dos caucasianos e $1 \%$ a $5 \%$ dos afro-americanos e asiáticos, a atividade das enzimas do CYP2D6 é muito baixa ou ausente, sendo, portanto, denominados de "metabolizadores fracos" (APA, 2004). Por essa razão, os níveis sangüíneos dos agentes psicotrópicos metabolizados por CYP2D6 (como a risperidona) podem aumentar, e essas substâncias

Tabela 2. Farmacocinética de antipsicóticos selecionados

\begin{tabular}{|c|c|c|c|}
\hline Agente & $\begin{array}{l}\text { Nível plasmático } \\
\text { máximo (em horas) }\end{array}$ & $\begin{array}{c}\text { Meia-vida de } \\
\text { eliminação (em horas) }\end{array}$ & Enzimas CYP* \\
\hline \multicolumn{4}{|c|}{ Antipsicóticos de primeira geração } \\
\hline $\begin{array}{l}\text { Clorpromazina } \\
\text { Haloperidol }\end{array}$ & $\begin{array}{l}2-4 \\
3-6\end{array}$ & $\begin{array}{c}30 \\
14-20\end{array}$ & $\begin{array}{c}1 \mathrm{~A} 2,2 \mathrm{D} 6,3 \mathrm{~A} 4 \\
2 \mathrm{D} 6,3 \mathrm{~A} 4\end{array}$ \\
\hline \multicolumn{4}{|c|}{ Antipsicóticos de segunda geração } \\
\hline $\begin{array}{l}\text { Amisulprida } \\
\text { Aripiprazol } \\
\text { Clozapina } \\
\text { Olanzapina } \\
\text { Quetiapina } \\
\text { Risperidona } \\
\text { Ziprasidona } \\
\text { Zotepina }\end{array}$ & $\begin{array}{c}1-3 \\
3-5 \\
1,5-3,6 \\
5-8 \\
1-1,8 \\
0,8-1,4 \\
3,8-5,2 \\
2,8-4,5\end{array}$ & $\begin{array}{c}12-20 \\
75-146(94) \\
16-23 \\
21-54 \\
6,8 \\
3,6 \\
3,2-10 \\
8-16(12)\end{array}$ & $\begin{array}{c}? \\
\text { 2D6, 3A4 } \\
1 \mathrm{~A} 2,3 \mathrm{~A} 4,(2 \mathrm{C} 19,2 \mathrm{D} 6) \\
\text { 1A2, (2C19, 2D6) } \\
3 \mathrm{~A} 4 \\
\text { 2D6, (3A4) } \\
\text { 3A4, (1A2, 2D6) } \\
\text { 3A4, (1A2, 2D6) }\end{array}$ \\
\hline
\end{tabular}

" Enzimas secundárias envolvidas são mostradas entre parênteses.

Fonte: Adaptado de Burns, 2001. 
podem causar efeitos colaterais indesejáveis mesmo quando administrados em doses terapêuticas. Por outro lado, os metabolizadores ultra-rápidos (devido a cópias múltiplas do gene do CYP2D6) são expostos a níveis subterapêuticos da droga e podem ser incorretamente rotulados de não-aderentes ou resistentes ao tratamento (Albers e Ozdemir, 2004).

\section{Efeitos colaterais}

Diferenças no risco de efeitos colaterais específicos das medicações antipsicóticas são freqüentemente previsíveis a partir dos perfis de ligação do receptor dos vários agentes. Alguns efeitos colaterais resultam de efeitos receptor-mediados no sistema nervoso central (efeitos colaterais extrapiramidais, hiperprolactinemia, sedação) ou fora do sistema nervoso central (consti- pação, hipotensão), enquanto outros efeitos colaterais são de fisiopatologia não-esclarecida (ganho de peso, hiperglicemia). Os efeitos colaterais compartilhados por APGs e ASGs incluem efeitos neurológicos (efeitos extrapiramidais agudos e crônicos, síndrome neuroléptica maligna), sedação, efeitos cardiovasculares (hipotensão, taquicardia e distúrbios da condução), efeitos anticolinérgicos e antiadrenérgicos, ganho de peso e anormalidades metabólicas de glicose e lipídios e disfunção sexual, todos com frequiências e intensidades específicas por classe e substância (freqüentemente dose-dependentes). A tabela 3 dá uma visão geral da freqüência estimada de alguns efeitos colaterais importantes dos ASGs e do haloperidol. A tabela 4 fornece as recomendações para monitorização.

Tabela 3. Efeitos colaterais selecionados de antipsicóticos comumente usados

\begin{tabular}{|c|c|c|c|c|c|c|c|c|}
\hline \multicolumn{9}{|c|}{ Medicação antipsicótica } \\
\hline $\begin{array}{l}\text { Efeitos } \\
\text { colaterais }\end{array}$ & Haloperidol & Amisulprida & Clozapina & Olanzapina & Risperidona & Quetiapina & Ziprasidona & Aripiprazol \\
\hline $\begin{array}{l}\text { Acatisia/ } \\
\text { parkinsonismo }\end{array}$ & +++ & $0-+$ & 0 & $0-+$ & $0-++$ & $0-+$ & $0-+$ & + \\
\hline $\begin{array}{l}\text { Discinesia } \\
\text { tardia }\end{array}$ & +++ & $(+)$ & 0 & $(+)$ & $(+)$ & $?$ & $?$ & $?$ \\
\hline Convulsões & + & 0 & ++ & 0 & 0 & 0 & 0 & $(+)$ \\
\hline $\begin{array}{l}\text { Prolongamento } \\
\text { de } \mathrm{OT}\end{array}$ & + & $(+)$ & $(+)$ & $(+)$ & $(+)$ & $(+)$ & + & 0 (?) \\
\hline $\begin{array}{l}\text { Anormalidades } \\
\text { da glicose }\end{array}$ & $(+)$ & $(+)$ & +++ & +++ & ++ & ++ & 0 & 0 \\
\hline $\begin{array}{l}\text { Anormalidades } \\
\text { dos lipídios }\end{array}$ & $(+)$ & $(+)$ & +++ & +++ & ++ & ++ & 0 & 0 \\
\hline Constipação & + & ++ & +++ & ++ & ++ & + & 0 & 0 \\
\hline Hipotensão & ++ & 0 & $(+)$ & $(+)$ & ++ & ++ & + & + \\
\hline Agranulocitose & 0 & 0 & + & 0 & 0 & 0 & 0 & 0 \\
\hline $\begin{array}{l}\text { Ganho de } \\
\text { peso* }^{*}\end{array}$ & + & + & +++ & +++ & ++ & ++ & $0-+$ & + \\
\hline $\begin{array}{l}\text { Elevação } \\
\text { da prolactina }\end{array}$ & +++ & +++ & 0 & $(+)$ & ++ & $(+)$ & $(+)$ & 0 \\
\hline Galactorréia & ++ & ++ & 0 & 0 & ++ & 0 & 0 & 0 \\
\hline $\begin{array}{l}\text { Dismenorréia/ } \\
\text { amenorréia }\end{array}$ & ++ & ++ & 0 & 0 & ++ & $(+)$ & 0 & 0 \\
\hline Sedação & +++ & $0-(+)$ & +++ & +-++ & + & ++ & $0-(+)$ & 0 \\
\hline $\begin{array}{l}\text { Síndrome } \\
\text { neuroléptica } \\
\text { maligna }\end{array}$ & $(+)$ & $?$ & $(+)$ & $(+)$ & $(+)$ & $(+)$ & $?$ & $(+)$ \\
\hline
\end{tabular}

"Ganho de peso durante 6 a 10 semanas: + baixo $(0-1,5 \mathrm{~kg}) ;++$ médio $(1,5-3 \mathrm{~kg}) ;+++$ alto $(>3 \mathrm{~kg})$.

0: ausência de risco; (+): ocasionalmente, não há diferença em relação ao placebo; +: leve $(<1 \%) ;++$ : algumas vezes $(<10 \%) ;+++$ : freqüentemente (> 10\%); ?: nenhuma declaração possível pela falta de dados.

Nota: A freqüência e a intensidade dos efeitos colaterais referem-se à informação obtida pelas companhias fornecedoras das drogas, FDA, literatura adicional e outras diretrizes (APA, 2004). 
Tabela 4. Monitorização de pacientes em uso de antipsicóticos de segunda geração*

\begin{tabular}{l|c|c|c|c|c|c}
\hline & Período basal & 4 semanas & 8 semanas & 12 semanas & Trimestral & Anualmente \\
\hline História pessoal/familiar & $\mathrm{x}$ & $\mathrm{x}$ & $\mathrm{x}$ & $\mathrm{x}$ \\
\hline Peso (IMC) & $\mathrm{x}$ & $\mathrm{x}$ & $\mathrm{x}$ & $\mathrm{x}$ & $\mathrm{x}$ \\
\hline Circunferência da cintura & $\mathrm{x}$ & $\mathrm{x}$ & & $\mathrm{x}$ & $\mathrm{x}$ \\
\hline Pressão arterial & $\mathrm{x}$ & $\mathrm{x}$ & & $\mathrm{x}$ & \\
\hline Glicose plasmática em jejum & $\mathrm{x}$ & & $\mathrm{x}$ & $\mathrm{x}$ \\
\hline Perfil lipídico em jejum & $\mathrm{x}$ & & $\mathrm{x}$ & \\
\hline $\begin{array}{l}\text { Contagem de células } \\
\text { sangüíneas }\end{array}$ & $\mathrm{x}$ & & & $\mathrm{x}$ \\
\hline ECG & & & & \\
\hline
\end{tabular}

ECG: eletrocardiograma; IMC: índice de massa corpórea.

"Avaliações mais freqüentes podem ser realizadas com base no estado clínico.

Nota: As avaliações referem-se principalmente ao American Diabetes Association e à American Psychiatric Association (Diabetes Care 2004; 27: 596-601).

Efeitos colaterais neurológicos

Efeitos colaterais extrapiramidais - Os efeitos colaterais extrapiramidais podem ser divididos em categorias agudas e crônicas. Efeitos colaterais extrapiramidais agudos são sinais e sintomas que ocorrem nos primeiros dias e semanas de administração da medicação antipsicótica, são dose-dependentes, reversíveis com a redução da dose da medicação ou sua descontinuação (Goetz e Klawans, 1981). A distonia aguda tipicamente ocorre com APGs de alta potência e mais freqüentemente em jovens e pacientes masculinos, mas também tem sido relatada em associação com ASGs (como a risperidona) (Rupniak et al., 1986; Leucht et al., 1999). Acredita-se que o parkinsonismo induzido por antipsicóticos afete de $10 \%$ a $80 \%$ (dependendo da população e das doses) dos pacientes que se submetem à terapia com APGs de alta potência (Bollini et al., 1994). A acatisia ocorre com freqüência média de aproximadamente $20 \%$ a $25 \%$ dos pacientes tratados com APGs (Braude et al., 1983; Grebb, 1995). A discinesia tardia (DT) pode persistir após a descontinuação da medicação, ocorrendo com incidência de $4 \%$ a $8 \%$ por ano de tratamento com antipsicóticos convencionais (Glazer, 2000). Após 4 anos de terapia com APGs de alta potência, aproximadamente $20 \%$ dos pacientes têm discinesia tardia, e a taxa é mais alta (até 50\%) em pacientes idosos (Fenton, 2000; Glazer, 2000; Jeste, 2000). Os fatores de risco são: idade, gênero feminino, presença de sintomas parkinsonianos induzidos por droga, diabetes melito, distúrbios afetivos, doses mais elevadas e duração mais prolongada da terapia antipsicótica (Morgenstern, 1993). Os ASGs induzem menos SEP numa faixa de dose terapêutica que os APGs e mostram redução significativa no risco de discinesia tardia quando comparados aos APGs (Leucht et al., 1999; Correll et al., 2004). Estudos vêm fornecendo evidências de que SEP induzidos por clozapina e provavelmente por quetiapina não são dose-dependentes (Buchanan et al., 1995; Cheer e Wagstaff, 2004).

Síndrome neuroléptica maligna - A síndrome neuroléptica maligna (neuroleptic malignant syndro$m e, \mathrm{NMS})$ é caraterizada por: distonia, rigidez, febre, instabilidade autonômica, tal como taquicardia, delírio, mioglobinúria e níveis elevados de creatinoquinase, enzimas leucocitárias e hepáticas. A prevalência de NMS é incerta, ocorrendo provavelmente em menos de $1 \%$ dos pacientes tratados com APGs (Adityanjee $e t$ al., 1999) e sendo ainda mais rara entre os pacientes tratados com ASGs (Caroff et al., 2000). Os fatores de risco para NMS incluem: agitação aguda, idade mais jovem, gênero masculino, incapacidade neurológica preexistente, doença física, desidratação, escalonamento rápido de dose antipsicótica, uso de medicações de alta potência e uso de preparações intramusculares (Pelonero et al., 1998).

Convulsões epilépticas - Convulsões epilépticas ocorrem numa média de $0,5 \%$ a $0,9 \%$ dos pacientes que recebem medicações antipsicóticas (Devinsky et al., 1991). A clozapina está associada à mais elevada taxa de incidência (em torno de $3 \%$ ) e a risco cumulativo (em torno 10\%) após 4 anos de tratamento (Devinsky et al., 1991; Buchanan et al., 1995). A dose e os aumentos iniciais de dose de clozapina parecem representar fatores de risco para convulsões (Devinsky et al., 1991). Convulsões epilépticas dose-dependentes também têm sido descritas com zotepina em taxas relevantes de $7 \%$ a 17\% (Hori et al., 1992).

Efeitos colaterais cognitivos - Apesar de as medicações antipsicóticas melhorarem efetivamente as funções cognitivas em pacientes esquizofrênicos, problemas de memória e distúrbios cognitivos representam possíveis efeitos colaterais da terapia antipsicótica, particularmente associados ao efeito anticolinérgico de medicações 
antipsicóticas e ao uso de agentes anticolinérgicos, como o biperideno. Distúrbios cognitivos induzidos por drogas têm sido mais freqüentemente relatados no tratamento com antipsicóticos típicos (Buchanan et al., 1994; Keefe et al., 1999; Meltzer e McGurk, 1999; Purdon et al., 2000; Harvey e Keefe, 2001; Bilder et al., 2002; Green et al., 2002; Velligan et al., 2002).

Sedação - A sedação é um efeito colateral comum dos APGs, assim como de vários dos ASGs, e está relacionada ao antagonismo sobre os receptores histaminérgicos, adrenérgicos e dopaminérgicos (Kinon e Lieberman, 1996). A sedação ocorre mais freqüentemente com antipsicóticos típicos de baixa potência e com a clozapina. A sedação é mais pronunciada nas fases iniciais do tratamento, e a maior parte dos pacientes desenvolve alguma tolerância aos efeitos sedativos com o uso continuado.

\section{Obesidade e ganho de peso}

Indivíduos com esquizofrenia têm mais sobrepeso ou obesidade que os indivíduos da população geral (Marder et al., 2004). Combinado com outros fatores de risco (como tabagismo, atividade física reduzida, diabetes e dislipidemia), o risco de morbidade e mortalidade cardiovasculares se mostra aumentado. Além disso, fatores relacionados ao estilo de vida (como dieta inadequada e sedentarismo, tratamento com APGs ou ASGs) podem contribuir para o ganho de peso (Marder et al., 2004). O ganho de peso é uma ocorrência multifatorial durante $o$ tratamento com agentes neurolépticos. De acordo com uma metanálise, o ganho médio de peso associado a medicações antipsicóticas típicas é mais elevado com a clozapina e a olanzapina e mais baixo com a risperidona, enquanto a ziprasidona dificilmente afeta o peso corporal (Allison et al., 1999). Deve-se dar a devida atenção ao efeito colateral do ganho de peso, já que ele afeta a aderência à terapia, produz sequielas somáticas e aumento de mortalidade, além de estigmatização e piora da qualidade de vida (Allison et al., 2003). Portanto, os clínicos devem sensibilizar os pacientes e seus cuidadores para os riscos referentes à saúde associados ao excesso de peso e devem encorajá-los a automonitorar seu peso. $\mathrm{O}$ índice de massa corpórea (IMC) e a circunferência da cintura podem servir como indicadores de risco (Marder et al., 2004).

\section{Efeitos colaterais metabólicos}

Diabetes - Há evidências de que a esquizofrenia per se é um fator de risco independente para intolerância à glicose e um fator de risco conhecido para o desenvolvimento de diabetes do tipo 2 , constatações que parecem independentes do uso da medicação antipsicótica (Bushe e Holt, 2004; Ryan et al., 2003). É provável que as interações entre esquizofrenia e diabetes sejam multifatoriais e incluam fatores genéticos e ambientais. Além disso, sistemas endócrinos de estresse (como o eixo simpático-adrenal-medular e o eixo hipotálamo-hipófise-adrenal), bem como fatores referentes ao estilo de vida (como dieta inadequada, obesidade e falta de exercício), estão envolvidos com a gênese do diabetes (Dinan, 2004; Marder et al., 2004). Estudos farmacoepidemiológicos revelaram uma taxa mais elevada de diabetes em pacientes que estão recebendo antipsicóticos atípicos comparados àqueles que não estão recebendo antipsicóticos ou àqueles que estão recebendo agentes convencionais (Haddad, 2004). Estudos que procuraram estabelecer se a associação com diabetes varia entre os diferentes antipsicóticos atípicos ainda se mostram inconclusivos (Koro et al., 2002a; Wirshing et al., 2002; Bushe e Leonard, 2004; Haddad, 2004). De qualquer forma, acredita-se que a clozapina e a olanzapina são os agentes mais comumente associados ao diabetes (Marder et al., 2004). Desse modo, uma determinação dos níveis de glicose plasmática (de jejum) no período basal deve ser realizada para todos os pacientes antes de iniciar um novo antipsicótico. Como alternativa, pode ser feita a determinação da taxa de hemoglobina glicosilada (Marder et al., 2004). Pacientes e seus cuidadores devem ser informados a respeito dos sintomas do diabetes, e os pacientes devem ser monitorados em intervalos regulares quanto à presença desses sintomas (GCP).

Hiperlipidemia - Relatos retrospectivos e estudos farmacoepidemiológicos constataram elevação significativamente maior de triglicérides em pacientes fazendo uso de determinados antipsicóticos atípicos (olanzapina e clozapina) do que em pacientes que estavam recebendo outros antipsicóticos (haloperidol, quetiapina, risperidona) (Koro et al., 2002b; Wirshing et al., 2002). De forma similar ao diabetes, a hiperlipidemia está ligada à gênese multifatorial, estando associada à obesidade e a fatores inerentes ao estilo de vida (como dieta inadequada e falta de exercícios físicos). Níveis elevados de triglicérides e colesterol estão associados a doença cardíaca coronariana, incluindo doença cardíaca isquêmica e infarto do miocárdio. Portanto, os níveis de colesterol total, lipoproteína de baixa (LDL) e alta (HDL) densidades e os triglicérides devem ser avaliados (Marder et al., 2004). Se o nível de LDL for maior que $130 \mathrm{mg} / \mathrm{dl}$, o paciente deve ser encaminhado a um clínico geral no sentido de avaliar se há indicação para o tratamento com estatinas.

Hiperprolactinemia e disfunção sexual

Antipsicóticos - Os APGs, a amisulpirida e a risperidona podem causar hiperprolactinemia pelo bloqueio dos receptores D2 (Mota et al., 2003; Marder et al., 2004). A hiperprolactinemia pode levar a galactorréia, distúrbios menstruais e sexuais em mulheres e galactorréia, ginecomastia e disfunção reprodutiva e sexual em homens (Dickson e Glazer, 1999). As concentrações plasmáticas de prolactina permanecem elevadas por até 2 semanas após a cessação da terapia oral com um antipsicótico convencional e por até 6 meses após a cessação da terapia com formulações de depósito (Cutler, 2003). Estudos com os ASGs (com exceção da amisulpirida e da risperidona) sugeriram que os níveis de prolactina 
transitoriamente elevados tendem a retornar à faixa da normalidade em poucos dias (Marder et al., 2004). Os efeitos sobre os mecanismos dopaminérgicos, adrenérgicos, colinérgicos e serotonérgicos podem também acarretar disfunção sexual, motivo pelo qual é difícil distinguir entre este e uma deficiência da atividade sexual relacionada à doença (Baldwin e Birtwistle, 1997; Fortier et al., 2000). O bloqueio alfa-adrenérgico periférico pode ser responsável por priapismo (Cutler, 2003). Dos ASGs, a clozapina, a olanzapina e a ziprasidona estiveram associadas apenas a pouca ou modesta elevação da prolactina (Cutler, 2003), e a quetiapina não levou à hiperprolactinemia (Arvanitis et al., 1997). Uma associação clara entre a elevação de prolactina e a disfunção sexual ainda não foi estabelecida (Aizenberg et al., 1995; Kleinberg et al., 1999). Ainda é motivo de discussão se a hiperprolactinemia aumenta o risco de câncer de mama, mas os estudos são inconclusivos até agora (Marder et al., 2004). Suspeita-se que a hiperprolactinemia causa osteoporose se prejudicar a produção de esteróide sexual.

\section{Efeitos colaterais cardiovasculares}

Hipotensão e hipotensão ortostática decorrem do bloqueio alfa-adrenérgico de determinadas medicações antipsicóticas e estão particularmente associadas aos antipsicóticos típicos de baixa potência e a alguns ASGs, como a clozapina (Buchanan et al., 1995; APA, 2004). Pacientes que apresentam hipotensão postural grave devem ter cautela nas variações posturais (por exemplo, ao se levantar rapidamente e sem assistência), uma vez que podem resultar em acidentes e quedas, com eventuais fraturas de quadril, particularmente em pacientes idosos. A titulação gradual da dose (começando com uma dose baixa e monitorizando os sinais de hipotensão ortostática) minimiza o risco de complicações. A taquicardia é particularmente relevante em pacientes com doença cardíaca preexistente, podendo resultar de efeitos anticolinérgicos das medicações antipsicóticas, mas também ocorrendo como resultado de hipotensão postural. Taquicardia não-relacionada a alterações ortostáticas da pressão arterial (que resultam de efeitos anticolinérgicos) pode ocorrer em até $25 \%$ dos pacientes tratados com clozapina (APA, 2004).

Efeitos colaterais cardíacos das medicações antipsicóticas registradas como anormalidades do ECG incluem: prolongamento do intervalo QT, ondas $\mathrm{T}$ anormais, ondas $\mathrm{U}$ proeminentes e alargamento do complexo QRS (Haddad e Anderson, 2002). O intervalo QTc médio em adultos saudáveis é de aproximadamente $400 \mathrm{~ms}$. Intervalos QTc acima de 500 ms estão associados a risco aumentado de torsade de pointes e transição para fibrilação ventricular (Glassman e Bigger, 2001). Em graus variáveis, todos os antipsicóticos podem causar efeitos colaterais cardíacos (dose-dependentes). Entre os APGs, isso se aplica predominantemente aos neurolépticos tricíclicos do grupo das fenotiazinas (clorpromazina, prometazina, pirazina e, especialmente, tioridazina) e à pimozida. Além disso, a administração de haloperidol intravenoso em altsa doses tem sido associada ao risco de prolongamento do QTc (Al Khatib et al., 2003). Entre os ASGs, constatou-se que o sertindol e a ziprasidona aumentam o intervalo QT de maneira significativa (Glassman e Bigger, 2001; Marder et al., 2004). Antes do início e em aumentos subseqüentes de dose, de terapia antipsicótica com tioridazina, mesoridazina e pimozida, a monitorização do ECG é obrigatória. Essa recomendação se aplica também à ziprasidona se houver fatores de risco cardíaco como doença cardíaca conhecida, síndrome do QT longo congênito, história pessoal de síncope e história familiar de morte súbita em jovens. Se esses fatores de risco estiverem presentes, a tioridazina, a mesoridazina e a pimozida não devem ser administradas (Marder et al., 2004). A aplicação de dois ou mais antipsicóticos ou outros agentes adjuntivos poderia aumentar o risco de efeitos colaterais cardíacos (como prolongamento do QTc). Relatos de caso indicam que o uso de clozapina está associado ao risco de miocardite em 1:500 a 1:10.000 dos pacientes tratados (Killian $e t$ al., 1999; Warner et al., 2000; La Grenade et al., 2001). Se o diagnóstico for provável, clozapina deve ser suspensa imediatamente, e o paciente, encaminhado urgentemente para um especialista (Marder et al., 2004).

\section{Outros efeitos colaterais}

Efeitos hematológicos, como inibição da leucopoiese, ocorrem em pacientes tratados com clorpromazina, sendo a leucopenia benigna observada em até $10 \%$ e a agranulocitose, em aproximadamente $0,3 \%$ dos pacientes (APA, 2004). O risco de agranulocitose, definido com uma contagem absoluta de neutrófilos inferior a $500 / \mathrm{mm}^{3}$, tem sido estimado em $0,05 \%$ a $2 \%$ ao ano entre pacientes tratados com clozapina (Buchanan et al., 1995). Esse risco é mais alto nos primeiros 6 meses de tratamento, sendo, portanto, requerida a monitorização semanal da contagem de leucócitos totais e de neutrófilos. Após 18 semanas, a frequiência dessa monitorização pode ser reduzida a cada 2 ou 4 semanas, uma vez que o risco de agranulocitose parece diminuir consideravelmente para uma taxa estimada em 3:1.000 pacientes. O número de leucócitos deve permanecer acima de $3.000 / \mathrm{mm}^{3}$ durante o tratamento com clozapina, e a contagem absoluta de neutrófilos deve permanecer acima de $1.500 / \mathrm{mm}^{3}$. Com o tratamento de manutenção, os pacientes devem ser aconselhados a relatar imediatamente qualquer sinal de infecção (dor de garganta, febre, fraqueza ou letargia) (APA, 2004).

Efeitos alérgicos e dermatológicos, incluindo fotossensibilidade, ocorrem menor frequiência, sendo mais comuns com as medicações de baixa potência (fenotiazinas). Os pacientes devem ser instruídos a evitar exposição excessiva ao sol e a fazer uso de protetor solar (APA, 2004).

Alterações hepáticas, como a elevação de enzimas hepáticas, podem ser desencadeadas por um certo número de medicações antipsicóticas, condição 
usualmente assintomática. Hepatotoxicidade direta ou icterícia colestática ocorrem de forma extremamente rara e estão particularmente associadas às fenotiazinas de baixa potência (APA, 2004). Estudos com a olanzapina têm relatado elevações discretas e reversíveis das enzimas hepáticas (Beasley et al., 1996a).

Efeitos oftalmológicos, tais como hiperpigmentação do cristalino e da córnea, retinopatias, edema de córnea, distúrbios da acomodação visual e glaucoma, têm sido bem descritos como efeitos colaterais de certos antipsicóticos. Para prevenir as retinopatias pigmentares, as opacidades da córnea e a catarata, os pacientes tratados com tioridazina e clorpromazina devem fazer exames oftalmológicos periódicos (aproximadamente a cada 2 anos para pacientes tratados continuamente por um período superior a 10 anos), sendo recomendada a dose máxima de $800 \mathrm{mg}$ /dia de tioridazina (APA, 2004). Como a catarata é observada em cães de caça (principalmente da raça beagle) que receberam quetiapina, os psiquiatras devem interrogar o paciente a respeito da qualidade de sua visão a distância e quanto à presença de sintomas como visão borrada, devendo encaminhálo para uma avaliação oftalmológica a cada 1 ou 2 anos (Marder et al., 2004).

Problemas do trato urinário, tais como retenção e incontinência urinária, podem ser provocados particularmente por medicações antipsicóticas com componentes anticolinérgicos acentuados, como as fenotiazinas. Boca seca, olhos secos e constipação podem resultar de estimulação adrenérgica e anticolinérgica, freqüentemente descritas durante o tratamento com APGs. A sialorréia e a eliminação externa de saliva, que ocorrem com frequiência no tratamento com clozapina, decorrem do clearance diminuído de saliva, relacionado aos mecanismos deficientes de deglutição ou, possivelmente, como resultado do antagonismo de receptores muscarínicos M4, ou ainda da atividade agonista alfa-adrenérgica (Rabinowitz et al., 1996).

\section{Medicações COMPLEMENTARES}

\section{Benzodiazepínicos}

A eficácia dos benzodiazepínicos no tratamento da esquizofrenia tem sido avaliada como monoterapia e como complemento dos antipsicóticos (APA, 2004). Numa revisão de estudos duplo-cegos com benzodiazepínicos em monoterapia, alguns efeitos superiores aos do placebo foram relatados na maioria dos estudos, mas não em todos (reduções de ansiedade, agitação, comprometimento global ou sintomas psicóticos) (Wolkowitz e Pickar, 1991). Sete de 16 estudos duplo-cegos avaliando benzodiazepínicos como medicações adjuntas aos antipsicóticos mostraram efeitos positivos sobre a ansiedade, a agitação, a psicose ou o comprometimento global, e 5 de 13 demonstraram eficácia no tratamento dos sintomas psicóticos (Wolkowitz e Pickar, 1991). Observou-se que os benzodiazepínicos podem melhorar a resposta às medicações antipsicóticas, mas esse efeito pode se limitar à fase aguda e não ser sustentado
(Altamura et al., 1987; Csernansky et al., 1988). A eficácia em pacientes com agitação proeminente foi um dos achados mais consistentes em estudos retrospectivos e abertos (Nível A) (Salzman et al., 1991; Wolkowitz e Pickar, 1991). Efeitos colaterais comuns dos benzodiazepínicos incluem sedação, ataxia, deficiência cognitiva e tendência a causar desinibição comportamental em alguns pacientes.

\section{Estabilizadores do humor e anticonvulsivantes}

Uma metanálise recente incluindo vinte ECRs duplo-cegos e usando critérios de resposta dicotômicos (como redução de sintomas a pelo menos $50 \%$ do nível basal) não constatou vantagem no uso do lítio em monoterapia quando comparado ao placebo ou aos antipsicóticos. Contudo, focalizando primariamente os não-respondedores, observou-se uma discreta superioridade do lítio (versus placebo) quando em associação a antipsicóticos (Leucht et al., 2004a). Além disso, o lítio em monoterapia se mostrou inferior aos antipsicóticos quando os pacientes com transtorno esquizoafetivo foram excluídos da análise.

De modo geral, há evidências da eficácia do lítio quando adicionado à terapia com antipsicóticos, especialmente em pacientes com sintomas referentes ao humor (Nível A) e em casos de esquizofrenia resistente ao tratamento (Nível B). Os pacientes devem ser monitorizados quanto aos efeitos adversos comumente associados ao uso do lítio (poliúria, tremor) e quanto ao risco de interação com antipsicóticos (SEP, confusão, deterioração, outros sinais de síndrome neuroléptica maligna), além da avaliação da litemia em curto prazo, particularmente durante o período inicial de tratamento combinado (APA, 2004).

Uma revisão recente identificou cinco estudos randomizados e controlados que examinaram a eficácia do valproato em associação a antipsicóticos no tratamento da esquizofrenia (Basan et al., 2004). Um desses estudos foi simples-cego (Hesslinger et al., 1999), os outros foram duplo-cegos (Fisk e York, 1987; Dose et al., 1998; Wassef et al., 2000; Casey et al., 2003a). Os resultados globais dessa metanálise foram inconclusivos. Em resumo, há evidências limitadas de que a adição de valproato ao tratamento antipsicótico pode ser bem-sucedida na redução de sintomas específicos, como hostilidade (Citrome et al., 2004). Portanto, pode ser útil introduzir o valproato em casos específicos (Nível C).

Uma metanálise incluindo dez ECRs duplo-cegos constatou que a carbamazepina em monoterapia, comparada ao placebo e aos antipsicóticos, não revelou efeitos benéficos no tratamento da esquizofrenia (Leucht et al., 2004b). O acréscimo de carbamazepina aos antipsicóticos (versus placebo) foi superior em relação aos antipsicóticos isoladamente em termos de melhora global, mas sem diferenças em relação à evolução do estado mental (Leucht et al., 2004b). Existem evidências limitadas de que a adição de carbamazepina ao tratamento antipsicótico pode ser bem-sucedida na redução de sintomas específicos, como comportamento 
agressivo ou sintomas afetivos (Luchins, 1987; Okuma et al., 1989), mas não para uso geral no tratamento da esquizofrenia (Nível C).

Em um ECR com pacientes portadores de esquizofrenia refratária, a adição de lamotrigina (200 mg/dia) ao tratamento com clozapina foi efetiva na redução de sintomas psicopatológicos gerais e sintomas positivos (Tiihonen et al., 2003). Em outro ECR, a adição de lamotrigina ( $400 \mathrm{mg} / \mathrm{dia})$ aos antipsicóticos convencionais (risperidona, olanzapina ou clozapina) melhorou os sintomas psicopatológicos gerais e positivos na análise da amostra total, mas nenhuma diferença foi verificada na análise da "última observação levada a diante" (Kremer et al., 2004). Há evidências de que a lamotrigina, em associação especialmente à clozapina, possa reduzir a psicopatologia esquizofrênica (Nível C), mas é preciso ter em mente os elevados riscos potenciais de leucopenia e agranulocitose (Kossen et al., 2001). Em um estudo aberto e não-randomizado, nenhum efeito benéfico do topiramato adicionado à clozapina, à olanzapina, à risperidona ou ao flupentixol foi observado no tratamento da esquizofrenia refratária (Dursun e Deakin, 2001).

\section{Antidepressivos}

Estudos com antidepressivos em esquizofrenia focalizaram principalmente sua eficácia no tratamento da depressão comórbida ou dos sintomas negativos (APA, 2004). Uma metanálise sugeriu algumas evidências de eficácia sobre os sintomas depressivos em comparação ao placebo, enquanto a deterioração dos sintomas psicóticos ou o agravamento dos efeitos adversos, especialmente SEP, não foi observado (Whitehead et al., 2004), muito embora esses eventos tenham sido descritos em alguns estudos individuais. Uma revisão do uso de antidepressivos em pacientes com transtorno esquizoafetivo ou esquizofrenia com sintomas afetivos chegou a uma conclusão positiva, recomendando o tratamento com agentes antidepressivos se indicado (Levinson et al., 1999). Existem também algumas evidências referentes à eficácia dos antidepressivos sobre os sintomas negativos da esquizofrenia (Nível B) (APA, 2004; Möller, 2004a). Desde que a maioria dos estudos foi realizada em combinação com antipsicóticos de primeira geração, os achados podem ser diferentes com antipsicóticos de segunda geração (APA, 2004). A clomipramina (Berman et al., 1995) e a fluvoxamina (Reznik e Sirota, 2000) mostraram vantagens no tratamento de sintomas obsessivo-compulsivos em esquizofrenia, derivados de dois pequenos estudos abertos (Nível D). Num estudo cruzado, o citalopram revelou eficácia em pacientes com história de agressão em que a medicação reduziu a frequiência de incidentes (Nível D) (Vartiainen et al., 1995).

\section{Outros}

Uma metanálise de cinco ECRs duplo-cegos, nos quais os betabloqueadores foram adicionados ao tratamento com uma droga de referência em esquizofrenia, não encontrou eficácia global para essa estratégia. Ainda assim, vários estudos pequenos abertos e relatos de caso mostraram benefícios na evolução de pacientes refratários ao tratamento (Cheine et al., 2004).

Com base nas considerações fisiopatológicas e na pesquisa experimental, os agentes glutamatérgicos, glicina, d-cicloserina e d-serina têm sido estudados como tratamentos adicionais aos antipsicóticos em esquizofrenia, com resultados controversos (Tsai et al., 1998 e 1999; Goff et al., 1999; Potkin et al., 1999; Evins et al., 2000; Javitt et al., 2001; Möller, 2003; APA, 2004). Os principais estudos negativos de substâncias glutamatérgicas associadas à clozapina podem ser devidos à sua ação similar sobre os sintomas negativos pela via glutamatérgica.

O baclofen, um agonista GABA-B, não mostrou qualquer benefício relevante em estudos abertos $\mathrm{e}$ duplo-cegos placebo-controlados na monoterapia ou quando adicionado aos antipsicóticos-padrão, seguindose a um relato de um caso inicial bem-sucedido (Soares et al., 2004; Wassef et al., 2003b). O piracetam adicionado ao haloperidol numa dose de $3.200 \mathrm{mg} /$ dia demonstrou efeitos benéficos num estudo placebo-controlado randomizado (Noorbala et al., 1999). Os inibidores da acetilcolinesterase (como o donepezil) revelaram, em relatos de caso (Risch et al., 2001) e num estudo não-controlado, resultados positivos em uma variedade de medidas cognitivas (Buchanan et al., 2003), mas não num estudo randomizado, placebo-controlado em pacientes com esquizofrenia crônica (Friedman et al., 2002). A adição de estrógeno $(0,05 \mathrm{mg} / \mathrm{dia})$ ao tratamento com haloperidol mostrou maior melhora nos sintomas psicopatológicos gerais e positivos em mulheres com esquizofrenia crônica (Kulkarni et al., 2001; Akhondzadeh et al., 2003), mas não com esquizofrenia aguda $(0,625 \mathrm{mg} /$ dia de estrógeno conjugado, adicionado ao haloperidol) (Louza et al., 2004). Incrementar com ácidos graxos essenciais insaturados (como o ácido eicosapentanóico) trouxe resultados controversos em quatro estudos randomizados placebo-controlados (Emsley et al., 2003). Uma revisão da Biblioteca Cochrane não estabeleceu efeitos claros dos ácidos graxos v-3 (Joy et al., 2004), mas deu suporte à sugestão de se fazer uma pesquisa adicional nessa direção.

\section{TERAPIA ELETROCONVULSIVA}

Introduzida em 1938, a eletroconvulsoterapia (ECT) envolve a indução de convulsões para fins terapêuticos pela administração de uma frequiência variável de estímulos elétricos para o cérebro por meio de eletrodos aplicados ao couro cabeludo. O procedimento é usualmente modificado pelo uso de anestésicos de curta duração e relaxantes musculares (Tharyan e Adams, 2004). Na prática clínica, recomenda-se o seguinte: convulsões motoras generalizadas com duração de 25 a 30 segundos, monitorando-se por EEG e pela observação de convulsões motoras em antebraço isolado a partir de relaxantes musculares; um estímulo com intensidade aproximada de 2,5 vezes o limiar de convulsão; 
freqüências de tratamento de 2 a 3 vezes por semana; entre 12 e 20 tratamentos (Tharyan e Adams, 2004). A avaliação que precede a ECT deve consistir numa avaliação médica geral para identificar fatores de risco (incluindo história e exame físico, avaliação de sinais vitais, testes laboratoriais básicos e ECG), avaliação anestésica referente à natureza e à extensão do risco anestésico e obtenção de consentimento informado. Embora não existam contra-indicações absolutas à ECT, as seguintes condições se caracterizam como contra-indicações relativas, requerendo extrema cautela e supervisão de um especialista em medicina interna: infarto do miocárdio recente, arritmias cardíacas ou uso de marcapasso, insuficiência cardíaca congestiva, insuficiência coronariana grave, aneurismas abdominal e intracraniano e lesões intracranianas que ocupam espaço (APA Task Force, 2001).

Durante o processo de consentimento informado, informações a respeito do procedimento, incluindo $o$ ato anestésico, devem ser fornecidas, e os riscos e benefícios potenciais da ECT e relação a outras abordagens terapêuticas alternativas devem ser descritos. Em termos da colocação dos eletrodos, dois ensaios randomizados comparando ECT bilateral (bitemporal) versus ECT unilateral (em hemisfério não-dominante) em pacientes com esquizofrenia não mostrou diferenças significantes em relação ao estado mental, melhora global ou funcionamento cognitivo (Thayran e Adams, 2004). Embora os achados em pacientes com depressão sugiram que o posicionamento do eletrodo em localização unilateral, e talvez bifrontal, possa estar associado a menos efeitos adversos cognitivos e que a eficácia com a colocação em posição unilateral possa depender de quanto a intensidade do estímulo excede o limiar de convulsão, a aplicabilidade dessas observações a pacientes com esquizofrenia ainda é incerta (APA, 2004). Em um ensaio clínico randomizado que avaliou três diferentes intensidades de estímulos em ECT bitemporal, constatou-se que as taxas de remissão e os efeitos sobre a cognição foram comparáveis, mas o grupo que atingiu a remissão com baixas intensidades de estímulos recebeu maior número de aplicações de ECT e necessitou de mais dias para alcançar o estado de remissão quando comparado os grupos com que receberam estímulos em intensidades duas ou quatro vezes maiores que o limiar convulsivo (Chanpattana et al., 2001).

Séries de casos clínicos, primariamente provenientes da literatura mais antiga, sugerem que, para se alcançar os benefícios clínicos plenos para os pacientes com esquizofrenia, pode ser necessário um curso mais longo de tratamento agudo do que para pacientes com distúrbios do humor (Kalinowsky, 1943). Um ensaio randomizado mostrou vantagens para 20 tratamentos em relação a outros 12 (Baker et al., 1960).

A eficácia do tratamento agudo com ECT para pacientes com esquizofrenia tem sido descrita em diversos casos, estudos não-controlados e controlados. Portanto, detalhes das revisões publicadas foram disponibilizados por diversos autores (Hawkins et al., 1995; Fink e Sackeim, 1996; Rey e Walter 1997; Walter et al., 1999; APA Task Force, 2001; Greenhalgh (UK ECT Group) et al., 2002; Tharyan e Adams, 2004). Um resultado das revisões citadas é que o tratamento antipsicótico isolado geralmente produz melhores evoluções em curto prazo quando comparado à ECT apenas (Nível A). Também há evidências, a partir de pelo menos três estudos, de que a ECT proporciona uma impressão global de melhora significativamente superior ao placebo (falso tratamento ou sham) (Nível A) (Thayran e Adams, 2004). Ainda assim, existem opiniões diferentes, e outros autores não encontraram vantagem significativa para a ECT em comparação ao tratamento sham em relação ao estado mental (APA, 2004). Observou-se que o tratamento combinado com ECT e medicações antipsicóticas de primeira geração (APGs) é mais efetivo que o tratamento com ECT isoladamente na maioria dos estudos, mas não em todos (APA, 2004).

Uma revisão sobre a eficácia da ECT em adolescentes não identificou estudos controlados e revelou taxas de melhora de $63 \%$ para depressão, $80 \%$ para mania, $42 \%$ para esquizofrenia e $80 \%$ para catatonia. Conclui-se, assim, que a ECT em jovens parece similar em efetividade e efeitos colaterais à ECT em adultos, sem esquecer da ausência de evidências sistemáticas (Rey e Walter, 1997).

Os efeitos colaterais da ECT sobre o sistema cardiovascular são comuns, mas tipicamente benignos e autolimitados (APA Task Force, 2001). Raramente, a ECT se associa a arritmias cardíacas mais sérias, isquemia e infarto, embora a probabilidade, o tipo e a gravidade das complicações cardíacas estejam geralmente relacionados ao tipo e à gravidade da doença cardíaca preexistente (Rice et al., 1994). O tratamento com ECT e sua anestesia são freqüentemente associados a um estado confusional pós-ictal transitório, por vezes acompanhado de agitação pós-ictal. Efeitos colaterais cognitivos também podem ser observados com ECT, embora haja bastante variação individual na extensão e na severidade desses efeitos (APA Task Force, 2001). Para a maior parte dos pacientes, no entanto, o comprometimento da memória retrógrada se resolve em poucas semanas ou meses após a interrupção do tratamento (APA, 2004). Raramente, os pacientes relatam déficit cognitivo mais pervasivo ou persistente, acometendo memórias mais distantes (Donahue, 2000). Uma revisão ampla concluiu que não existem evidências claras de que a ECT realmente causa dano estrutural cerebral (Devanand et al., 1994).

Mais frequientemente, a ECT proporciona melhora da concentração e da atenção (e, em consequiência, das funções mnésicas) paralelamente à resposta clínica (Prudic et al., 2000). Outros efeitos colaterais comumente observados após a ECT incluem: cefaléia, dores musculares generalizadas, náuseas e/ou vômitos. Esses 
efeitos em geral se resolvem espontaneamente ou com medicações analgésicas ou antieméticas (Datto, 2000). $\mathrm{Na}$ esquizofrenia catatônica, a ECT freqüentemente é o tratamento de escolha. Em resumo, exceto pelo que se observa na catatonia, a ECT deve ser usada apenas em casos excepcionais de esquizofrenia refratária ao tratamento, já que nenhuma vantagem foi demonstrada de forma consistente quando comparada aos tratamentos farmacológicos (Nível C). A maior parte dos estudos sobre ECT não faz uma comparação em relação à monoterapia com agentes atípicos como uma alternativa. A ECT deve ser considerada na catatonia (ou nos sintomas afetivos graves), uma vez que existem evidências limitadas em estudos e no conhecimento clínico para confirmar sua eficácia em tais casos, sendo raras as opções alternativas (Nível C).

\section{ESTIMULAÇÃO MAGNÉTICA TRANSCRANIANA REPETITIVA}

A estimulação magnética transcraniana repetitiva ( $r e-$ petitive transcranial magnetic stimulation, rTMS) não é um tratamento aprovado atualmente para os distúrbios neuropsiquiátricos. Ainda assim, essa recente técnica somática tem sido estudada em muitas doenças neuropsiquiátricas (Burt et al., 2002), e existem alguns poucos estudos controlados sugerindo que a rTMS pode melhorar os sintomas psicóticos em esquizofrenia. A rTMS estimula neurônios corticais de forma não-invasiva por indução magnética, utilizando um campo magnético breve e de alta intensidade. As vantagens dessa técnica quando comparada à ECT são a melhor tolerabilidade, a menor incidência de efeitos colaterais e o fato de não haver necessidade de anestesia. A melhora das alucinações auditivas após estimulação do córtex temporoparietal esquerdo em associação ao tratamento antipsicótico foi observada em um estudo randomizado, duplo-cego e controlado pela intervenção sham e em dois estudos randomizados, duplo-cegos e cruzados, cada um deles com uma amostra pequena (Hoffman et al., 2000 e 2003; Rollnik et al., 2000). Outro estudo pequeno, randomizado e controlado não mostrou qualquer efeito da rTMS estimulando o córtex pré-frontal dorsolateral direito (Klein et al., 1999). Pesquisas adicionais são requeridas para avaliar a eficácia e os benefícios potenciais da rTMS na esquizofrenia.

\section{Psicoterapia e intervenções psicossociais}

Como mencionado anteriormente, estas diretrizes concentram-se nos tratamentos biológicos (somáticos) da esquizofrenia. Consequientemente, as abordagens psicoterapêuticas isoladas ou em combinação com a farmacoterapia serão descritas apenas de forma resumida. Os objetivos dos métodos de tratamento psicológico na esquizofrenia são a redução da vulnerabilidade individual, o alívio das influências adversas dos fatores de estresse externos, a melhora na qualidade de vida, a redução dos sintomas da doença, a promoção e a melhora das capacidades de comunicação e de enfrentamento da doença por parte do paciente. A psicoterapia precisa con- siderar os fatores biológicos envolvidos na esquizofrenia e deve ter como objetivo capacitar o paciente a enfrentar a doença e suas conseqüências (aceitação das recaídas, autocontrole, enfretamento dos problemas). As intervenções psicoterapêuticas e psicossociais tornam-se mais importantes no tratamento prolongado da esquizofrenia, sendo restritas principalmente ao aconselhamento e à psicoterapia de apoio, às abordagens psicoeducacionais e às intervenções familiares, além da terapia cognitivocomportamental (TCC) na fase aguda do tratamento. Por essa razão, a avaliação baseada em evidências, relacionada aos principais tópicos considerados nestas diretrizes, incluindo metanálises e revisões sistemáticas, será apresentada no módulo sobre o tratamento de longo termo destas diretrizes.

\section{Primeiro episódio esquizofrênico}

Um paciente com sintomas que caracterizam um primeiro episódio esquizofrênico pode estar apresentar, na realidade, um episódio esquizofrênico, o início de um distúrbio esquizofreniforme ou ainda alguma outra doença ou transtorno que pode causar sintomas semelhantes. Assim, uma avaliação inicial cuidadosa deve ser conduzida, conforme descrito anteriormente. A observação de um paciente, mesmo que por um curto intervalo de tempo, pode fornecer pistas sobre a natureza do diagnóstico. Em estudos naturalistas e controlados, pacientes com primeiro episódio de psicose foram mais responsivos ao tratamento que pacientes com múltiplos episódios de psicose, mas, ao mesmo tempo, muito sensíveis aos efeitos colaterais, especialmente SEP (Lieberman et al., 1996). A incidência de discinesia tardia com haloperidol em dose baixa foi observada pelo menos com a mesma frequiência que em outras amostras tratadas com dosespadrão de APGs, e características clínicas adicionais não identificaram pacientes sob risco de discinesia tardia (Ooshuizen et al., 2003). Os preditores de pior resposta ao tratamento num estudo foram: sexo masculino, história de complicações obstétricas ao nascimento, alucinações e delírios mais graves, déficits de atenção e desenvolvimento de parkinsonismo durante o tratamento antipsicótico (Robinson et al., 1999). Em outros estudos, a presença de sintomas depressivos no início do seguimento foi preditiva de um menor número de sintomas negativos no curso da doença e melhores resultados globais (Oosthuizen $e t$ al., 2002). A distonia mostrou-se associada a idade mais jovem, sintomas negativos proeminentes e maior gravidade da doença (Aguilar et al., 1994). A instituição precoce do tratamento antipsicótico (ou a menor duração da psicose não-tratada) foi associada a melhores resultados no primeiro episódio de esquizofrenia, enquanto o mau funcionamento pré-mórbido pode indicar um subtipo da doença com menor probabilidade de responder ao tratamento antipsicótico, independentemente de quando tenha sido iniciado (Perkins et al., 2004). Observou-se que o uso de maconha (cannabis), comum em esquizofrênicos no primeiro episódio, interferiu e retardou o início do tratamento do episódio psicótico. 
EFICÁCIA DOS ANTIPSICÓTICOS DE PRIMEIRA GERAÇÃO

Num ECR de 5 semanas comparando o flupentixol (dose média de $20 \mathrm{mg} /$ dia) à pimozida (dose média de 18,8 $\mathrm{mg} /$ dia), observou-se eficácia comparável na melhora dos sintomas positivos, enquanto a resposta dos sintomas negativos variou. A pimozida produziu elevação maior dos níveis de prolactina (The Scottish Schizofrenia Research Group, 1987). Um estudo randomizado detectou que uma dose mais alta de flufenazina $(20 \mathrm{mg} /$ dia) revelou melhora global superior, mas maior número de efeitos colaterais incapacitantes que as doses menores (de $5 \mathrm{a} 10 \mathrm{mg} / \mathrm{dia}$ ) (Van Putten et al., 1991). Uma revisão que avaliou a farmacoterapia do primeiro episódio de esquizofrenia informou que, nos estudos abertos com aumento subsequiente da dose nos casos de não-respondedores, o haloperidol proporcionou maior melhora ( $72 \%$ dos casos) em doses de 2 e $5 \mathrm{mg}$ /dia comparadas a doses mais altas (de $10 \mathrm{a}$ $20 \mathrm{mg} / \mathrm{dia}$ ) (Remington et al., 1998). Estudos abertos e não-comparativos de 6 semanas de flufenazina (de 20 a $40 \mathrm{mg} /$ dia) e haloperidol (de 20 a $40 \mathrm{mg} /$ dia) mostraram que aproximadamente $70 \%$ dos pacientes no primeiro episódio foram estabilizados nesse período (Remington $e t$ $a l ., 1998)$. Num estudo randomizado, doses mais altas de haloperidol ( $20 \mathrm{mg} / \mathrm{dia})$ demonstraram apenas de forma intermitente (inferior a 2 semanas) melhor eficácia sobre a psicopatologia comparada a doses mais baixas (de 5 a $10 \mathrm{mg} /$ dia), antes da piora da evolução em razão de SEP (Van Putten et al., 1990). Estudos mais recentes, abertos (Ooshuizen et al., 2001), randomizados e controlados (Ooshuizen et al., 2004) mostraram que doses baixas de haloperidol $(<2 \mathrm{mg} /$ dia) foram no mínimo tão eficazes e mais bem toleradas (com menos SEP) que as dose mais altas de haloperidol.

EFICÁCIA DOS ANTIPSICÓTICOS DE SEGUNDA GERAÇÃO

Apenas um número pequeno de estudos randomizados controlados que compararam a eficácia dos ASG à dos APGs se encontra disponível. Comparada ao haloperidol (dose média de $6 \mathrm{mg} /$ dia, em posologia flexível), a risperidona mostrou melhoras comparáveis nos sintomas psicóticos e menos SEP num estudo de 6 semanas, demonstrando que doses baixas $(<6 \mathrm{mg} /$ dia $)$ já podem assegurar sucesso no controle dos sintomas (Emsley et $a l ., 1999)$. Em outro ECR com duas doses diferentes de risperidona (2 versus $4 \mathrm{mg} / \mathrm{dia}$ ), os pacientes com doses mais altas demonstraram maior comprometimento em tarefas motoras finas, mas nenhuma superioridade expressiva na melhora dos sintomas psicóticos foi verificada (Merlo et al., 2003). Num estudo aberto não-comparativo em pacientes no primeiro episódio psicótico, concluiu-se que a risperidona em baixas doses $(<6 \mathrm{mg} / \mathrm{dia})$ foi eficaz e bem tolerada, e melhoras significativas puderam ser mantidas ao longo de 1 ano de tratamento (Huq et al., 2004). Esses resultados subsidiam as conclusões de outros estudos abertos (Kopala et al., 1997; Yap et al., 2001).

Um estudo pequeno, randomizado e aberto com risperidona em baixa dose comparada ao zuclopentixol em baixa dose não revelou evidência de efeitos diferenciais sobre a psicopatologia ou a função cognitiva se corrigido para as co-variáveis SEP e o uso de medicamento anticolinérgico (Fagerlund et al., 2004). O zuclopentixol em baixa dose, no entanto, causou significativamente mais SEP quando comparado à risperidona. Pacientes no primeiro episódio tratados com olanzapina tiveram melhor resposta clínica, com resultados superiores quanto aos sintomas gerais e positivos (Sanger et al., 1999) e aos sintomas gerais e negativos (Lieberman $e t$ $a l$. 2003), exibindo menor taxa de SEP quando comparados aos que receberam haloperidol (Sanger et al., 1999; Lieberman et al., 2003a).

Num estudo randomizado e duplo-cego comparando os efeitos neurocognitivos da olanzapina a baixas doses de haloperidol, um efeito benéfico sobre a função neurocognitiva pôde ser observado com a olanzapina, mas a diferença no beneficio em relação ao haloperidol em baixa dose foi pequena (Keefe et al., 2004). Num estudo prospectivo, comparativo, aberto, não-randomizado que comparou a olanzapina aos agentes convencionais, observou-se eficácia superior na resposta clínica, nos sintomas positivos e negativos, na agitação e na depressão, além de menor freqüência de SEP com a olanzapina (Bobes et al., 2003). Pacientes em primeiro episódio de esquizofrenia tratados com clozapina tiveram como resultado a melhora e a remissão mais rápidas, demonstrando maior benefício sobre a impressão clínica global, e mostraram taxa de SEP reduzida em comparação àqueles que receberam clorpromazina (Lieberman et al., 2003b). Numa revisão da Biblioteca Cochrane incluindo dois ECRs (Emsley et al., 1999; Sanger et $a l ., 1999)$, os autores não observaram superioridade consistente quanto à eficácia dos ASGs versus APGs no primeiro episódio de esquizofrenia. Porém, taxas mais baixas de SEP (e uso reduzido de anticolinérgicos) foram observadas nos pacientes tratados com risperidona ou olanzapina comparadas ao haloperidol. A olanzapina revelou superioridade na avaliação da psicopatologia global (Rummel et al., 2003). Outra revisão sugeriu os ASGs como tratamento de primeira linha para pacientes com o primeiro episódio (Bradford et al., 2003).

Num estudo randomizado, duplo-cego que comparou a olanzapina (dose média de $15 \mathrm{mg} /$ dia) à risperidona (dose média de $4 \mathrm{mg} /$ dia) não foi observada diferença na eficácia sobre os sintomas positivos e negativos nem na frequiência e na gravidade dos eventos adversos (Van Bruggen et al., 2003).

Em resumo, há evidências para a eficácia de APGs (particularmente haloperidol, flupentixol, pimozida, clorpromazina, todos nível C) e ASGs (particularmente clozapina, nível $\mathrm{C}$; olanzapina e risperidona, ambas nível B) no tratamento de pacientes com primeiro episódio de esquizofrenia.

ReCOMEndações geRAIS

Em algumas diretrizes recentes, o tratamento inicial é recomendado em cenário ambulatorial ou domiciliar, se 
possivel, porque esta abordagem pode minimizar o trauma, a ruptura e a ansiedade para o paciente e a família, que em geral estão mal informados e têm receios sobre a doença mental, além de preconceitos contra os cuidados psiquiátricos em ambiente hospitalar (NICE, 2002; RANZCP, 2003). Em outras diretrizes, esses benefícios são ponderados contra as vantagens de um cenário hospitalar, que permite um monitoramento mais cuidadoso dos sintomas psicóticos, bem como de quaisquer efeitos colaterais, incluindo distonia aguda, acatisia ou síndrome neuroléptica maligna em decorrência do tratamento com medicamentos antipsicóticos (DGPPN, 1998; APA, 2004). A internação do paciente é necessária se houver risco significativo de autoflagelação ou agressão, se o nível de apoio na comunidade for insuficiente ou se a crise for muito grave para ser manejada em ambiente familiar, mesmo com suporte domiciliar. Os cuidados durante a internação devem ser fornecidos em ambiente o menos restrito possível (RANZCP, 2003). Infelizmente, as recomendações precedentes podem ser seguidas apenas em situação ideal. Frequientemente, com pacientes psicóticos e possivelmente violentos, uma entrevista diagnóstica adequada ou o exame físico não pode ser conduzido. Contudo, não importa quão agitado o paciente está, a equipe da admissão deve fazer tudo para ter certeza de que o paciente não está sofrendo de outra doença que possa requerer intervenção imediata (APA, 2004).

Os tratamentos farmacológicos devem ser introduzidos com muito cuidado em pacientes virgens de tratamento. Cuidados especializados de enfermagem, ambiente seguro e de apoio e doses regulares e independentes de benzodiazepínicos podem ser implementados para aliviar a angústia, a insônia e os distúrbios de comportamento secundários à psicose, ao mesmo tempo que o medicamento antipsicótico faz seu efeito (RANZCP, 2003).

\section{ESCOLHA DO MEDICAMENTO ANTIPSICÓTICO}

Com base nos resultados dos estudos citados e na experiência clínica, o uso de ASGs como primeira linha (exceto a clozapina) é recomendado para indivíduos com esquizofrenia recentemente diagnosticada, principalmente quanto à melhor tolerabilidade $\mathrm{e}$ ao risco reduzido de SEP, em especial discinesia tardia (NICE, 2002; RANZCP, 2003; APA, 2004). O uso precoce de clozapina pode ser considerado se o risco de suicídio for proeminente ou persistente (RANZCP, 2003), mas normalmente a clozapina não deve ser a droga de escolha no primeiro episódio de esquizofrenia. No longo prazo, a relação risco-benefício pode mudar para alguns pacientes, como nos casos de ganho de peso ou efeitos colaterais sexuais associados aos ASG (RANZCP, 2003).

\section{POSOLOGIA}

Os ASGs e os APGs no limite inferior da faixa de dose-padrão são os tratamentos preferidos para quem apresenta um primeiro episódio de esquizofrenia (DGPPN, 1998; NICE, 2002; RANZCP, 2003; APA, 2004). Com base nos achados mencionados, essa recomendação posológica é confirmada principalmente para o haloperidol e a risperidona (Nível B), enquanto, para os outros antipsicóticos, existem apenas evidências esparsas (Nível D).

\section{Exacerbação aguda (recaída)}

Os fatores que mais contribuem para a recaída são a não-aderência ao tratamento antipsicótico, o uso de substâncias e os eventos estressantes, embora as recaídas não sejam incomuns como resultado da evolução natural da doença, mesmo com o tratamento contínuo. Se houver suspeita de não-aderência, recomenda-se que as razões para tal sejam avaliadas e consideradas no plano de tratamento (DGPPN, 1998; APA, 2004).

\section{EFICÁCIA DOS ANTIPSICÓTICOS DE PRIMEIRA GERAÇÃO}

Numa revisão, com exceção da mepazina e da promazina, todos os APGs demonstraram eficácia superior ao placebo no tratamento agudo, apesar de haver diferenças quanto à dose, à potência e aos efeitos colaterais das diferentes drogas (Davis et al., 1989; Baldessarini et al., 1990; Kane e Marder, 1993; Dixon et al., 1995). Concluiu-se que o haloperidol foi eficaz no controle dos episódios agudos de esquizofrenia quando comparado ao placebo, mas também demonstrou alta propensão para causar distúrbios de movimento (Joy et al., 2004). Em dois ECTs, a pirazina mostrou eficácia similar à do haloperidol, com menor incidência de SEP (Schmidt et al., 1982; Klimke et al. 1993). Dois ECR comparando a pirazina aos antipsicóticos atípicos mostraram resultados controversos: um deles encontrou superioridade da zotepina na melhora da psicopatologia (Wetzel et al., 1991), enquanto o outro verificou vantagem da pirazina nessa condição (Dietrele et al., 1991). De acordo com esses estudos e com um estudo adicional que comparou a pirazina à amisulpirida, conclui-se que a pirazina está associada ao baixo índice de SEP, sendo os efeitos colaterais extrapiramidais similares aos dos agentes atípicos mencionados (Ruther e Blanke, 1988).

\section{EFICÁCIA dOS ANTIPSICÓTICOS DE SEGUNDA GERAÇÃO}

Pacientes selecionados em estudos controlados com placebo e amisulpirida exibiram predominantemente sintomas negativos (Pailliere-Martinot et al., 1995). Comparada ao haloperidol, à flufenazina ou ao flupentixol, a amisulpirida se mostrou associada à melhora semelhante ou ainda maior dos sintomas globais (Pichot et al., 1988; Delcker et al., 1990; Muller et al., 1997; Pucch et al., 1998; Wetzel et al., 1998; Colonna et al., 2000), à melhora comparável nos sintomas positivos (Delcker $e t$ al., 1990; Möller et al., 1997; Pucch et al., 1998; Wetzel et al., 1998; Carriere et al., 2000; Colonna et al., 2000) e à maior melhora dos sintomas negativos (Muller et al., 1997; Pucch et al., 1998; Colonna et al., 2000). Num ECR pequeno de 6 semanas comparando a amisulpirida (de $400 \mathrm{a} 800 \mathrm{mg} / \mathrm{dia}$ ) com a risperidona (de 4 a $8 \mathrm{mg} / \mathrm{dia}$ ) em pacientes com sintomas positivos, nenhuma diferença significativa foi observada em termos de eficácia ou 
tolerabilidade global (Hwang et al., 2003). Numa revisão, a amisulpirida foi considerada, no mínimo, tão eficaz quanto o haloperidol e o flupentixol no tratamento das exacerbações agudas da esquizofrenia com uma faixa de dose ótima de 400 a $800 \mathrm{mg} /$ dia (Freeman, 1997). Em resumo, há evidências convincentes para a eficácia do tratamento com amisulpirida nos episódios agudos de esquizofrenia (Nível B).

Numa metanálise de dados agrupados de cinco estudos clínicos duplo-cegos, controlados comparando aripiprazol com placebo e haloperidol em pacientes com recaída aguda, o aripiprazol mostrou um perfil favorável de segurança e tolerabilidade (Marder et al., 2003). Comparado ao placebo, foi observada uma melhora significativamente superior dos sintomas negativos apenas com $15 \mathrm{mg} /$ dia de aripiprazol e $10 \mathrm{mg} /$ dia de haloperidol, e não com $30 \mathrm{mg} /$ dia de aripiprazol (Kane et al., 2002), assim como em outro estudo com doses de 20 e $30 \mathrm{mg} /$ dia de aripiprazol e $6 \mathrm{mg} /$ dia de risperidona (Potkin et al., 2003). Estudos randomizados, duplo-cegos e controlados exibiram melhoras comparáveis nos sintomas gerais, positivos e negativos com aripiprazol em relação ao haloperidol ou à risperidona (Kane $e t$ al., 2002; Potkin et al., 2003). Em resumo, existem evidências convincentes para a eficácia do aripiprazol nos episódios agudos de esquizofrenia (Nível B).

Para pacientes esquizofrênicos agudamente doentes, a clozapina possibilitou melhora psicopatológica comparada ao placebo em dois ECR com casuísticas pequenas (Shopsin et al., 1979; Honigfeld et al., 1984). Em estudos europeus duplo-cegos, randomizados e multicêntricos, a eficácia de clozapina foi comparável à do haloperidol, da clorpromazina, da trifluopirazina e do clopentixol (Fischer-Cornelssen e Ferner, 1976). Além disso, outros ECRs pequenos revelaram eficácia global comparável (Chiu et al., 1976; Guirguis et al., 1977; Gelenberg e Doller, 1979) ou superior à da clorpromazina (Shopdin et al., 1979). A clozapina foi tão eficaz quanto o haloperidol (Klieser et al., 1994) ou a risperidona (Heinrich et al., 1994) nos episódios agudos de esquizofrenia e superior à clorpromazina em pacientes no primeiro episódio (Lieberman et al., 2003). Em resumo, há evidência para a eficácia da clozapina nos episódios agudos de esquizofrenia (Nível B), mas, por causa de seu perfil de efeitos colaterais, especialmente efeitos adversos hematológicos, não é recomendada no tratamento de primeira linha da esquizofrenia aguda.

Em pacientes esquizofrênicos agudamente doentes, o tratamento com olanzapina foi superior ao placebo na melhora dos sintomas gerais e positivos uma faixa de dose de 5 a 20 mg/dia (Beasley et al., 1996a e 1996b; Hamilton et al., 1998). Em comparação ao haloperidol, resultados semelhantes ou superiores sobre os sintomas gerais, positivos e negativos foram observados (Beasley et al., 1996b e 1997; Tollefson et al., 1997; Hamilton et al., 1998; Revicki et al., 1999; Ishigooka et al., 2001; Lieberman et al., 2003). Em resumo, há evidências convin- centes quanto à eficácia da olanzapina para o tratamento de episódios agudos de esquizofrenia (Nível A).

Em pacientes com recaída aguda, o tratamento com quetiapina comparado ao placebo foi superior na melhora dos sintomas gerais e positivos nas doses de 150 a 750 mg/dia (Fabre et al., 1995; Borison et al., 1996; Arvanitis et al., 1997; Small et al., 1997). Houve também melhora significativamente superior na sintomatologia negativa, mas não em todas as faixas de dose (Fabre et al., 1995; Borison et al., 1996; Arvanitis et al., 1997; Small et al., 1997). Melhorias maiores ou comparáveis dos sintomas gerais, positivos e negativos foram observadas com quetiapina comparada ao haloperidol ou à clorpromazina nos ECRs que trataram de pacientes com doença aguda (Arvanitis et al., 1997; Peuskens e Link, 1997; Copolov et al., 2000). Conseqüentemente, foi revelada evidência para o uso de quetiapina no tratamento da esquizofrenia (Nível A).

Para a esquizofrenia na fase aguda, numa faixa de dose de $6 \mathrm{a} 16 \mathrm{mg} / \mathrm{dia}$, a risperidona demonstrou eficácia nos estudos controlados com placebo no tratamento dos sintomas gerais e positivos (Borrison et al., 1992; Chouinard et al., 1993; Marder e Meibach, 1994). Num estudo de curta duração, apenas $6 \mathrm{mg} /$ dia de risperidona proporcionaram melhora superior dos sintomas negativos quando comparados ao placebo em uma amostra de pacientes com esquizofrenia crônica (Chouinard $e t$ al., 1993). Comparado ao haloperidol (Claus et al., 1992; Ceskiva e Svestka, 1993; Chouinard et al., 1993; Min et al., 1993; Marder e Meibach, 1994; Peuskens et al., 1995; Blin et al., 1996), à ferfenazina (Hoyberg et al., 1993) e ao flupentixol (Huttunen et al., 1995), houve resposta similar, ou melhor, na psicopatologia global e nos sintomas positivos com risperidona na maior parte das doses fixas ou com doses flexíveis, com taxa de SEP dose-dependente. Na maioria dos estudos, a risperidona produziu um número significativamente menor de SEP que os agentes convencionais de comparação. Em resumo, existem evidências convincentes para a eficácia do tratamento com risperidona nos episódios agudos de esquizofrenia (Nível A).

Nos estudos duplo-cegos, randomizados com doses de 80 a $160 \mathrm{mg} /$ dia, a ziprasidona foi superior na melhora geral e nos sintomas positivos quando comparada ao placebo em pacientes com doença aguda (Keck et al., 1998; Daniel et al., 1999). Em outro estudo também houve melhora superior na sintomatologia negativa (Daniel et al., 1999). Comparada ao haloperidol, a ziprasidona mostrou melhoras similares quanto aos sintomas gerais, positivos e negativos em ECRs de fase aguda (Goff et al., 1998; Hirsch et al., 2002). Em resumo, existem evidências convincentes para a eficácia da ziprasidona no tratamento dos episódios agudos de esquizofrenia (Nível A).

Um ECR, comparando doses de 150 a $300 \mathrm{mg} / \mathrm{dia}$ de zotepina ao placebo, demonstrou melhora superior na psicopatologia geral, positiva e negativa (Cooper et al., 
2000a). Comparada ao haloperidol (Fleischhacker et al., 1989; Barnas et al., 1992; Petit et al., 1996; Hwang et al., 2001), à clorpromazina (Cooper et al., 2000a) e à pirazina (Dieterle et al., 1991; Wetzel et al., 1991), a zotepina mostrou melhora comparável ou superior quanto à psicopatologia global e aos sintomas positivos e negativos. Em resumo, há boa evidência para a eficácia da zotepina no tratamento da esquizofrenia aguda (Nível A).

RECOMENDAÇõES GERAIS

Em pacientes com múltiplos episódios, recomenda-se que o tratamento farmacológico antipsicótico seja iniciado imediatamente, desde que não interferira na avaliação diagnóstica, pois as exacerbações psicóticas agudas podem estar associadas à angústia emocional, à ruptura da vida do paciente e a um risco substancial de comportamentos perigosos para si próprio, para os outros ou para a propriedade (APA, 2004). A monoterapia antipsicótica é recomendada pelas diretrizes (DGPPN, 1998; NICE, 2002; RANZCP, 2003; APA, 2004) no tratamento inicial do episódio agudo da esquizofrenia (Nível D).

ESCOLHA DO MEDICAMENTO ANTIPSICÓTICO

A escolha do medicamento antipsicótico deve ser feita em conjunto pelo indivíduo e pelo clínico responsável por seu tratamento com base numa discussão sobre os benefícios relativos dos medicamentos e seus perfis de efeitos colaterais (NICE, 2002; RANZCP, 2003; APA, 2004). Quando não for possível uma discussão completa entre o clínico responsável pelo tratamento e o indivíduo envolvido, em particular no controle de um episódio agudo de esquizofrenia, os ASGs orais devem ser considerados como as opções de escolha no tratamento por causa do baixo risco potencial de sintomas extrapiramidais (NICE, 2002) e da eficácia similar quando comparados aos APGs (RANZCP, 2003; APA, 2004). Contudo, a seleção de um medicamento antipsicótico é frequientemente guiada pela experiência prévia do paciente com os antipsicóticos, incluindo o grau de resposta do sintoma, a experiência pregressa de efeitos colaterais, a via preferencial de administração do medicamento, a presença de comorbidades e as potenciais interações com outros medicamentos prescritos (DGPPN, 1998; APA, 2004). Todos os ASGs disponíveis, exceto a clozapina (RANZCP, 2003; APA, 2004), devem ser considerados como opções de tratamento para indivíduos que estejam recebendo atualmente drogas antipsicóticas convencionais que, apesar do controle adequado do sintoma, apresentam efeitos colaterais inaceitáveis e também para aqueles em recaída que apresentaram previamente controle insatisfatório ou efeitos colaterais inaceitáveis às drogas antipsicóticas convencionais. Não se recomenda que, na prática clínica diária, os indivíduos mudem para um dos medicamentos antipsicóticos atípicos orais caso tenham alcançado um bom controle de sua condição sem efeitos colaterais inaceitáveis com os medicamentos antipsicóticos convencionais (Nível D) (DGPPN, 1998; NICE, 2002; APA, 2004).

\section{Posologia}

Uma descrição geral dos estudos que compararam diferentes doses de APGs concluiu que doses diárias $\leq 300$ $\mathrm{mg}$ de $\mathrm{CPZ}$ são inadequadas para o tratamento ótimo e doses $\geq 940 \mathrm{mg}$ de $\mathrm{CPZ}$ não produziram respostas melhores que na faixa entre 504 e $940 \mathrm{mg}$ em equivalentes de CPZ (Nível A) (Davis et al., 1989). Outra revisão encontrou melhora superior em quase dois terços dos estudos usando doses $\leq 300 \mathrm{mg}$ de $\mathrm{CPZ}$ e uma superioridade consistente para doses diárias $\geq 500 \mathrm{mg}$ de $\mathrm{CPZ}$ em comparação ao placebo (Nível A) (Baldessarini et al., 1990). Além disso, a melhor resposta dose-dependente foi encontrada numa faixa de 2 a $10 \mathrm{mg} /$ dia de haloperidol (Baldessarini et al., 1990). Nenhuma vantagem significativa foi encontrada para doses maiores que 10 a 20 $\mathrm{mg}$ /dia de haloperidol no tratamento agudo comparado a doses menores (Kane e Marder, 1993; Dixon et al., 1995). ECRs recentes de APGs para o tratamento agudo enfocando as estratégias de administração mostraram de forma consistente que doses modestas (principalmente $<10 \mathrm{mg} /$ dia de haloperidol ou equivalente ou níveis plasmáticos $<18 \mathrm{ng} / \mathrm{ml}$ de haloperidol) foram tão ou mais eficazes que doses mais altas (Nível A) (Coryell et al., 1998; Stone et al., 1995; Volavka et al., 2000). Doses médias de APGs mostraram melhora da depressão comórbida (Koreen et al., 1993; Volavka et al., 1996; Krakowski et al., 1997), enquanto doses mais altas se mostraram associadas a um risco maior de SEP e disforia (Bollini et al., 1994; Krakowski et al., 1997).

Numa revisão sistemática de 16 ECRs com 19 comparações diferentes de doses randomizadas de haloperidol, usando doses baixas (entre 3 e $7,5 \mathrm{mg} /$ dia comparados aos intervalos de 7,5 a $15 \mathrm{mg} /$ dia e 15 a 35 $\mathrm{mg}$ /dia, respectivamente), não houve perda de eficácia, mas essas doses estavam associadas a uma taxa menor de efeitos adversos extrapiramidais clinicamente significativos do que as doses mais altas (Nivel A) (Wairach et al., 2004). Uma revisão adicional afirmou que a dose máxima próxima da eficácia esteve entre 3 e $10 \mathrm{mg} /$ dia. Contudo, doses altas de haloperidol mostraram-se não menos eficazes que as doses médias (Nível A) (Davis e Chen, 2004). A adaptação individual da dose, e não a posologia-padrão, parece ser a melhor estratégia de tratamento (Klieser e Lehmann, 1987; Dixon et al., 1995).

Em resumo, a recomendação de doses diárias entre 300 e $1.000 \mathrm{mg}$ em equivalentes a CPZ para os APGs no tratamento de um episódio de sintoma agudo por um período mínimo de 6 semanas permanece estável entre a diretrizes e ao longo do tempo (APA, 1997 e 2004; DGPPN, 1998; Lehman et al., 1998; Grupo de Trabalho da Associação Canadense de Psiquiatria, 1998; NICE, 2002), devendo-se utilizar a dose mínima eficaz. A dose ótima para cada paciente deve ser estabelecida por meio de julgamento clínico.

Estudos randomizados, controlados com placebo de ASGs, que compararam duas ou mais doses de um antipsicótico foram usados numa revisão para calcular a 
curva dose-resposta (para cada APG ou ASG e como um grupo baseado na equivalência da dose). A dose eficaz próxima do máximo foi definida como a dose-limite necessária para produzir todas ou quase todas as respostas clínicas para cada droga. Observou-se que a dose eficaz próxima do máximo foi de $4 \mathrm{mg}$ /dia para a risperidona, $120 \mathrm{mg} /$ dia para a ziprasidona, $10 \mathrm{mg} /$ dia para o aripiprazol, $>400 \mathrm{mg} /$ dia para a clozapina e provavelmente $>16 \mathrm{mg}$ /dia para a olanzapina (Davis e Chen, 2004). A evidência para o ajuste de dose com base na prática clínica, que difere das recomendações iniciais baseadas em estudos de aprovação e de comercialização, advém das pesquisas de alcance nacional. De 1997 até 2001, a dose média de risperidona usada para pacientes internados no sistema estadual de Nova York diminuiu de 7,1 para $4,9 \mathrm{mg} /$ dia (Citrome et al., 2002). Adicionalmente, com base muma pesquisa retrospectiva, uma titulação menos rápida de risperidona (de 0,5 a $2 \mathrm{mg} / \mathrm{dia}$ ) foi recomendada para manter os pacientes aderentes aos seus medicamentos (Luchins et al., 1998). Por outro lado, as doses de olanzapina no sistema do Estado de Nova York para os pacientes internados aumentou. Em 2001, quase $26 \%$ dos pacientes em uso de olanzapina recebiam doses $>20 \mathrm{mg}$ /dia (Citrome et al., 2002).

Com base numa revisão dos achados publicados e da experiência clínica, um início mais rápido que o atual do regime para quetiapina foi proposto para o tratamento em pacientes hospitalizados com esquizofrenia aguda. Adicionalmente, doses mais altas (até $1.600 \mathrm{mg} / \mathrm{dia}$ ) de quetiapina foram bem toleradas em alguns pacientes em virtude de seu perfil favorável (Arango e Bobes, 2004). Uma revisão concluiu que não ainda há dados suficientes disponíveis para assegurar uma relação dose-resposta clara de todos os ASGs aprovados e para se fazer recomendações sobre as estratégias ótimas de administração (Kinon et al., 2004). A dose pode ser titulada tão rapidamente quanto tolerada até a dose terapêutica-alvo do medicamento antipsicótico, a menos que haja evidência de que o paciente apresenta efeitos colaterais indesejáveis (APA, 2004). Há um acordo amplo nas revisões (Davis et al., 1989; Baldessarini et al., 1990; Kane e Marder, 1993; Dixon et al., 1995; Davis e Chen, 2004; Kinon et al., 2004) e nas diretrizes (DGPPN, 1998; NICE, 2002; APA, 2004) de que doses agudas maciças de medicamento antipsicótico, citadas na literatura como "neuroleptização rápida”, não fornecem nenhuma vantagem sobre a administração-padrão no tratamento inicial e podem estar associadas ao risco mais elevado de SEP (Nível D). Portanto, essa estratégia de tratamento não deve ser usada em episódios agudos de esquizofrenia.

\section{Características clínicas específicas que influenciam o plano de tratamento}

\section{TRATAMENTO DOS SINTOMAS PREDOMINANTEMENTE POSITIVOS}

$\mathrm{Na}$ prática clínica, os pacientes com episódio agudo de esquizofrenia se apresentam com sintomas predominantemente positivos. Esse tópico já foi discutido numa seção anterior desta diretriz. Em pacientes com múltiplos episódios, recomenda-se que o tratamento farmacológico com antipsicóticos seja iniciado imediatamente, desde que não interfira nas avaliações diagnósticas, pois as exacerbações agudas psicóticas podem estar associadas a angústia emocional, ruptura na vida do paciente e risco substancial de comportamentos perigosos a si próprio e aos outros. Para pacientes no primeiro episódio, a observação em curto prazo e a administração de baixas de doses de benzodiazepínicos podem ser úteis no estabelecimento do diagnóstico antes de o tratamento antipsicótico ser introduzido. Outros medicamentos psicoativos são comumente adicionados aos medicamentos antipsicóticos quando o paciente continua a demonstrar sintomas psicóticos ativos apesar do estudo de medicamentos adequados. Para sintomas positivos persistentes apesar da farmacoterapia, a resistência ao tratamento deve ser considerada.

Em resumo, nenhuma recomendação específica sobre o tratamento é dada aos pacientes com predomínio de sintomas positivos, e o leitor é recomendado a ver a seção que discute as estratégias para o tratamento da recaída aguda ou outras características clínicas específicas que influenciam o plano de tratamento.

\section{TRATAMENTO dA AGITAÇÃO}

Pacientes esquizofrênicos desenvolvem comportamento agitado, agressivo ou violento em decorrência principalmente de sintomas psicóticos (como delírios persecutórios, mania ou alucinações), como resultado de outros sintomas (como medo e ansiedade) ou ainda quando os controles internos estão comprometidos (Angermeyer, 2000). Fatores relacionados ao ambiente do paciente ou das instituições envolvidas no tratamento (como enfermarias com muitos pacientes, falta de privacidade e tempo longo de espera) contribuem para a ocorrência do comportamento agressivo. A predição de um comportamento agressivo e violento durante a hospitalização é difícil, mas foi verificada uma associação com hostilidade e desordens de pensamento (Steinert, 2002).

Diante de um paciente esquizofrênico agressivo com doença aguda, o médico e a equipe clínica devem fornecer estrutura, reduzir a estimulação e tentar tranqüilizar verbalmente e acalmar a pessoa, minimizando a situação o quanto antes (Osse e Sigadel, 2001). Se possível, a administração oral de medicamentos é preferivel à administração parenteral. A menor dose eficaz deve ser administrada, sendo, caso necessário, gradativamente aumentada. $O$ controle emergencial da violência na esquizofrenia pode incluir sedação e, como última opção, reclusão e isolamento. Da mesma forma, nesse contexto, o uso de drogas para controlar o distúrbio de comportamento (tranqüilização rápida) é visto freqüentemente como último recurso, quando abordagens psicológicas apropriadas e abordagens comportamentais tenham falhado ou sejam inapropriadas.

O objetivo do tratamento medicamentoso em tais circunstâncias é acalmar a pessoa e reduzir o risco de 
violência e perigo em vez de tratar a condição psiquiátrica de base. Os psiquiatras e a equipe multidisciplinar que fazem uso da tranquilização rápida devem ser treinados para a correta avaliação e controle dos usuários do serviço, especialmente nesse contexto, o que deve incluir desde a avaliação e o controle dos riscos dos medicamentos (benzodiazepínicos e antipsicóticos), prescrevendo-os de acordo com os limites terapêuticos, até a utilização e a manutenção de técnicas e equipamentos necessários para a ressuscitação cardiopulmonar, além da utilização do flumazenil (antagonista do benzodiazepínico) (DGPNN, 1998; NICE, 2002; APA, 2004).

Dois ECRs mostraram que a combinação de haloperidol (5 mg) e lorazepam (4 mg) por via intramuscular produz resposta geral superior e resposta clínica mais rápida que o haloperidol isoladamente (Bienick et al., 1998; Garza-Trevino et al., 1989). Comparada à monoterapia com benzodiazepínicos ou antipsicóticos isoladamente, a associação do lorazepam (ou flunitrazepam) ao haloperidol, ambos administrados por via intramuscular, demonstrou eficácia similar no controle da agitação e na resposta geral ao tratamento (Battaglia et al., 1997; Foster et al., 1997; Dorevitch et al., 1999). Num estudo, $2 \mathrm{mg}$ de lorazepam foram superiores a $5 \mathrm{mg}$ de haloperidol na melhora da impressão global (Foster $e t$ $a l ., 1997)$. Em um estudo aberto, randomizado e controlado, a administração de midazolam (15 mg) mostrou-se superior em termos de sedação (e, conseqüentemente, de redução da agitação) em relação à combinação de haloperidol $(5 \mathrm{mg})$ e prometazina $(50 \mathrm{mg})$, ambos por via intramuscular (TREC, 2003).

Embora o uso de ASGs com responsabilidade menor quanto aos efeitos colaterais extrapiramidais se mostre promissor para a tranqüilização rápida, um estudo comparando a olanzapina (10 $\mathrm{mg}$ por via intramuscular) ao haloperidol (7,5 $\mathrm{mg}$ por via intramuscular) constatou eficácia similar na redução da agitação em 2 e 24 horas após a primeira injeção (Wright et al., 2001). A olanzapina demonstrou um perfil de efeitos colaterais favorável, com redução da necessidade adicional de benzodiazepínicos, menor incidência de distonia e SEP e menor necessidade de receber drogas anticolinérgicas (Altamura et al., 2003). Há um risco de morte súbita após a aplicação intramuscular de olanzapina e benzodiazepínicos. Portanto, esse uso combinado deve ser evitado. Um estudo aberto demonstrou igual eficácia da ziprasidona (20 a $80 \mathrm{mg}$ por via intramuscular) comparada ao haloperidol (10 a $40 \mathrm{mg}$ por via intramuscular) em pacientes com esquizofrenia aguda e agitação (Swift et al., 2003). Um estudo randomizado mostrou eficácia comparável da ziprasidona (40 mg) e do haloperidol (10 mg) por via intramuscular (Brook et al., 2000). Além disso, um estudo de determinação da faixa posológica mostrou superioridade da ziprasidona $(20 \mathrm{mg})$ em relação à ziprasidona $(2 \mathrm{mg})$ por via intramuscular na redução da agitação aguda (Daniel $e t$ $a l ., 2001)$. A sedação rápida também pode ser atingida pela administração de antipsicóticos de baixa potência (como a levomepromazina e o clorprotixeno) ou zuclopentixolacetato (DGPPN, 1998), mas essa estratégia não é mais recomendada nas diretrizes recentes (APA, 2004). Quando o tratamento oral é aceito, a combinação de risperidona oral (2 $\mathrm{mg})$ e lorazepam $(2 \mathrm{mg}$ ) parece ser comparável à de haloperidol (5 mg) intramuscular e lorazepam (2 mg) (Currier e Simpson, 2001).

\section{Recomendações}

O lorazepam e os agentes neurolépticos convencionais mostraram eficácia comparável no tratamento agudo da agressão e da agitação psicomotora (Nível C). Em razão do perfil de efeito colateral mais favorável do lorazepam, o tratamento inicial deve ser realizado com 2 a $4 \mathrm{mg}$ nos pacientes em que não ainda não se decidiu quanto a seguir uma estratégia medicamentosa ou não-medicamentosa ou sobre qual tipo de tratamento antipsicótico será adotado. A administração de diazepam ou outro benzodiazepínico diferente do lorazepam, ou de agentes neurolépticos de baixa potência (como o clorprotixeno ou a levopromazina), não é recomendada no tratamento da agitação e da excitação por causa da eficácia inferior ou da baixa tolerabilidade. Nos pacientes cujo comportamento agressivo é claramente decorrente de sintomas psicóticos, um tratamento combinado de lorazepam com um agente neuroléptico pode ser utilizado (Nível C). Em virtude da melhor tolerabilidade, um agente neuroléptico atípico (como a olanzapina ou a ziprasidona), preferencialmente na forma parenteral, pode ser usado, quando possível, em preferência ao agente neuroléptico convencional (Nível C). Há risco de morte súbita após a aplicação intramuscular de olanzapina e benzodiazepínicos. Portanto, esse uso combinado deve ser evitado. Da mesma forma, cautela deve ser recomendada quando se combinar clozapina e benzodiazepínicos (Rupprecht et al., 2004). Os clínicos também devem estar cientes das anormalidades cardíacas, especialmente quando se administra ziprasidona por via intramuscular.

Se for necessária uma sedação extremamente rápida, o haloperidol e o lorazepam podem ser administrados por via parenteral. Se o tratamento não for suficiente para tratar os sintomas de excitação, tensão ou ansiedade, o tratamento adicional com carbamazepina, valproato ou lítio pode ser considerado (Nível D). Medidas como contenção e isolamento devem ser adotadas apenas em situações excepcionais de emergência, devendo ser cuidadosamente documentadas e explicadas ao paciente. Em todos os casos, o paciente deve ter permissão para expressar suas opiniões e discutir sua experiência. O médico deve acompanhar um paciente contido ou isolado tão freqüentemente quanto necessário para monitorar quaisquer alterações em sua condição física ou mental e cumprir com as leis locais.

\section{TRATAMENTO DOS SINTOMAS PREDOMINANTEMENTE NEGATIVOS}

Os sintomas negativos na esquizofrenia podem ser diferenciados em: sintomas negativos primários, suge- 
rindo uma sintomatologia central na esquizofrenia; sintomas negativos secundários, como consequiência dos sintomas positivos (reclusão social por causa de idéias paranóides); sintomas devidos a SEP (acinesia induzida por neuroléptico); sintomas depressivos (depressão pós-psicótica ou farmacogênica); fatores ambientais (subestimulação social em razão de hospitalismo) (Carpenter et al., 1985).

Em razão de seu perfil farmacológico, especialmente o bloqueio preferencial dos receptores 5-HT2A, concluiu-se que os ASGs possuem habilidade favorável para tratar os sintomas negativos quando comparados aos APGs (Muller, 2003). Infelizmente, a maioria dos estudos foi conduzida em pacientes que apresentaram exacerbações agudas ou uma mistura de sintomas positivos e negativos, e, por conseguinte, a melhora dos sintomas negativos poderia ser interpretada como uma diminuição nos sintomas negativos secundários. A sobreposição entre os efeitos adversos dos antipsicóticos (SEP) e a depressão dificulta a interpretação dos resultados dos estudos. Além disso, a dose da maioria dos APGs comparativos foi retrospectivamente julgada como muito altas e associadas a uma taxa elevada de SEP. Mesmo quando abordagens estatísticas mais elaboradas são utilizadas, a interpretação requer cautela (Muller $e t$ al., 1995). Por outro lado, a eficácia dos antipsicóticos atípicos no tratamento dos sintomas negativos pode ser subestimada na metanálise por causa de "armadilhas" metodológicas inerentes a tais análises (Möller, 2003).

\section{Eficácia dos antipsicóticos de primeira geração}

$\mathrm{Na}$ maioria dos estudos, houve também melhora dos sintomas negativos com os APGs, mas os estudos se concentram principalmente nos sintomas positivos (Dixon et al., 1995). Comparados ao placebo, há evidência de eficácia dos APGs no tratamento dos sintomas negativos (Davis et al., 1989). Mas, mesmo quando as classificações dos sintomas negativos são fornecidas, não há distinção entre os sintomas negativos primários e secundários. Estudos comparativos com ASGs demonstram tendência favorável de doses menores no tratamento dos sintomas negativos. Não existem estudos em pacientes com sintomas predominantemente negativos.

\section{Eficácia dos antipsicóticos de segunda geração}

ECRs de curta duração sugerem que, no tratamento dos sintomas negativos, a amisulpirida, em doses de até 800 $\mathrm{mg} /$ dia, mostrou eficácia superior à do haloperidol (20 $\mathrm{mg} / \mathrm{dia}$ ) (Möller et al., 1997) e similar à da risperidona (8 mg/dia) (Peuskens et al., 1999). Num estudo de 1 ano, duplo-cego, randomizado e de manutenção com doses flexíveis, a amisulpirida foi associada à melhora mais expressiva da sintomatologia negativa quando comparada ao haloperidol (Colonna et al., 2000). A seleção de pacientes com sintomas predominantemente negativos num estudo randomizado, duplo-cego de longa duração, comparando seis níveis de dose de amisulpirida com haloperidol, revelou efeito superior (mas não significa- tivo) da amisulpirida nos sintomas negativos depois de 1 ano de tratamento (Speller et al., 1997). Dois ECRs mostraram superioridade da amisulpirida quando comparada ao placebo na melhora dos sintomas negativos, em doses de 100 a $300 \mathrm{mg} /$ dia ao longo de 6 semanas (Boyer et al., 1995) e $100 \mathrm{mg} /$ dia ao longo de 6 meses (Loo et al., 1997).

Adicionalmente, dois ECRs exibiram a melhor eficácia da amisulpirida no tratamento dos sintomas negativos em comparação ao placebo num amostra de pacientes sofrendo predominantemente de sintomatologia negativa persistente (Palliere-Martinot et al., 1995; Danion et al., 1999). Em metanálises baseadas em estudos de pacientes agudamente doentes (Leucht et al., 1999; 2002; Leucht, 2004), a amisulpirida, a olanzapina e a risperidona mostraram superioridade no tratamento dos sintomas negativos quando comparadas aos APGs. Em três ECRs pequenos, comparando a amisulpirida aos APGs em pacientes com sintomas predominantemente negativos, houve apenas uma tendência a favor da amisulpirida, mas sem atingir a significância estatística (Pichot e Boyer, 1989; Saletu et al., 1994; Speller et al., 1997). Contudo, a amisulpirida é o único ASG que tem sido amplamente estudado nessa população de pacientes. Especialmente em relação aos estudos controlados com placebo, há evidência de que o tratamento com amisulpirida é eficaz numa faixa de dose de 50 a 300 $\mathrm{mg} /$ dia na melhora dos sintomas negativos (Nível A) (Leucht, 2004).

\section{Aripiprazol}

O aripiprazol na dose de $15 \mathrm{mg} /$ dia (mas não de $30 \mathrm{mg}$ / dia) e o haloperidol na dose de $10 \mathrm{mg} /$ dia mostraram eficácia superior na melhora dos sintomas negativos em relação ao placebo num ECR de 4 semanas de duração (Kane et al., 2002). Em outro ECR de curta duração, a eficácia do aripiprazol (20 e $30 \mathrm{mg} /$ dia) no tratamento dos sintomas negativos foi comparável à da risperidona (6 mg/dia) (Potkin et al., 2003). Num ECR controlado com placebo, $o$ aripiprazol demonstrou eficácia superior na melhora dos sintomas negativos ao longo de 6 meses (Pigott et al., 2003). Dados agrupados de dois ECR de 52 semanas comparando o aripiprazol ( $30 \mathrm{mg} / \mathrm{dia})$ e ao haloperidol (10 mg/dia) mostraram resposta superior do aripiprazol na sintomatologia negativa (Kasper et al. , 2003). Em resumo, apesar de haver evidências sobre a eficácia no tratamento dos sintomas negativos (Nível A), não existe uma experiência clara com o aripiprazol em pacientes com sintomas predominantemente negativos.

\section{Clozapina}

A clozapina mostrou-se eficaz nos estudos abertos nãocomparativos no tratamento de pacientes refratários com sintomas negativos mais ou menos predominantes (Meltzer et al., 1989; Meltzer, 1992; Lindenmayer et al., 1994) e num estudo duplo-cego comparativo com a clorpromazina (Kane et al., 1988). Em outro ECR duplo- 
cego, com casuística pequena, nenhuma diferença foi detectada entre a clozapina e o haloperidol na melhora dos sintomas negativos (Breier et al., 1994). Num ECR multicomparativo e duplo-cego já mencionado anteriormente, a clozapina (dose-alvo de $500 \mathrm{mg}$ /dia) revelou superioridade estatisticamente significativa sobre os sintomas negativos em relação ao haloperidol (dose-alvo de $20 \mathrm{mg}$ /dia) em pacientes com resposta subótima ao tratamento prévio. Porém, esse efeito foi descrito como clinicamente modesto (Volavka et al., 2002). Enquanto uma metanálise mostrou evidência ligeiramente significativa da superioridade da clozapina em relação aos APGs no tratamento dos sintomas negativos (Wahlbeck et al., 2004), outra revisão metanalítica relatou vantagem da clozapina nessa condição por meio da análise de sua eficácia no tratamento de pacientes resistentes (Chakos et al., 2001). Em resumo, embora existam evidências sobre a eficácia no tratamento dos sintomas negativos (Nível A), há apenas uma experiência limitada com a clozapina em pacientes com sintomas predominantemente negativos.

\section{Olanzapina}

Estudos clínicos randomizados de fase aguda com a olanzapina mostram evidências de eficácia superior ao placebo e ao haloperidol no tratamento dos sintomas negativos (Beasley et al., 1996a, 1996b e 1997; Tollefson et al., 1997). Contudo, num estudo de extensão, a diferença estatisticamente significativa entre a olanzapina e o haloperidol (a favor da primeira droga) na redução dos sintomas negativos não se manteve após 24 semanas de seguimento (Hamilton et al., 1998). Outra análise desses estudos (path-analysis) mostrou que a maior parte das mudanças nos sintomas negativos não pode ser explicada por outras combinações (sintomas positivos, depressão, SEP) (Tollefson et al., 1997). Embora um estudo de curta duração, duplo-cego e randomizado tenha demonstrado a superioridade da olanzapina (dose média de $17,2 \mathrm{mg} / \mathrm{dia}$ ) na melhora dos sintomas negativos quando comparada à risperidona (dose média de $7,2 \mathrm{mg} / \mathrm{dia}$ ) (Tran et al., 1997), outro ECR (olanzapina na dose média de $12,4 \mathrm{mg} /$ dia versus risperidona 4,8 $\mathrm{mg} / \mathrm{dia})$ não replicou este achado, provavelmente pelo fato de a dose menor de risperidona estar associada a menos SEP (Conley e Mahmoud, 2001). Em resumo, apesar de haver evidência para eficácia no tratamento dos sintomas negativos (Nível A), não existe uma experiência consistente com a olanzapina em pacientes com sintomas predominantemente negativos.

\section{Quetiapina}

A quetiapina produziu melhora significativamente superior nos sintomas negativos quando comparada ao placebo apenas na dose mais alta (750 mg/dia) no tratamento da fase aguda em um ECR (Small et al., 1997). Em outro estudo, esse efeito foi observado na faixa de dose total (de 75 a $750 \mathrm{mg} / \mathrm{dia}$ ), com os melhores resultados na dose de $300 \mathrm{mg} /$ dia (Arvanitis et al., 1997). Comparada ao haloperidol (12 mg/dia), não houve diferença significativa (Arvanitis et al., 1997). Comparada à clorpromazina $(750 \mathrm{mg} / \mathrm{dia})$, houve tendência de melhor eficácia na sintomatologia negativa com a quetiapina (Peuskens e Link, 1997). No geral, há evidência de eficácia similar, mas não para vantagens significativas da quetiapina quando comparada aos APGs no tratamento dos sintomas negativos (Nível A) (Cheer e Wagstaff, 2004).

\section{Risperidona}

A risperidona mostrou resposta significativamente superior nos sintomas negativos que o haloperidol e $o$ placebo apenas na dose de $6 \mathrm{mg} /$ dia (Peuskens et al., 1995). Uma segunda exploração desses dados, utilizando a abordagem path-analysis, revelou um efeito direto do tratamento sobre os sintomas negativos (Möller, 2003). Em pacientes esquizofrênicos parcialmente refratários, foi detectada uma eficácia sobre os sintomas negativos similar à da clozapina e da perfenazina (Möller, 2003). Em estudos duplo-cegos randomizados com olanzapina, observaram-se resultados similares ou indicativos de resposta inferior na sintomatologia negativa (Tran $e t$ al., 1997; Conley e Mahmoud, 2001). No tratamento de manutenção, em comparação ao haloperidol, foram relatados efeitos benéficos da risperidona sobre a sintomatologia negativa (Csernansky et al., 2002). Uma metanálise dos resultados agrupados de seis ECRs duplo-cegos, comparando a risperidona aos APGs, observou que a risperidona proporcionou melhora significativamente superior dos sintomas negativos (Carman et al., 995). Em resumo, há evidências sobre a eficácia no tratamento dos sintomas negativos (Nível A), mas nenhuma experiência consistente em pacientes com sintomas predominantemente negativos.

Ziprasidona

A ziprasidona mostrou eficácia superior ao placebo sobre os sintomas negativos num ECR de curta duração (Daniel et al., 1999), mas não de maneira estatisticamente significativa num outro ECR (Keck et al., 1998), ambos em pacientes com doença aguda. Num estudo de extensão de mais de 1 ano, duplo-cego e randomizado, que incluiu pacientes com esquizofrenia crônica apresentando predominantemente sintomas negativos, foi observada uma melhora estatisticamente significativa nos sintomas negativos em favor da ziprasidona (doses de 40, 80 e 160 $\mathrm{mg} /$ dia) quando comparada ao placebo no desfecho (Arato et al., 2002). Em resumo, há evidência da eficácia no tratamento dos sintomas negativos (Nível A) e evidências limitadas nesse aspecto em pacientes com sintomas predominantemente negativos (Nível C).

\section{Zotepina}

Nos ECRs inic iais, a zotepina revelou eficácia inconsistente sobre os sintomas negativos quando comparada aos APGs (Möller, 2003). Porém, ECRs duplo-cegos mais recentes demonstraram vantagens significativas da zotepina comparada ao haloperidol (Petit et al., 1996) 
ou à clorpromazina (Cooper et al., 2000a). Um estudo controlado com placebo em pacientes com sintomas predominantemente negativos deixou de demonstrar a eficácia da zotepina (Möller et al., 2004). Um ECR duplo-cego de prevenção de recaídas comparado a placebo não exibiu diferenças significativas em relação à sintomatologia negativa ao longo de 26 semanas (Cooper et al., 2000b). Em resumo, há evidências da eficácia no tratamento dos sintomas negativos (Nível A), mas nenhuma evidência em pacientes com sintomas predominantemente negativos.

\section{Eficácia dos antidepressivos}

Apesar da eficácia dos agentes antipsicóticos atípicos, os antidepressivos são usados como tratamento adjuvante em pacientes com sintomas predominantemente negativos (APA, 2004). O papel dessa estratégia permanece incerto, porque os estudos disponíveis, a maioria deles realizada com inibidores seletivos da recaptura de serotonina (ISRS), são inconsistentes, e freqüentemente faltam padrões metodológicos mais rigorosos (Möller, 2004a). Um ECR inicial indicou que a imipramina adicionada a um APG de longa ação pode proporcionar benefícios nos sintomas negativos em pacientes ambulatoriais estáveis (Siris et al., 1991), enquanto a adição de desipramina ou amitriptilina em pacientes agudamente descompensados se associou a uma resposta antipsicótica mais fraca, sem melhora da depressão (Kramer et al., 1989). A maprotilina não revelou diferença significativa num estudo duplo-cego cruzado (Waehrens e Gerlach, 1980).

Em seis estudos controlados com placebo de ISRS para sintomas negativos, um relatou modesta vantagem da fluoxetina $(20 \mathrm{mg} /$ dia $)$ adicionada à medicação antipsicótica injetável (Goff et al., 1995), e outro constatou melhora significativamente superior em relação aos sintomas negativos com a fluoxetina (Spina et al., 1994), embora quatro estudos não tenham encontrado nenhuma vantagem em relação aos ISRS: fluoxetina combinada a clozapina em curso (Buchanan et al., 1996) e fluoxetina (Arango et al., 2000), citalopram (Salokangas et al., 1996) ou sertralina (Lee et al., 1998) adicionada a antipsicóticos de primeira geração. Quatro estudos controlados com a associação de fluvoxamina (100 mg/dia) demonstraram resultados positivos (Silver e Nassar 1992; Silver e Shmugliakov, 1998; Silver et al., 2000, 2003). Todavia, não houve benefício em relação à maprotilina $(100 \mathrm{mg} / \mathrm{dia})$ adicionada ao tratamento antipsicótico (Silver e Shmugliakov, 1998). Num estudo duplo-cego e controlado com placebo, a mirtazapina demonstrou efeito benéfico sobre a sintomatologia negativa depois de 6 semanas (Berk et al., 2001). Por outro lado, a reboxetina ( $8 \mathrm{mg} / \mathrm{dia})$ não mostrou efeitos sobre os sintomas negativos num estudo duplo-cego controlado com placebo (Schutz e Berk, 2001).

Outro estudo controlado com placebo não encontrou vantagens para o uso adjuvante de selegilina comparada ao placebo (Jungemann et al., 999). Em geral, as evidências sobre a eficácia dos antidepressivos para os sintomas negativos da esquizofrenia são limitadas (Nível C), especialmente quando se considera o fato de que a diferenciação entre a melhora dos sintomas depressivos e dos sintomas negativos é difícil em alguns casos. Visto que a maioria dos estudos foi realizada em combinação com antipsicóticos de primeira geração, é possível que os achados possam ser diferentes com os antipsicóticos de segunda geração, embora essa possibilidade pareça improvável (APA, 2004). A adição de antidepressivos a pacientes agudamente descompensados pode ainda piorar os sintomas psicóticos, observação válida pelo menos para os antidepressivos tricíclicos (ADTs).

\section{Eficácia de outros medicamentos}

Relatos iniciais indicaram que o acréscimo do lítio aos antipsicóticos melhorou especificamente os sintomas negativos (Small et al., 1975; Growe et al., 1979), mas esses achados não foram confirmados em estudos posteriores nem em metanálises (Leucht et al., 2004). Há alguma evidência da adição de agentes glutamatérgicos no tratamento dos sintomas negativos, como a d-cicloserina (Möller, 2003; APA, 2004), ou a combinação de d-serina e APGs ou risperidona (Tsai et al., 1998). Além disso, não há evidências do benefício da adição de estrógenos ou inibidores das colinesterases, mas estudos preliminares demonstraram alguns resultados encorajadores (Möller, 2003). Para futuras estratégias de tratamento, consulte a seguir o item "Esquizofrenia resistente ao tratamento".

\section{Recomendações}

Para o tratamento dos sintomas negativos, os antipsicóticos de segunda geração devem ser preferidos (Nível A). Dos compostos atípicos, a amisulpirida parece oferecer vantagens, sendo o único antipsicótico investigado em diversos estudos nessa população especial de pacientes esquizofrênicos (Nível A). A clozapina pode ser superior aos outros antipsicóticos no tratamento dos sintomas negativos no contexto da esquizofrenia resistente ao tratamento (Nível B). Nos casos de resposta inadequada, a associação com ISRS (Nível B) e, possivelmente, mirtazapina (Nível C) pode ser benéfica. As interações farmacocinéticas com ISRS devem ser cuidadosamente consideradas. Terapias de adição com agentes glutamatérgicos ou estrógenos podem ser discutidas como abordagens experimentais.

\section{TRATAMENTO DOS SINTOMAS COGNITIVOS}

Déficits neurocognitivos têm sido reconhecidos com uma importante característica, ou até mesmo um déficit central, da esquizofrenia. A função cognitiva é um correlato do prognóstico funcional global e específico na esquizofrenia, e o prejuízo cognitivo é responsável por uma variância significativa nas medidas do estado funcional (Green, 1996). Os ASGs têm sido relatados como mais benéficos sobre o funcionamento cognitivo que os APGs. No entanto, a metodologia utilizada para avaliar os déficits cognitivos na esquizofrenia tem 
sido deficiente em muitos estudos clínicos (Harvey e Keefe, 2001).

Eficácia dos antipsicóticos de primeira e segunda gerações Nas revisões e na maioria dos estudos, os APGs não demonstraram nenhum efeito sobre a cognição, ou apenas efeitos benéficos secundários (Cassens et al., 1990; Sharma, 1999), em que faixas de dosagens inapropriadamente grandes, combinadas com SEP ou medicamentos anticolinérgicos concomitantes, podem ter exercido efeitos negativos sobre a cognição. Uma metanálise de 20 estudos clínicos (consistindo de 11 estudos de troca de medicação, 4 estudos abertos comparativos randomizados e 5 estudos randomizados duplo-cegos) revelou evidências de que os ASGs são superiores nos aspectos essenciais de cognição quando comparados aos APGs (Nível A) (Harvey e Keeefe, 2001), o que foi confirmado para alguns domínios cognitivos num estudo randomizado duplo-cego que comparou a olanzapina, a risperidona, a clozapina e o haloperidol em pacientes com história de resposta subótima aos antipsicóticos convencionais (Bilder et al., 2002). Uma revisão sistemática mostrou efeitos benéficos superiores sobre a cognição em pacientes tratados com ASGs (clozapina, risperidona, olanzapina, quetiapina e zotepina) em relação aos APGs, embora alguns estudos fornecessem resultados conflitantes e houvesse uma variedade de limitações metodológicas (Weiss et al., 2002). Além disso, um estudo randomizado duplo-cego demonstrou efeitos comparáveis de melhora cognitiva em relação ao tratamento prévio (principalmente haloperidol ou risperidona) em pacientes internados agudamente doentes tratados com olanzapina ou ziprasidona (Harvey et al., 2004).

Diferente desses resultados, num estudo randomizado duplo-cego, a risperidona ( $6 \mathrm{mg} / \mathrm{dia})$, comparada ao haloperidol em baixa dose ( $5 \mathrm{mg} / \mathrm{dia}$ ), não mostrou benefícios sobre os déficits neurocognitivos ao longo de um período de 2 anos (Green et al., 2002). Em outro estudo randomizado, duplo-cego, com pacientes em primeiro episódio esquizofrênico, a olanzapina (média de $9,6 \mathrm{mg} / \mathrm{dia}$ ) demonstrou apenas uma pequena vantagem em relação aos déficits neurocognitivos sobre o haloperidol em baixa dose (média de 4,6 mg/dia) (Keefe et al., 2004).

\section{Recomendações}

Em pacientes esquizofrênicos com déficits cognitivos, os ASGs, comparados aos APGs, fornecem um efeito benéfico no mínimo modesto sobre as funções cognitivas (Nível A), embora alguns estudos revelem resultados conflitantes. Medicamentos adjuntivos, tratamentos prévios e doses de APGs devem ser considerados antes de se efetivar a troca para ASGs no sentido de melhorar a cognição.

TRATAMENTO DOS SINTOMAS PREDOMINANTEMENTE CATATÔNICOS

Sintomas catatônicos tendem a estar presentes em aproximadamente $10 \%$ dos pacientes admitidos em instituições psiquiátricas (Blumer, 1997). Embora o sub- tipo catatônico da esquizofrenia seja diagnosticado em aproximadamente $5 \%$ de todos os pacientes no primeiro episódio (Jablensky et al., 1992), a catatonia maligna é extremamente rara. A diferenciação entre catatonia e síndrome neuroléptica maligna pode ser impossível em alguns casos, mencionados como "dilema catatônico" (Lausberg e Hellweg, 1998).

\section{Eficácia dos antipsicóticos de primeira geração}

Os antipsicóticos em geral, especialmente os APGs, demonstraram eficácia limitada no tratamento da catatonia (Nível C) (Zemlan et al., 1986; Hawkins et al., 1995). Adicionalmente, pacientes com sintomas catatônicos pregressos ou atuais são particularmente vulneráveis à síndrome neuroléptica maligna (SNM) (Lausberg e Hellweg 1998), e, conseqüentemente, os antipsicóticos com propriedades de bloqueio preferencial pelo receptor $\mathrm{D} 2$ podem não ser benéficos para tratar a catatonia, podendo até mesmo piorar os sintomas catatônicos (Blumer, 1997).

\section{Eficácia dos antipsicóticos de segunda geração}

Alguns relatos de caso sugerem que os ASGs podem ser mais eficazes no tratamento dos sintomas catatônicos que os APGs, como a amisulpirida (French e Eastwood, 2003), a clozapina (Lausberg e Hellweg, 1998; Gaszner e Makkos, 2004), a olanzapina (Martenyi et al., 2001), a risperidona (Poyurousky et al., 1997; Kopala e Caudle, 1998; Hesslinger et al., 2001; Valevski et al., 2001) e a zotepina (Harada et al., 1991) (Nível D).

\section{Outros}

Os benzodiazepínicos revelaram eficácia nas reações catatônicas agudas (Rosebush et al., 1990; Ungvari et al., 1994; Bush et al., 1996; Lee et al., 2000) e mostraram benefícios quando adicionados aos antipsicóticos na catatonia crônica (Nível C) (Ungvari et al., 1999).

Pacientes com características proeminentes de catatonia parecem receber beneficio particular com o tratamento por ECT. Contudo, a evidência é limitada pela inclusão de pacientes com diagnóstico de distúrbio do humor e consiste, principalmente, de relatos de caso, séries de casos e estudos abertos prospectivos (Nível C) (Bush et al., 1996; Petrides et al., 1997; Suzuki et al., 2003). Revisando os relatos de caso e as séries de casos, a ECT pareceu tão eficaz quanto o lorazepam (melhora de $85 \%$ versus $79 \%$ ) e mostrou maior chance de proporcionar um resultado positivo nos casos de catatonia maligna (Hawkins et al., 1995). Os achados dos estudos citados anteriormente confirmam a impressão clínica de que o ECT é benéfico nos pacientes com esquizofrenia catatônica que não responderam ao tratamento de primeira linha com lorazepam (Nivel D) (APA, 2004).

\section{Recomendações}

Os benzodiazepínicos, como o lorazepam, parecem oferecer um tratamento de primeira linha, seguro e eficaz na catatonia (Nível C). A ECT deve ser considerada quando for necessária uma resolução rápida (como na catatonia maligna) ou quando as tentativas 
iniciais com o lorazepam falharem (Nível C). Ao iniciar o tratamento antipsicótico com ASGs, a clozapina deve ser preferida nos pacientes que se apresentam com sintomas de catatonia por causa do risco reduzido de devolver síndrome neuroléptica maligna e pela maior eficácia sugerida (Nível D).

\section{Esquizofrenia resistente ao tratamento}

Dependendo da definição de esquizofrenia resistente ao tratamento (ERT), cerca de $10 \%$ a $30 \%$ dos pacientes têm pouca ou nenhuma resposta aos medicamentos antipsicóticos, e um adicional de até $30 \%$ dos pacientes têm respostas parciais ao tratamento, significando que eles exibem melhora na psicopatologia, mas continuam a ter alucinações e delírios leves a graves (Brenner et $a l ., 1990$; Essock et al., 1996a). Mesmo se os sintomas positivos de um paciente entram em remissão com o tratamento antipsicótico, outros sintomas residuais, incluindo os sintomas negativos e o prejuízo cognitivo, frequientemente persistem. A resistência ao tratamento muitas vezes está associada a longos períodos de hospitalização. No entanto, a hospitalização crônica também pode ocorrer na presença de sintomas psicóticos menos graves, não sendo um indicador confiável de má resposta aos antipsicóticos.

O uso de critérios amplos para ERT, incluindo o nível funcional, levou a prevalências de $55 \%$ a $65 \%$ após o tratamento com ASGs, número que provavelmente seria mais alto se os déficits cognitivos e a má qualidade de vida também fossem incluídos (Helgason, 1990; Hegarty et al., 1994). O tratamento pode se apresentar completa ou parcialmente sem sucesso por uma variedade de razões. $\mathrm{O}$ paciente pode receber uma dose subótima de antipsicóticos (ou por causa da prescrição de uma dose subótima ou, pelo menos em parte, por causa da não-aderência), ou o antipsicótico prescrito pode ser parcial ou totalmente ineficaz (APA, 2004). O uso de substâncias também pode causar ou contribuir para a resistência ao tratamento. No entanto, a ERT pode estar associada a fatores neurológicos (como anormalidades na morfologia cerebral) ou pode depender de fatores ambientais (como ambiente familiar desfavorável, emoções muito exacerbadas).

A avaliação multidimensional da ERT deve considerar sintomas persistentes positivos ou negativos, disfunção cognitiva importante, comportamento bizarro, sintomas afetivos recorrentes, comportamento suicida, déficits nas atividades vocacional e social e qualidade de vida ruim. Dessa forma, ao se suspeitar de ERT, os sintomas alvo-devem ser precisamente definidos. Em razão dos critérios modificados nas diretrizes recentes, assume-se como resistência ao tratamento a falta total de melhora ou apenas melhora insuficiente nos sintomasalvo, apesar do tratamento efetuado na dose recomendada por uma duração de, no mínimo, 6 a 8 semanas, com pelo menos dois antipsicóticos, um dos quais deve ser um antipsicótico atípico (NICE, 2002; APA, 2004).
A aderência deve ser assegurada, se necessário pela verificação da concentração da droga.

\section{EFICÁCIA DOS ANTIPSICÓTICOS DE PRIMEIRA GERAÇÃO}

Há apenas evidência limitada para a eficácia dos APGs na ERT. Uma revisão que compilou mais de 100 estudos que compararam dois ou mais APGs identificou apenas um estudo sustentando que qualquer APG é mais eficaz que outro (Janicak et al., 1993). Como resultado, em termos de eficácia, os APGs foram considerados intercambiáveis (Conley e Buchanan, 1997). Na maioria dos estudos controlados de APGs em pacientes com sintomas de resistência ao tratamento, a porcentagem de respondedores foi menor que 5\% (Kane et al., 1988) ou na faixa de $3 \%$ a $7 \%$ (Kinon et al., 1993), trocando o APG uma ou duas vezes em caso de falha na resposta. Assim, as principais razões para escolher entre as drogas foram no sentido de reduzir os efeitos colaterais e prover diferentes estratégias posológicas ou outras vias de administração (Conley e Buchanan, 1997). Com base nas considerações neuroquímicas, os dados do bloqueio de $80 \%$ a $90 \%$ dos receptores D2 por meio de equivalentes de $400 \mathrm{mg}$ de CPZ (Farde et al., 1992), e, de acordo com as impressões clínicas provenientes dos estudos de tratamento agudo (Baldessarini et al., 1988; Bollini et al., 1994; Dixon et al., 1995), sugere-se que doses mais elevadas de APGs não produzem benefícios terapêuticos na ERT, mas levam à maior incidência e intensidade de SEP e a outros efeitos colaterais incapacitantes (Kane, 1994; Möller, 1996).

\section{EFICÁCIA dOS ANTIPSICÓTICOS DE SEGUNDA GERAÇÃO}

Uma metanálise com 12 ECRs comparando a eficácia e a tolerabilidade dos ASGs versus APGs para ERT observou mais resultados favoráveis entre os pacientes tratados com clozapina, refletidos pela melhora na psicopatologia geral, na taxa de resposta categórica, na incidência de SEP e na taxa de aderência, e naqueles tratados com olanzapina em relação à resposta categórica e às taxas de aderência (Chakos et al., 2001).

A eficácia da clozapina na ERT foi ressaltada numa metanálise que usou os critérios de Cochrane (Wahlbeck et al., 1999) e pela avaliação de todos os 10 ECRs que compararam a clozapina a outros agentes antipsicóticos (NICE, 2002). Nessa revisão, seis estudos duplo-cegos, randomizados e controlados de ERT durando de 6 a 52 semanas demonstraram eficácia superior na psicopatologia global e na taxa global de resposta usando doses médias de 176 a $600 \mathrm{mg} /$ dia de clozapina, quando comparada à clorpromazina (dose média de aproximadamente $1.200 \mathrm{mg} / \mathrm{dia}$ ) e ao haloperidol (doses entre 16 e 28 mg/dia) (Kane et al., 1988 e 2001; Kumra et al., 1996; Hong et al., 1997; Buchanan et al., 1998; Rosenheck et al., 1997). Além disso, um estudo aberto, randomizado e controlado de longa duração (2 anos) revelou evidência de taxa de resposta global superior com a clozapina (dose média de $496 \mathrm{mg} / \mathrm{dia}$ ) comparada a APGs-padrão (dose média de $1.386 \mathrm{mg} /$ dia 
de equivalentes de CPZ) (Essock et al., 1996b). Outra revisão sistemática de clozapina na ERT, incluindo 18 estudos clínicos prospectivos, controlados (15 duplo-cegos), 23 estudos observacionais prospectivos e 9 estudos observacionais retrospectivos, encontrou resposta ao tratamento nos desenhos experimentais em $36 \%$ e na análise retrospectiva em até $54 \%$, enquanto as taxas de abandono variaram de $33 \%$ a $20 \%$, respectivamente (Brambilla et al., 2002). Como resultado dessa revisão, concluiu-se que a clozapina também demonstrou eficácia e boa tolerabilidade geral no tratamento da ERT nas condições da prática clínica. Adicionalmente, a eficácia superior da aderência, da qualidade de vida e da participação nas terapias psicossociais foi relatada em estudos subsequientes (Lieberman et al., 1994; Alvarez et al., 1997; Ciaparelli et al., 2003). O tempo transcorrido para melhora com a clozapina foi diferente e variou de 4 a 8 semanas (Conley et al., 1997; Rosenheck et al., 1999), enquanto, em outros estudos, a melhora foi observada após períodos de 6 a 12 meses (Spina et al., 2000). Em resumo, há boa evidência com base na pesquisa para recomendar o tratamento com a clozapina em pacientes esquizofrênicos resistentes ao tratamento (Nível B).

Para a risperidona $(6 \mathrm{mg} / \mathrm{dia})$ comparada ao haloperidol (15 mg/dia), uma superioridade nos efeitos sobre a psicopatologia geral foi observada apenas nas primeiras 4 semanas de um ECR de 8 semanas (Wirshing et al., 1999). Os preditores para resposta à risperidona foram o predomínio de sintomas positivos e SEP na entrada do estudo. Um estudo de 12 semanas em pacientes com ERT e exacerbações agudas revelou superioridade da risperidona (6 $\mathrm{mg} / \mathrm{dia})$ sobre os sintomas negativos e globais quando comparada ao haloperidol (20 mg/dia) (Zhang et al., 2001). Adicionalmente, os pacientes resistentes ao tratamento demonstraram melhora cognitiva adicional (memória verbal) (Green $e t$ $a l ., 1997)$ e na percepção de emoções (reconhecimento de faces) (Kee et al., 1998) mediante tratamento com risperidona comparado ao haloperidol. Num ECR duplocego de 14 semanas que comparou risperidona (dose média de 11,6 mg/dia), clozapina (dose média de 527 $\mathrm{mg} /$ dia), olanzapina (dose média de $30,4 \mathrm{mg} / \mathrm{dia}$ ) e haloperidol (dose média de $25,7 \mathrm{mg} / \mathrm{dia}$ ), a maior melhora na psicopatologia geral (escore total da Positive and Negative Syndrome Scale, PANSS) foi observada para os três antipsicóticos atípicos, mas, considerando a redução nos SEP como uma co-variável, a significância foi alcançada apenas para a clozapina e a olanzapina (Volavka et al., 2002).

Comparando a risperidona (3 a $10 \mathrm{mg} / \mathrm{dia})$ à clozapina (150 a 400 mg/dia), um ECR mostrou redução similar nos sintomas psicóticos e nenhuma diferença na taxa de SEP (Bondolfi et al., 1998). Dois outros ECRs revelaram a superioridade da clozapina na melhora da psicopatologia total, dos sintomas positivos e depressivos (doses médias de $5,9 \mathrm{mg} /$ dia de risperidona versus 404 $\mathrm{mg} /$ dia de clozapina) (Breier et al., 1999) e a melhora na impressão global, nos sintomas gerais e positivos (doses médias de $9 \mathrm{mg} /$ dia de risperidona versus $642 \mathrm{mg} / \mathrm{dia}$ de clozapina) (Azorin et al., 2001). Em estudos abertos, prospectivos e cruzados, $40 \%$ a $80 \%$ dos não-respondedores à risperidona e $0 \%$ a $15 \%$ dos não-respondedores à clozapina melhoraram com a troca para outro agente (Cavallaro et al., 1995; Still et al., 1996), ou foi observada eficácia similar (Daniel et al., 1996; Konrad et al., 2000). Como resultado desses estudos, pode-se admitir uma vantagem na troca de risperidona por clozapina com relação à taxa de resposta na ERT. Adicionalmente, estudos abertos comparativos apontaram em direção a uma eficácia superior da clozapina (Flynn et al., 1998; Lindenmayer et al., 1998; Wahlbeck et al., 2002). Em resumo, há evidências sobre a superioridade da risperidona comparada ao haloperidol, mas podem existir desvantagens se comparada à clozapina no tratamento da esquizofrenia resistente à terapia (Nível B).

Uma metanálise identificou dois ECRs que compararam a olanzapina aos APGs na ERT e calculou probabilidade aproximadamente $1,7 \mathrm{vez}$ maior de resposta em favor da olanzapina (Chakos et al., 2001). Os pacientes em tratamento com olanzapina sofreram um número significativamente inferior de SEP. Num estudo randomizado de 8 semanas, foi observada uma resposta apenas ligeiramente superior ( $7 \%$ versus $0 \%$ ) nos pacientes tratados com olanzapina ( $25 \mathrm{mg} / \mathrm{dia})$ comparados àqueles tratados com clorpromazina $(1.200 \mathrm{mg} / \mathrm{dia})$ (Conley et al., 1998). A reanálise de um estudo que enfocou a ERT (definido como um estudo sem sucesso com APG) revelou taxa de resposta mais alta ( $47 \%$ versus $35 \%)$ para olanzapina (dose média de $11,1 \mathrm{mg} /$ dia) comparada ao haloperidol (dose média de $10 \mathrm{mg} /$ dia) (Breier e Hamilton, 1999). Nesse estudo, observou-se benefício adicional nos sintomas gerais, positivos, negativos e depressivos no grupo tratado com olanzapina. Como mencionado anteriormente, a olanzapina demonstrou superioridade na psicopatologia total e nos sintomas negativos quando comparada ao haloperidol, controlando os SEP (Volavka et al., 2002). No entanto, os efeitos clínicos de todos os antipsicóticos atípicos avaliados (clozapina, olanzapina e risperidona) diferiram apenas ligeiramente do haloperidol nesse estudo randomizado e duplo-cego. Em outro ECR comparado a clozapina (dose média de $304 \mathrm{mg} /$ dia), houve melhora similar dos sintomas gerais mediante tratamento com olanzapina (dose média de $20,5 \mathrm{mg} / \mathrm{dia}$ ), enquanto os pacientes em uso de olanzapina revelaram menos efeitos adversos (Tollefson et al., 2001). A troca de clozapina para olanzapina (5 a $25 \mathrm{mg} / \mathrm{dia}$ ) elevou a resposta em mais de $40 \%$ dos pacientes nos estudos prospectivos (Henderson et al., 1998; Dossenbach et al., 2000), embora, em outro estudo, a maior redução nos sintomas psicóticos tenha sido observada nas semanas 3 e 6 (Dossenbach et al., 2000). Estudos posteriores de transferência sob condições naturalistas, principalmente da risperidona, revelaram resultados similares (Lindenmayer et al., 2001 
e 2002; Rodriguez-Perez et al., 2002; Chiu et al., 2003; Karagianis et al., 2003). Em resumo, há evidências da superioridade da olanzapina em relação ao haloperidol ou à clorpromazina, mas evidências limitadas de eficácia similar à clozapina no tratamento da esquizofrenia refratária ao tratamento (Nível B).

Num ECR com duração de 12 semanas, apenas os pacientes com resposta parcial ao tratamento com flufenazina $(20 \mathrm{mg} / \mathrm{dia})$ demonstraram taxa de resposta significativamente maior ( $52 \%$ versus $38 \%$ ) com a quetiapina (600 mg/dia) do que com o haloperidol (20 $\mathrm{mg} / \mathrm{dia}$ ) (Emsley et al., 2000). A substituição de haloperidol, olanzapina ou risperidona para a quetiapina (dose média de $505 \mathrm{mg} /$ dia) revelou melhora clínica em $69 \%$ dos pacientes (De Nayer et al., 2003).

O tratamento com aripiprazol (dose média de 28,8 $\mathrm{mg} /$ dia) comparado à perfenazina (dose média de 39,1 $\mathrm{mg} / \mathrm{dia}$ ) num estudo randomizado duplo-cego mostrou resposta similar na ERT em relação à definição recente (insucesso do estudo com um ASG e risperidona ou olanzapina) (Ebrecht et al., 2004). Melhora significativa na psicopatologia total foi observada em ambas as condições de tratamento. Num estudo aberto de troca para o aripiprazol (30 mg/dia) em pacientes crônicos estáveis, observou-se melhora na impressão global, nos sintomas gerais, nos sintomas positivos e negativos (Casey et al., 2003). A troca dos antipsicóticos convencionais (olanzapina ou risperidona para ziprasidona, com dose média de $91 \mathrm{mg} / \mathrm{dia}$ ) em pacientes ambulatoriais estáveis, mas sintomáticos, mostrou ser bem tolerada e associada à melhora dos sintomas (Weiden et al., 2003).

Num ECT duplo-cego que comparou a zotepina (150 a $450 \mathrm{mg} / \mathrm{dia})$ à clozapina (150 a $450 \mathrm{mg} / \mathrm{dia})$, melhoras similares nos sintomas positivos e negativos, assim como em alguns domínios cognitivos, foram observadas durante o tratamento de 6 semanas (MeyerLindenberg et al., 1997). Dois estudos abertos encontraram melhora global, no mínimo moderada, em 1 ano de tratamento com zotepina (50 a $500 \mathrm{mg} / \mathrm{dia}$ ), enquanto a resposta terapêutica (definida como redução em pelo menos $20 \%$ no escore BPRS total) foi observada em quase $80 \%$ dos pacientes, ocorrendo nas primeiras 12 semanas (Harada et al., 1992). Em resumo, existem evidências muito limitadas sobre a eficácia do aripiprazol, da quetiapina, da ziprasidona e da zotepina no tratamento da esquizofrenia refratária à terapia (Nível D).

RECOMENDAÇõES GERAIS

O primeiro passo no controle clínico da esquizofrenia resistente ao tratamento (ERT) é estabelecer quais drogas antipsicóticas foram adequadamente estudadas em termos de posologia, duração e aderência. Outras causas de não-resposta devem ser consideradas na avaliação clínica, tais como abuso de drogas, má aderência ao tratamento, uso concomitante de outros medicamentos prescritos, polifarmacoterapia incluindo interações farmacocinéticas e farmacodinâmicas, doença física, ambiente social ruim e suporte psicossocial precário
(DGPPN, 1998; NICE, 2002, McGorry et al., 2003; APA, 2004). Especialmente quando se utilizar um ASG (dose menor), pode ser útil considerar o peso do paciente para o ajuste da dose (Kane et al., 2003a). O fato de haver algum atraso entre o início do tratamento e a resposta clínica completa complica a avaliação da reposta ao tratamento, e algumas vezes os sintomas podem continuar a melhorar por até 6 meses. Se o paciente demonstrar resposta parcial, admite-se prolongar a prescrição do antipsicótico atual para 4 a 10 semanas, e aproximadamente 5 a 11 semanas para um segundo antipsicótico (Kane et al., 2003a). Os sintomas-alvo devem ser definidos. Se os sintomas-alvo da esquizofrenia forem não-responsivos aos antipsicóticos convencionais, deve ser fornecido um tratamento com um ASG.

Com base nas evidências disponiveis até o momento, a olanzapina ou a risperidona pode ser opção válida quando se considera uma primeira linha de tratamento (Nível B) (NICE, 2002). Nos indivíduos com resistência ao tratamento claramente definida (incluindo pelo menos um tratamento adequado com ASG), a clozapina deve ser introduzida como tratamento de escolha por causa de sua eficácia superior nesse contexto (Nível B) (DGPPN, 1998; NICE, 2002; APA, 2004). Para os pacientes não-aderentes, esforços especiais para aumentar a adesão terapêutica devem ser feitos, incluindo intervenções psicoterapêuticas e psicossociais, (como aderência à terapia, psicoeducação) e intervenções na família. Antipsicóticos de depósito podem ser considerados se houver má aderência, mas a clozapina pode ser preferível também porque a melhora na psicopatologia e o monitoramento exigido muitas vezes acentuam a adesão (McGorry et al., 2003). Terapia cognitivo-comportamental deve ser oferecida em conjunto com a clozapina para melhorar a atividade social e a qualidade de vida e reduzir os sintomas positivos e negativos (Nível C) (conforme exposto no item "Psicoterapia e intervenções psicossociais"). Além da clozapina, há opções limitadas para pacientes que continuam a apresentar sintomas residuais importantes e graves mesmo depois da otimização sem sucesso da monoterapia com antipsicóticos. Esta pode ser a razão pela qual várias estratégias de aumento e a polifarmacoterapia são utilizadas, apesar do fato de haver apenas evidências limitadas ou não haver evidências que sustentem essa abordagem. Estratégias de aumento e combinação são revisadas e discutidas a seguir. Antes de trocar o medicamento utilizado por um outro agente, o consenso de especialistas concorda com o aumento da dose do antipsicótico atual, a menos que os efeitos colaterais levem à troca mais precoce (Kane et al., 2003).

\section{EstratÉGIAS DE MUDANÇA}

Existem três estratégias principais para mudar de um agente para outro: titulação cruzada (redução gradativa da dose do primeiro antipsicótico com aumento gradativo da dose do segundo); sobreposição e retirada gradativas (continuar com a mesma dose do primeiro 
antipsicótico ao mesmo tempo que se aumenta gradativamente o segundo até o nível terapêutico e então se retira de forma gradativa o primeiro); mudança abrupta dos antipsicóticos. Alguns estudos compararam essas estratégias, especialmente as duas primeiras modalidades de troca mencionadas, e não encontraram diferenças na eficácia e na tolerabilidade (Kane et al., 2003a). A maioria das diretrizes prefere a titulação cruzada, com exceção da troca para clozapina (APA, 2004). Nesse caso, a retirada gradativa do primeiro antipsicótico deve ser concluída antes da introdução da clozapina em razão dos potenciais efeitos colaterais hematológicos. Nesse sentido, muitos especialistas também preferem a titulação cruzada, refletindo provavelmente a necessidade de uma titulação relativamente lenta da clozapina (Kane et al., 2003a).

\section{Mudando para clozapina}

Como discutido anteriormente, um número substancial de estudos demonstrou de forma consistente que a clozapina é superior aos agentes neurolépticos convencionais na terapêutica da esquizofrenia refratária ao tratamento (Nível B). Nesse caso, nenhuma recomendação geral quanto à posologia deve ser apresentada. No entanto, apesar da dose média nos estudos ser de 400 a 500 $\mathrm{mg} /$ dia de clozapina, alguns pacientes respondem bem a apenas 100 a $200 \mathrm{mg} /$ dia, e outros se beneficiam com doses de até $900 \mathrm{mg} /$ dia. De acordo com a prática clínica, uma dose-alvo de até $400 \mathrm{mg} /$ dia pode ser indicada. Depois da não-resposta, apesar da continuidade do tratamento ao longo de 4 a 6 semanas e da obtenção de níveis sangüíneos suficientes de clozapina, o próximo passo deve consistir no aumento da dose até $900 \mathrm{mg} / \mathrm{dia}$ e no monitoramento cuidadoso dos efeitos adversos (NívelD). Se ainda não houver uma resposta adequada, o aumento ou a combinação das estratégias deve ser considerado (Nível D).

\section{Mudança para outro ASG}

Como já mencionamos, poucos estudos geraram evidências quanto à superioridade de ASGs diferentes da olanzapina, principalmente a risperidona e a olanzapina, comparados a agentes neurolépticos atípicos na esquizofrenia refratária ao tratamento (Nível B). Há algumas evidências, provenientes de estudos de troca, de que a substituição da clozapina por outros ASGs (como a olanzapina) pode proporcionar benefícios (Nível D). É preciso que mais pesquisas sejam urgentemente desenvolvidas no sentido de desenvolver estratégias de troca baseadas em evidências, especialmente em relação à clozapina.

\section{Antipsicóticos COMBINAdos}

Apesar da freqüente combinação de dois ou mais antipsicóticos na prática clínica (como em mais de 50\% dos pacientes hospitalizados), existem poucos estudos randomizados e controlados disponíveis avaliando a eficácia das estratégias de combinação (Freudenreich e Goff, 2002). Em pacientes com ERT, a adição de um antipsicótico à clozapina foi mencionada como uma opção de tratamento razoável. Até o momento, foram publicados quatro estudos duplo-cegos, controlados com placebo e randomizados que avaliaram a terapia combinada com clozapina. Embora a combinação da clozapina com a clorpromazina não tenha revelado benefício (Potter et al., 1989), a adição de sulpirida à clozapina possibilitou diminuição de mais de $20 \%$ na psicopatologia (escore total da Brief Psychiatric Rating Scale, BPRS) e melhora maior quando comparada ao placebo (Shiloh et al., 1997).

Junto aos estudos abertos iniciais e a relatos de caso, um ECR duplo-cego recente mostrou melhora significativa dos sintomas positivos, negativos e da psicopatologia total quando se adicionou risperidona (até 6 $\mathrm{mg} /$ dia) à clozapina (dose média $400 \mathrm{mg} / \mathrm{dia}$ ) (Josiassen et al., 2005). Diferente desses resultados, outro ECR revelou resposta significativamente inferior dos sintomas positivos pela adição da risperidona em relação ao placebo (Yagcioglu et al., 2005). Nos estudos abertos, a pimozida (dose média de $4 \mathrm{mg} /$ dia) combinada à clozapina demonstrou melhora nos sintomas psicóticos, mas também aumentou ou modificou os efeitos colaterais (Freudenreich e Goff, 2002; Miller e Craig, 2002). Discutiu-se a possibilidade de o aumento no nível sérico de clozapina ser responsável pelo melhor resultado (como na combinação com a risperidona) (Tyson et al., 1995). $\mathrm{O}$ efeito de níveis crescentes de clozapina não pôde ser replicado em outro estudo de 4 semanas de duração na ERT (Henderson e Goff, 1996). Verificou-se uma diminuição significativa na psicopatologia sem alteração do nível sérico de clozapina. Uma série adicional de casos revelou evidência da eficácia da adição de risperidona à clozapina (McCarthy e Terkelsen, 1995; Morea et al., 1999; Raskin et al., 2000; Taylor et al., 2001). Relatos de caso e estudos abertos revelaram sucesso com a combinação de clozapina e olanzapina (Gupta et al., 1998), clozapina e amisulpirida (Allouche et al., 1994), clozapina e ziprasidona (Kaye, 2003).

Numa série de casos, foi relatada melhora dos sintomas positivos e negativos em pacientes que receberam olanzapina em combinação à sulpirida (Raskin et al., 2000). No entanto, num estudo randomizado e controlado com uma amostra pequena de pacientes com ERT, a adição de sulpirida (600 mg/dia) à monoterapia com olanzapina ao longo de 8 semanas não revelou benefícios significativos na sintomatologia positiva e negativa, mas possibilitou uma melhora dos sintomas depressivos (Kotler et al., 2004). Uma pequena série de casos comprovou a eficácia da combinação entre olanzapina e risperidona (Lerner et al., 2000).

\section{Recomendações}

Em geral, há apenas evidências limitadas sobre a eficácia da combinação de antipsicóticos na ERT. As combinações entre clozapina e risperidona e entre clozapina e sulpirida podem refletir as melhores opções de tratamento com base no sucesso dos ECRs (Nível C). Contudo, 
na prática clínica, para uma futura combinação, pode ser útil selecionar o antipsicótico com o qual a melhor resposta prévia foi obtida no passado (Nível D). Com base na farmacodinâmica teórica, antipsicóticos com diferentes perfis de receptores podem ser selecionados para a terapia combinada (clozapina combinada com amisulpirida) (Nível D). Por último, mas não menos importante, os clínicos devem estar cientes da potencialização dos efeitos colaterais ao combinar dois ou mais antipsicóticos e podem selecionar agentes com risco diminuído de interação.

\section{ESTRATÉGIAS DE POTENCIALIZAÇÃO}

As estratégias de potencialização devem ser selecionadas em relação aos sintomas-alvo definidos na ERT. Dependendo do tipo de sintoma residual predominantemente apresentado (comportamento agressivo, ansiedade, sintomas positivos, negativos de humor), o acréscimo inclui a adição de lítio, anticonvulsivantes, benzodiazepínicos, agentes betabloqueadores e, em alguns casos excepcionais, a tomada de abordagens mais ou menos experimentais com agonistas do receptor N-metil-daspartato (NMDA), como d-serina, glicina, d-cicloserina ou as drogas de ação pró-colinérgica (APA, 2004).

Para evitar o risco de efeitos colaterais e uma potencial interação medicamentosa, a eficácia do tratamento atual com os medicamentos adjuvantes escolhidos deve ser reavaliada em intervalos curtos de tempo, e os medicamentos associados que não produzam benefícios clínicos devem ser descontinuados. Ainda faltam estudos randomizados controlados com casuísticas maiores de estratégias de potencialização para ERT. Portanto, as recomendações são baseadas principalmente na experiência clínica (Freudenreich e Goff, 2002).

\section{Estabilizadores do humor e anticonvulsivantes}

Uma metanálise avaliando a eficácia do lítio em pacientes esquizofrênicos incluiu 20 estudos randomizados controlados. Desses estudos, 11 avaliaram a eficácia do lítio como tratamento de adição ao medicamento antipsicótico em curso (Leucht et al., 2004). Em geral, a estratégia de combinação revelou uma resposta melhor, mas a superioridade comparada à monoterapia antipsicótica não foi estabelecida de forma consistente em todos os estudos, desaparecendo quando os pacientes com sintomas de humor foram excluídos. Numa pequena série de casos, o acréscimo de lítio mostrou melhora na ERT (Simhandl et al., 1996).

Conforme mencionado anteriormente, a adição de valproato ao haloperidol, à olanzapina e à risperidona nos estudos randomizados controlados demonstrou, de forma inconsistente, efeitos positivos apenas em alguns aspectos específicos de resposta, como sintomas negativos e impressão global (Wassef et al., 2000), hostilidade (Dose et al., 1998; Citrome et al., 2004) e início de ação mais rápido (Casey et al., 2003a). Todavia, outro estudo não relatou nenhum benefício em qualquer uma das medidas de resultado (Hesslinger, 1999). Numa pequena série de casos, foi relatada melhora nos pacientes com ERT (Morinigo et al., 1989).

A adição de carbamazepina revelou resultados controversos. Em combinação com o haloperidol, observou-se piora dos sintomas, possivelmente devido a razões farmacocinéticas (diminuição do nível plasmático de haloperidol) (Hesslinger, 1999). Uma metanálise concluiu que não há evidência sobre a eficácia da combinação de carbamazepina com antipsicóticos na esquizofrenia (Leucht et al., 2002). Em geral, nos oito estudos avaliados controlados com placebo, a maior melhora foi observada apenas numa minoria dos pacientes no grupo com a substância ativa, e não houve superioridade em relação aos critérios de resposta (redução acima de 50\% no escore total BPRS). Pacientes acrescidos de carbamazepina mostraram menos SEP e tolerabilidade similar quando comparados aos que receberam placebo. Numa pequena série de casos, o acréscimo de carbamazepina mostrou melhora na ERT (Simhandl et al., 1996).

Em relatos de casos, observou-se que a lamotrigina reduziu os sintomas psicóticos em combinação com a clozapina (Dursun et al., 1999; Dursun e Deakin, 2001; Saba et al., 2002). Quando a lamotrigina foi adicionada à risperidona ou ao haloperidol, os relatos de caso foram controversos (Dursun e Deakin, 2001; Kolivakis et al., 2004). Nenhuma melhora significativa foi observada na adição à olanzapina ou ao flupentixol (Dursun e Deakin, 2001). Em dois ECRs, a adição de lamotrigina (200 $\mathrm{mg} / \mathrm{dia}$ ) versus placebo a um tratamento em curso com clozapina (Tiihonen et al., 2003) ou a antipsicóticos convencionais, risperidona, olanzapina ou clozapina, numa dose de $400 \mathrm{mg} /$ dia, foi ligeiramente eficaz (Kremer $e t$ $a l ., 2004)$ na redução dos sintomas positivos e na psicopatologia geral em pacientes esquizofrênicos resistentes ao tratamento. Em ambos os estudos, a lamotrigina foi bem tolerada. Num estudo aberto, não-randomizado, não se verificou nenhum efeito benéfico do topiramato adicionado a um tratamento em curso com clozapina, olanzapina, risperidona ou flupentixol na esquizofrenia resistente ao tratamento (Dursun e Deakin, 2001).

\section{Agentes antidepressivos}

Ao se acrescentar agentes antidepressivos, deve-se considerar o potencial dos sintomas psicóticos para exacerbação, decorrente do incremento das transmissões adrenérgica e dopaminérgica (Siris et al., 2000). Além de tratar os sintomas depressivos, a sintomatologia negativa persistente é a meta da adição de antidepressivos. É válido ressaltar que, numa revisão recente, a fluvoxamina e a fluoxetina demonstraram melhora dos sintomas negativos, independentemente da influência sobre o humor depressivo (Silver, 2003). Além disso, num estudo recente (duplo-cego, controlado com placebo), o acréscimo de mirtazapina (30 $\mathrm{mg} / \mathrm{dia})$ ao tratamento em curso com clozapina provocou redução significativa dos sintomas negativos e da psicopatologia total em 8 semanas (Zoccali et al., 2004). A eficácia dos antidepressivos no tratamento de pacientes esquizo- 
frênicos com sintomas predominantemente negativos é relatada em outro ponto destas diretrizes. Outros estudos foram conduzidos principalmente na depressão pós-psicótica. Dessa forma, nenhuma recomendação para a esquizofrenia resistente ao tratamento pôde ser extrapolada.

\section{Benzodiazepínicos}

$\mathrm{O}$ tratamento adicional com benzodiazepínicos não demonstrou superioridade consistente à monoterapia com antipsicóticos em pacientes com ERT. Dois ECRs duplo-cegos demonstraram melhora na psicopatologia total (Lingjaerde et al., 1979; Wolkowitz et al., 1992), enquanto outros estudos não revelaram benefícios (Holden et al., 1968; Hanlon et al., 1970; Ruskin et al., 1979; Pato et al., 1989). Na subamostra de pacientes com catatonia, os benzodiazepínicos oxazepam e clonazepam revelaram eficácia na catatonia aguda. Em contrapartida, o uso do lorazepam não proporcionou benefícios num ECR controlado com placebo em pacientes catatônicos crônicos (Ungvari et al., 1999). Contudo, pode-se dizer que o lorazepam é útil em abordagens combinadas por apresentar boa absorção da preparação oral e menor relaxamento muscular que os outros benzodiazepínicos (APA, 2004).

\section{Agentes betabloqueadores}

Estudos de revisão sistemática e metanálises concluíram que os betabloqueadores não são benéficos como medicamentos adjuvantes na esquizofrenia nem em pacientes com ERT (Cheine et al., 2004). Um ECR controlado com placebo demonstrou apenas uma ligeira melhora, não significativa, para a combinação com nadolol (80 a $120 \mathrm{mg} /$ dia) durante 3 semanas (Allan et al., 1996). Num estudo clínico randomizado, de 16 semanas, os pacientes não mostraram diferença significativa quando acrescidos de propranolol (até $1.920 \mathrm{mg} /$ dia) (Myers $e t$ $a l ., 1981)$. ECR adicionais não relataram melhora clínica com o acréscimo de oxprenolol (160 a $640 \mathrm{mg} / \mathrm{dia}$ ) (Karniol e Portela, 1982), ou propranolol numa faixa de dose de 80 a $640 \mathrm{mg} /$ dia (Pugh et al., 1983) ou numa dose média de $450 \mathrm{mg} /$ dia (Yorkston et al., 1977) durante 12 semanas de tratamento.

\section{Recomendações}

Em resumo, existe uma evidência muito limitada em relação ao acréscimo de estabilizadores do humor ou anticonvulsivantes no sentido de revelar benefícios aos pacientes com ERT. Conseqüentemente, a administração de ácido valpróico, carbamazepina ou lamotrigina deve ser considerada somente depois que outras opções terapêuticas tiverem sido esgotadas. Há ainda evidência de que a lamotrigina como tratamento adjuvante, especialmente à clozapina, pode reduzir a psicopatologia esquizofrênica (Nível C). A adição de valproato pode ser uma opção de terapia se a agressão e a hostilidade estiverem presentes de forma expressiva (Nivel C). O lítio pode trazer benefícios se os sintomas depressivos se mostrarem predominantes (Nível D). A carbamazepina não deve ser administrada junto com a clozapina em razão do aumento do risco de efeitos colaterais hematológicos. Em pacientes excitados, ansiosos e catatônicos, o uso adjuvante de benzodiazepínicos é benéfico (Nível C). Pacientes apresentando sintomas negativos persistentes (Nível C) ou sintomas depressivos (Nível B) podem ser tratados com antidepressivos.

TERAPIA ELETROCONVULSIVA NA ESQUIZOFRENIA RESISTENTE AO TRATAMENTO

Em pacientes com ERT, relatos e séries de casos sugerem que a ECT pode aumentar a resposta aos APGs (König e Glatter-Götz, 1990; Sajatovic e Meltzer, 1993; Chanpattana et al., 1999) e aumentar o benefício terapêutico em combinação com ASGs (Kupchik et al., 2000; Hirose et al., 2001). Assim, a combinação entre neurolépticos e ECT pode ser recomendada (Nível C) (APA, 2004). Revisando os ECRs, há apenas um estudo que adotou rigorosamente os critérios definidos para ERT e que comparou a ECT com o procedimento placebo (ECT-sham), estando ambos os grupos em uso concomitante de antipsicóticos: neste estudo, não foi encontrada nenhuma vantagem significativa para a ECT (Thayran e Adams, 2004). No entanto, um outro ECR que examinou a continuação da ECT para ERT revelou taxas de respondedores para remissão acima de 50\% (Chanpattana et al., 1999). Há apenas uma evidência inconsistente de que os sintomas do humor ou o diagnóstico de transtorno esquizoafetivo predizem melhor resposta ao ECT (Folstein et al., 1973; Dodwell e Goldberg, 1989) (Nivel D). Alguns relatos sugerem que benefícios maiores são observados em pacientes com idade mais jovem (Chanpattana et al., 1999), predominantemente com sintomas positivos (Landmark et al., 1987), menor tempo de duração da doença e episódios mais curtos (50\% a 70\% para os pacientes ficaram doentes por menos de 1 ano, mas menos de $20 \%$ para pacientes que se mantêm permanentemente doentes por mais de 3 anos) (Kalinowsky e Worthing, 1943; Chanpattana et al., 1999; Thayran e Adams, 2004), número menor de traços paranóides ou personalidade pré-mórbida esquizóide (Dodwell e Goldberg, 1989) (Nível D). A evidência disponível sugere que os medicamentos antipsicóticos devem ser continuados durante e após a ECT quando ela for usada no tratamento da esquizofrenia (Nível D) (APA, 2004). Uma revisão da série de casos afirmou que a adição da ECT à clozapina para pacientes não-respondedores (ou a medicação tradicional ou a uma tentativa isolada de clozapina) se mostrou bem tolerada e eficaz em 67\% dos casos (Nível D) (Kupchik et al., 2000).

Em resumo, existem apenas evidências isoladas sobre a eficácia da ECT na ERT. Consequientemente, a ECT pode ser uma opção de tratamento em pacientes que não respondem à clozapina ou quando uma tentativa com clozapina não for recomendada, como nos casos de efeitos colaterais prejudiciais (Nível C) (APA, 2004). As evidências disponíveis sugerem que os medicamentos antipsicóticos devem ser continuados durante a ECT e 
depois dela (Nível D) (APA, 2004). Depois de um tratamento de sucesso com ECT no tratamento da ERT, o uso de ECT de manutenção deve ser considerado (Nível C) (APA, 2004).

\section{Combinação com psicoterapia}

Uma revisão estabeleceu que as técnicas de terapia cognitivo-comportamental podem ter valor na melhora dos sintomas positivos e, assim, eficácia na esquizofrenia refratária ao tratamento (Cormac et al., 2004). Além disso, a modificação de padrões cognitivos pode ser útil como uma estratégia terapêutica para reduzir a intensidade dos déficits cognitivos (Bark et al., 2003). Para sintomas positivos persistentes ou para sintomatologia negativa incapacitante, um programa de TCC pode proporcionar benefícios superiores àqueles obtidos por meio de atendimento básico ou aconselhamento de apoio (Lewis et al., 2002). Em outro ECR, estratégias de TCC (administrada individualmente ou em grupo), somadas a intervenções familiares, foram úteis na melhora de delírios e alucinações (Drury et al., 2000). Atualmente, alguns outros estudos randomizados controlados estão em curso para avaliar a eficácia da TCC em pacientes agudamente doentes (Wiedemann e Klingberg, 2003). Quando comparada ao atendimento-padrão, a TCC foi mais eficaz no aumento da aderência ao tratamento (Kemp et al., 1998). Numa metanálise, concluiu-se que alguns ECRs mostraram eficácia das intervenções familiares quando comparadas aos cuidados-padrão (Falloon, 2003). Em resumo, especialmente a TCC e a intervenção familiar são úteis como adjuvantes ao tratamento antipsicótico em pacientes com ERT (Nível B).

\section{Tratamento em circunstâncias especiais}

\section{COMORBIDADES PSIQUIÁTRICAS}

\section{Comportamento suicida}

Estima-se em $10 \%$ a taxa de suicídio entre pacientes com esquizofrenia, sendo 2 a 5 vezes maior a incidência de tentativas de suicídio (Siris, 2001). Estudos de coorte mostraram que aproximadamente $10 \%$ dos pacientes no primeiro episódio de esquizofrenia tentam o suicídio no primeiro ano, e alucinações e comportamentos suicidas prévios representam os principais fatores de risco (Nordentoft et al., 2002). Variáveis demográficas associadas às tentativas de suicídio na esquizofrenia são: sexo masculino, idade jovem, início do curso da doença, família com condições socioeconômicas elevadas, ser muito inteligente, ter grandes expectativas, não ser casado, carecer de apoio social, ter conhecimento dos sintomas e ter recebido alta recente do hospital. Outros fatores associados são: baixa auto-estima, estigma, perda recente ou estresse, desesperança, isolamento, não-aderência ao tratamento e abuso de drogas (Siris, 2001). Clinicamente, os correlatos mais comuns do suicídio na esquizofrenia são os sintomas depressivos e a síndrome depressiva, embora sintomas psicóticos graves e crises de pânico também possam contribuir (Siris, 2001).
Em pacientes esquizofrênicos, as tentativas de suicídio freqüentemente são fatais, indicando que utilizam métodos mais violentos (Beautrais, 2001). Considera-se que fatores genéticos e neurobiológicos distintos influenciam no comportamento suicida, talvez de forma independente dos fatores genéticos associados à esquizofrenia (Meltzer, 2002). O suicídio é a principal causa de morte prematura entre pacientes com esquizofrenia (Meltzer, 2002). Idéias ou ameaças suicidas devem ser julgadas no contexto da história clínica, conforme relatada pelo paciente, pelos parentes e pelo terapeuta atual, se essas informações estiverem disponíveis (APA, 1997). Deve haver monitoramento cuidadoso dos pacientes vulneráveis durante os períodos de crise pessoal, alterações significativas do ambiente, aumento da angústia ou depressão durante o curso da doença. Pode ser necessário o aumento na frequiência de visitas ambulatoriais durante os períodos vulneráveis, incluindo altas recentes do hospital (APA, 1997).

Em alguns estudos abertos e randomizados controlados comparando os ASGs aos APGs, observou-se um efeito positivo na prevenção do suicídio. Contudo, esse efeito não foi demonstrado de forma consistente (Keck et al., 2000; Tondo et al., 2001; Barak et al., 2004). Assim, conclui-se até o momento que nenhuma diferença significativa separa os antipsicóticos típicos e atípicos na prevenção do comportamento suicida (Nível C). Se há um risco aumentado de suicídio, a clozapina pode ser superior aos outros agentes neurolépticos na redução do comportamento suicida, conforme sugerido por alguns estudos randomizados controlados e também por estudos abertos (Nível B) (Meltzer e Okayli, 1995; Meltzer et al., 2003; Wagstaff e Perry, 2003).

\section{Recomendações}

Para pacientes com alto risco de suicídio, deve-se considerar a hospitalização, e precauções quanto ao suicídio devem ser instituídas. E importante otimizar o tratamento somático da psicose e da depressão, acessando diretamente a idéia de suicídio do paciente com uma abordagem enfática e de apoio (APA, 2004). A terapia com clozapina deve ser considerada em caso de risco importante ou persistente de suicídio (Nível B).

\section{Depressão e ansiedade}

Os sintomas depressivos podem ocorrer em todas as fases da esquizofrenia, como, por exemplo, na fase prodômica, no primeiro episódio, durante o curso inicial e após a remissão. A depressão pode contribuir para os sintomas residuais da esquizofrenia, e a proporção de pacientes com esquizofrenia que também manifestam depressão varia de 7\% a 75\% (Siris, 2000). Os sintomas depressivos devem ser distinguidos dos efeitos colaterais dos medicamentos antipsicóticos (incluindo disforia induzida pelo medicamento, acinesia e acatisia) e dos principais sintomas negativos da esquizofrenia (APA, 2004). Se houver suspeita de disforia induzida pela medicação antipsicótica, então a simples redução da dose do antipsicótico pode ser sufuciente, 
ou, alternativamente, a mudança para um antipsicótico com risco menor de induzir sintomas extrapiramidais (como ASG) pode ser considerada. Alguns APGs (como a tioridazina) (Dufresne et al., 1993) e ASGs foram sugeridos como benéficos no tratamento dos sintomas depressivos na esquizofrenia. Os ASGs são indicados como superiores nesse contexto em comparação aos APG. No entanto, essa evidência ainda se mostra limitada (Tollefson et al., 1998; Peukens et al., 2000; Möller, 2005a) (ver também o item "Eficácia dos antipsicóticos de segunda geração").

Os sintomas depressivos nos episódios agudos podem melhorar paralelamente à melhora da psicose, mediante tratamento antipsicótico regular (Möller, 2005b). Em razão da piora potencial da psicose pelos agentes antidepressivos durante a fase aguda, os antidepressivos são advogados principalmente como tratamento adjuvante na fase estável da esquizofrenia (Mulholland e Cooper, 2000). O tratamento com antidepressivos adicionados aos antipsicóticos está indicado quando os sintomas preenchem os critérios sindrômicos para distúrbio depressivo maior ou são importantes e causam angústia significativa (como, por exemplo, quando acompanhados de idéias suicidas) ou quando interferem nas atividades (DGPPN, 1998; APA, 2004).

Os antidepressivos tricíclicos foram avaliados principalmente no tratamento da depressão pós-psicótica (Nível B) (Siris et al., 2000). Outros antidepressivos (ISRS e inibidores duais) também se mostraram úteis no tratamento da depressão na esquizofrenia (Nível B) (Siris, 2000). Contudo, um ECR não revelou nenhuma vantagem significativa com a sertralina quando comparada ao placebo, demonstrando alta resposta ao placebo (Addington et al., 2002). Um pequeno ECR comparando a sertralina e a imipramina na depressão pós-psicótica revelou eficácia comparável, mas início mais rápido com a sertralina (Kirli e Caliskan, 1998). No entanto, poucos estudos examinaram os efeitos dos antidepressivos em pacientes tratados com APG, dificultando a avaliação da atual utilidade terapêutica antidepressiva combinada. Quando prescritos, os antidepressivos são utilizados nas mesmas doses que no tratamento de distúrbios depressivos maiores (APA, 2004). No entanto, há interações farmacocinéticas potenciais com certos medicamentos antipsicóticos, como os ISRS (fluoxetina, paroxetina e fluvoxamina), que são inibidores das enzimas do citocromo $\mathrm{P} 450$ e, portanto, aumentam os níveis plasmáticos dos antipsicóticos. Da mesma forma, os níveis sanguiíneos constatados depois da administração de alguns antidepressivos podem ser elevados pelo uso concomitante de medicamentos antipsicóticos.

\section{Comportamento agressivo}

Em estudos observacionais e retrospectivos de coorte, o comportamento violento ocorreu mais freqüentemente (quase 4 vezes) em pacientes com esquizofrenia do que em pessoas sem qualquer forma de doença psiquiátrica (Angermeyer, 2000). Numa metanálise, idade jovem, maior taxa de re-hospitalização, transtorno comórbido de personalidade anti-social e envolvimento anterior em atos criminosos foram preditores de violência em pessoas esquizofrênicas vivendo na comunidade (Bonta et al., 1998). Outros fatores de risco para violência na esquizofrenia incluem: prisões prévias, abuso de drogas, presença de alucinações, delírios ou comportamentos bizarros, presença de disfunção neurológica, sexo masculino, falta de habilidades, baixo nível educacional e não estar casado (APA, 1997). Muitas vezes, os próprios familiares (geralmente os pais) são os alvos da violência (Angermeyer, 2000). A identificação dos fatores de risco para ideação e comportamento violentos faz parte da avaliação psiquiátrica-padrão. Quando um paciente representa uma séria ameaça a outra pessoa, o psiquiatra deve exercitar seu melhor julgamento de acordo com as exigências legais da jurisdição para proteger aquelas pessoas de riscos previsíveis (APA, 1997). $\mathrm{O}$ controle efetivo da agressão e da agressividade em pacientes com esquizofrenia pode freqüentemente ser alcançado por meio de abordagens comportamentais, do estabelecimento de limites e da escuta persuasiva (APA, 2004). Os medicamentos antipsicóticos são o esteio do controle. Os anticonvulsivantes (Citrome $e t$ $a l ., 2004)$, o lítio e os betabloqueadores em doses altas (propranolol, pindolol) (Caspi et al., 2001) também podem ser úteis (Nível C) (APA, 2004). ASGs como a risperidona (Chengappa et al., 2000; Aleman e Kahn, 2001) e, especialmente, a clozapina (Chengappa et al., 2002) revelam eficácia no tratamento da hostilidade e do comportamento agressivo (Nível C). O controle emergencial já foi discutido anteriormente (ver item "Tratamento da agitação").

\section{Distúrbios decorrentes do abuso de drogas}

$\mathrm{O}$ abuso de drogas em indivíduos com esquizofrenia é muito comum, devendo ser considerado a condição psiquiátrica comórbida mais prevalente associada à esquizofrenia (Cuffel et al., 1993). As taxas de prevalência estimada ao longo da vida para abuso de drogas na esquizofrenia variam de $15 \%$ a $65 \%$ (Kovanaszay et al., 1997; Regier et al., 1990; Wobrock et al., 2004). As taxas de prevalência variam com os diferentes instrumentos e o contexto da avaliação (paciente internado ou ambulatorial), dependendo de diferentes fatores sociais e culturais. Em estudos mais recentes, a prevalência do abuso ou da dependência de drogas entre pessoas com esquizofrenia em 6 meses e ao longo da vida foi de $27 \%$ e 60\%, respectivamente (Fowler et al., 1998). O abuso comórbido de drogas não-alcoólicas ao longo da vida foi relatado em $16 \%$ da população geral, e o abuso de maconha foi relatado em $60 \%$ dos homens esquizofrênicos com menos 36 anos de idade (Duke et al., 2001).

O distúrbio comórbido do uso de drogas tem sido associado a períodos mais freqüentes e mais longos de hospitalização, além de outros resultados negativos, incluindo taxas de recaída mais elevadas, mesmo em pacientes no primeiro episódio, não-aderência mais 
alta, taxas elevadas de SEP, desemprego, falta de abrigo, violência, encarceramento, suicídio e infecção pelo HIV (Mueser et al., 1990; Olivera et al., 1990; Soyka et al., 1993; Linszen et al., 1994; Blanchard et al., 2000; Mueser et al., 2000; Goldham et al., 2002; Hunt et al., 2002; Lacro et al., 2002). Além das substâncias comercializadas legalmente (tabaco e álcool), a maconha parece ser a droga ilícita mais utilizada pelos esquizofrênicos, sendo discutida como um importante fator de risco para o desenvolvimento da esquizofrenia (Bersani $e t$ al., 2002; Caspari e Wobrock, 2004). A presença do abuso ou da dependência de drogas muitas vezes é omitida nas avaliações, especialmente se o paciente é observado durante um episódio psicótico agudo. Uma vez que o auto-relato geralmente não é confiável, devemse procurar evidências que corroborem essa hipótese por meio de todas as fontes possíveis, incluindo testes laboratoriais (função hepática) e rastreio toxicológico de drogas (urina e sangue). Os efeitos das drogas de abuso sobre os sintomas esquizofrênicos variam, tornando difícil a diferenciação entre os sintomas relacionados a tais substâncias e aqueles decorrentes de psicose funcional (APA, 2004). As drogas de abuso podem acarretar o aumento das alucinações e dos sintomas paranóides ou da ansiedade nos pacientes com psicoses esquizofrênicas preexistentes (Dixon et al., 1991). Os antipsicóticos podem não neutralizar esses efeitos psicotomiméticos (Gawin, 1986). Em alguns casos, pode ser extremamente difícil a distinção entre a esquizofrenia e a psicose induzida pela droga.

O ponto-chave ao fornecer o tratamento para essa população é o desenvolvimento de uma dupla abordagem, que integre o tratamento do abuso de drogas e da esquizofrenia (Ridgely e Jerrel, 1996; Drake e Mueser, 2000; Wobrock et al., 2004). Atualmente, muitos programas proporcionam essa integração com o apoio de equipes interdisciplinares e especialistas no tratamento da esquizofrenia e do abuso de drogas. Essa forma de tratamento se baseia no gerenciamento assertivo do caso, em intervenções familiares, no abrigo domiciliar, na reabilitação e na farmacoterapia, incluindo também uma abordagem motivacional por etapas, sobretudo para pacientes que não reconhecem a necessidade do tratamento do abuso de drogas, e intervenções comportamentais para aqueles que tentam conquistar ou manter a abstinência. Estudos mostram que os programas de tratamento combinados com elementos motivacionais, psicoeducacionais e abordagens cognitivo-comportamentais, evitando um confronto direto, pode ser efetivo na redução do abuso de drogas e na diminuição da frequiência e da gravidade das descompensações psicóticas (Hellerstein et al., 1995; Addington e El-Guebaly, 1998; Drake e Mueser, 2000; Barrowclough et al., 2001; Clark, 2001; Baker et al., 2002).

Embora faltem estudos prospectivos randomizados controlados para pacientes esquizofrênicos com uso comórbido de drogas, as recomendações para o tratamento antipsicótico são derivadas principalmente dos estudos em esquizofrenia nos quais o abuso de drogas era um critério de exclusão. Nas revisões antigas, o haloperidol na dose de 5 a $10 \mathrm{mg} /$ dia (máximo de $20 \mathrm{mg} /$ dia), ou alternativamente o flupentixol 5 a $20 \mathrm{mg} / \mathrm{dia}$, era recomendado como droga de escolha para o tratamento antipsicótico (Soyka, 1996; Wilkins, 1997). Antipsicóticos com amplos efeitos colaterais anticolinérgicos devem ser evitados, pois os efeitos anticolinérgicos das drogas utilzadas podem ser potencializados. Sintomas positivos adicionais causados pelas substâncias normalmente sofrem rápida remissão com a abstinência. Portanto, pacientes esquizofrênicos com uso concomitante de drogas não precisam de doses mais altas de antipsicóticos que os pacientes esquizofrênicos sem essa condição comórbida (Richard et al., 1985; Siris, 1990; Wilkins, 1997). Em pacientes esquizofrênicos que usam cocaína, uma possível intensificação da hipertermia induzida pela cocaína deve ser levada em consideração durante o tratamento antipsicótico (Kosten e Kleber, 1988). A absorção prolongada (como no exemplo da maconha) a partir do tecido gorduroso visceral pode ser responsável pelos efeitos psicotomiméticos prolongados e pelas interações farmacocinéticas, especialmente nos estágios iniciais da terapia. O álcool, por exemplo, reduz os níveis séricos dos agentes antipsicóticos (como a flufenazina) (Soni et al., 1991).

Estudos abertos e séries de casos com APGs, em particular o flupentixol, sugerem eficácia na redução do uso comórbido de drogas ilícitas. Em pacientes esquizofrênicos com dependência alcoólica comórbida, o consumo de álcool foi acentuadamente reduzido pelo decanoato de flupentixol ( $10 \mathrm{a} 60 \mathrm{mg}$ por via intramuscular a cada 2 semanas), enquanto a psicopatologia quase não foi afetada (Soyka e Sand, 1995; Soyka et al., 2003). Além disso, para melhora no estado mental, pacientes esquizofrênicos com dependência comórbida de substâncias (álcool, cocaína, maconha, benzodiazepínicos e anfetaminas) que receberam decanoato de flupentixol exibiram redução na ingestão da substância de abuso (Schilkrut et al., 1988; Levin et al., 1998). Contrapondo-se a esses achados, o tratamento com decanoato de flupentixol (comparado ao placebo) se associou a mais recaídas nos alcoolistas sem esquizofrenia como comorbidade (Wiesbeck et al., 2001). Num estudo transversal, o tratamento com ASGs comparado aos agentes antipsicóticos convencionais se associou à redução no consumo de álcool, embora não tenham sido observadas diferenças na psicopatologia ou nos efeitos colaterais extrapiramidais (Scheller-Gilkey et al., 2003).

Dos ASGs, a maior evidência foi reunida para a clozapina no tratamento de pacientes esquizofrênicos com abuso comórbido de drogas. Nos registros e nas séries de caso, na análise retrospectiva de pacientes resistentes ao tratamento e em estudos transversais, foi relatada redução no consumo de sustâncias (particularmente álcool e cocaína) por meio do tratamento com clozapina. O uso 
reduzido de drogas foi associado à melhora dos sintomas esquizofrênicos (particularmente negativos) na maioria das séries de caso (Albanese et al., 1994; Yovell e Opler, 1994; Marcus e Snyder, 1995; Tsuang et al., 1999) e nos estudos retrospectivos e transversais (Lee et al., 1998; Drake e Muser, 2000; Zimmet et al., 2000), mas não em todas as análises retrospectivas (Buckley et al., 1994a e 1994b). Estudos controlados para manutenção da terapia e prevenção de recaídas em pacientes com esse duplo diagnóstico ainda não se encontram disponíveis. Em pacientes com esquizofrenia resistente ao tratamento tratados com clozapina, não foi encontrada nenhuma diferença na comparação de pacientes com e sem uso de substâncias em relação à taxa de readmissão num um estudo prospectivo observacional (Kelly et al., 2003).

Nos viciados em cocaína, a administração de clozapina pode aumentar as concentrações séricas de cocaína e induzir efeitos colaterais cardiovasculares. Portanto, indica-se o monitoramento cuidadoso durante a fase de titulação da dose da clozapina (Farren et al., 2000). Para pacientes que mostram sintomas psicóticos persistentes ou que desenvolvem efeitos colaterais aos antipsicóticos clássicos, recomenda-se o tratamento com clozapina nas doses de 50 a $600 \mathrm{mg}$ /dia (Soyka, 1996; Wilkins, 1997). Além disso, estudos retrospectivos, transversais e prospectivos (mudança de haloperidol para clozapina) revelaram evidência de redução no consumo de cigarros pelos pacientes esquizofrênicos (McEvoy et al., 1995; Procyshyn et al., 2001 e 2002). Para a risperidona, registros de caso e um estudo aberto prospectivo numa casuística pequena revelou evidência da redução do uso de drogas, da necessidade, da sintomatologia ou da recaída em comparação aos antipsicóticos típicos (haloperidol, flufenazina e clorpromazina) (Gupta e Basu, 2001; Smelson et al., 2002).

Num estudo piloto prospectivo com casuística pequena comparando a olanzapina ao haloperidol, observou-se redução no consumo de cocaína, paralelamente à melhora da condição psicopatológica e dos efeitos adversos da droga (Tsuang et al., 2002). Estudos clínicos abertos e prospectivos mostraram que a mudança do tratamento antipsicótico, passando de drogas antipsicóticas convencionais para olanzapina, pode diminuir o uso da substância e melhorar os sintomas esquizofrênicos (Noordsy e O'Keefe, 1999; Littrell et al., 2001). Ganho de peso substancial foi observado como efeito adverso. Um estudo prospectivo aberto com pacientes portadores de esquizofrenia resistente demonstrou que a olanzapina (nas doses de 10 a $25 \mathrm{mg} /$ dia) foi tão eficaz na redução dos sintomas psiquiátricos nos pacientes que não faziam abuso de drogas quanto naqueles que apresentavam uso comórbido de substâncias (Conley et al., 1998). Um estudo aberto prospectivo e alguns relatos de caso sugerem que a quetiapina pode ter sucesso na redução da necessidade do álcool e da cocaína, na recaída e na melhora dos sintomas em pacientes com uso comórbido de substâncias (Brown et al., 2002; Weisman, 2003). Num estudo retrospectivo comparando a eficácia da clozapina e da riperidona sobre o uso de álcool e maconha em pacientes esquizofrênicos, o tratamento com clozapina propiciou maior índice de abstinência (Green et al., 2003). Tendo em vista que os sintomas depressivos são frequientes em pacientes com esquizofrenia e uso de drogas, também foram realizados estudos com ADTs. Além do efeito antidepressivo, foi detectada a diminuição da necessidade e do consumo de drogas em pacientes esquizofrênicos dependentes de cocaína. Essa observação foi feita num estudo aberto (Ziedonis et al., 1992) e em outro controlado com placebo, em que se administrou a desipramina (Wilkins et al.,1997) ou a imipramina simultaneamente ao tratamento com neuroléptico (Siris et al., 1993). Por causa de seus efeitos anticolinérgicos, o tratamento com $\mathrm{ADT}$ s não deve ser iniciado até que a desintoxicação da droga esteja concluída. Outros efeitos adversos do tratamento com $\mathrm{ADT}$ s podem ser a precipitação de crise hipertensiva durante o uso concomitante de substâncias com estimulação adrenérgica e a exacerbação dos sintomas psicóticos (Siris, 1990).

Quanto aos agentes anticraving, como o acamprosato (modulador dos receptores NMDA) e a naltrexona (antagonista do receptor opióide), não há estudos controlados disponíveis para pacientes com esquizofrenia e dependência de drogas. A naltrexona foi citada em resumos de pesquisa como potencialmente útil (Sernyak et al., 1998; Maxwell e Shinderman, 2000). Não obstante, por causa de sua excelente tolerabilidade, esses medicamentos podem ser administrados em pacientes esquizofrênicos dependentes de álcool (Noordsy e Green, 2003). O dissulfiram pode, por si só, induzir psicose, presumivelmente por bloquear a enzima dopamina beta-hidroxilase (Ewing et al., 1977; Major et al., 1978; Noordsy e Green, 2003). Portanto, em razão da possível aceleração do metabolismo da droga antipsicótica, a discussão é controversa com relação ao uso do dissulfiram em pacientes com esquizofrenia e dependência do álcool, embora tenha sido reportado sucesso terapêutico nas doses de 250 a $500 \mathrm{mg} /$ dia nos registros de caso e na revisão de prontuários (Kofoed et al., 1986; Mueser et al., 2003).

Uma vez que a frequiência de SEP está aumentada em pacientes esquizofrênicos com distúrbio comórbido de uso de substâncias, a administração concomitante ou precoce de agentes anticolinérgicos, como o biperideno, poderia ser considerada (Soyka, 1996). O risco elevado de SEP nessa população poderia contar pontos a favor dos ASGs como opção de tratamento de primeira linha em pacientes esquizofrênicos com uso comórbido de drogas. A tiaprida, um antipsicótico derivado da benzamida, poderia se tornar o tratamento de escolha para as discinesias, uma vez que pode ter propriedades anticraving, sendo empregada no tratamento das síndromes de abstinência de álcool (Soyka, 1996).

Com base em evidências muito limitadas, mas sustentadas por considerações teóricas neurofarmaco- 
lógicas (menor SEP, melhora da disfunção cerebral de recompensa, redução da impulsividade) e por seu uso crescente na prática clínica, os ASGs podem ser recomendados como tratamento de primeira linha em pacientes com esquizofrenia e distúrbio comórbido de uso de substâncias (Nível D) (Krystal et al., 1999; Noordsy e Green, 2003; Potvin et al., 2003). Pode ser favorável aos pacientes com esse duplo diagnóstico reduzir o limiar para recomendação de um estudo com clozapina em pacientes sem distúrbio comórbido de uso de substância (Nível D). Por causa da freqüente não-aderência, o uso prolongado de antipsicóticos de depósito (como o decanoato de haloperidol e o decanoato de flupentixol) pode ser uma opção terapêutica favorável para esse grupo de pacientes (Nível D) (Soyka, 1996).

\section{Comorbidades SOMÁtICAS}

Pesquisas epidemiológicas demonstram que pacientes com esquizofrenia sofrem em maior proporção de uma variedade de comorbidade somáticas, incluindo doenças cardiovasculares e respiratórias, diabetes e moléstias infecciosas. As comorbidades somáticas são determinadas por múltiplos fatores, incluindo associações com a esquizofrenia, estilo de vida (tabagismo, uso de drogas, obesidade, falta de atividade física), ambiente e uso de medicamentos (Jeste et al., 1996). Portanto, a seleção do tratamento e o controle clínico dos pacientes com esquizofrenia devem considerar a história médica pregressa do paciente e a condição médica geral para a determinação do plano de tratamento (APA, 2004). Pelo fato de os pacientes com psicose e retardo mental estarem sob maior risco de efeitos colaterais extrapiramidais e discinesia tardia, os antipsicóticos de segunda geração, particularmente aqueles com risco mínimo de SEP (como a quetiapina), são recomendados (APA, 2004).

Para pacientes com osteopenia ou osteoporose preexistente, deve-se prescrever, se possível, um antipsicótico com efeitos mínimos sobre a prolactina. Além disso, para mulheres com câncer de mama, os antipsicóticos com efeitos de elevação da prolactina devem ser evitados ou prescritos apenas depois de consulta com o oncologista. Em tais situações, o aripiprazol, que suprime parcialmente a liberação de prolactina, pode estar especificamente indicado (APA, 2004). Para pacientes obesos, as considerações especiais do tratamento podem ser úteis (ver o item "Controle dos efeitos colaterais relevantes" na parte 2 destas diretrizes). A seleção do tratamento deve sempre avaliar os benefícios esperados do tratamento antipsicótico em relação a seu potencial para exacerbar ou contribuir com o desenvolvimento de condições médicas específicas. Pacientes com síndrome do QT, bradicardia, certos distúrbios eletrolíticos, insuficiência cardíaca ou infarto do miocárdio recente e aqueles que estejam tomando drogas que prolonguem o intervalo QT não devem ser tratados com um antipsicótico que possa prolongar ainda mais o intervalo QT ou aumentar o risco de arritmia (torsade de pointes).
Esses antipsicóticos incluem a tioridazina, a pimozida, o droperidol e a ziprasidona (Marder et al., 2004).

Medicamentos com baixa afinidade para os receptores alfa-adrenérgicos devem ser usados nos pacientes vulneráveis a hipotensão ortostática, incluindo os idosos, pacientes com doença vascular periférica ou condição cardiovascular comprometida e aqueles severamente debilitados (APA, 2004). Para pacientes com glaucoma de ângulo agudo, constipação importante, história de íleo paralítico, retenção urinária, hipertrofia prostática ou delirium/demência, devem ser prescritos os antipsicóticos com pouco ou nenhum antagonismo aos receptores colinérgicos. Estudos demonstraram evidências de que pacientes com demência avançada podem estar sob maior risco de acidente vascular cerebral quando tratados com risperidona ou olanzapina se comparados aos que receberam placebo. Não obstante, esse risco elevado também pode existir para os APGs ou outros ASGs, mas ainda não foram sistematicamente investigados. A clozapina não deve ser usada em pacientes com doenças hematológicas, especialmente quando apresentarem neutropenia $\left(<1.500 / \mathrm{mm}^{3}\right)$, baixa contagem de glóbulos brancos $\left(<3.000 / \mathrm{mm}^{3}\right)$ ou ainda história de tais sensibilidades a medicamentos prévios (como o clorprotixeno e a mianserina). Pacientes com doença hepática podem ter o metabolismo dos medicamentos antipsicóticos prejudicado, estando sob risco de toxicidade. É importante notar que todos os medicamentos antipsicóticos reduzem o limiar convulsivo, com riscos aumentados para a clorpromazina, a clozapina e a zotepina.

\section{Pacientes idosos}

Entre indivíduos de meia-idade e idosos com esquizofrenia, aproximadamente $20 \%$ têm esquizofrenia de início tardio (após os 40 anos de idade) ou psicose esquizofreniforme de início muito tardio (após os 60 anos) (APA, 2004). A abordagem para o tratamento de pessoas idosas com esquizofrenia é semelhante àquela indicada para pacientes mais jovens e envolve a combinação entre farmacoterapia e intervenções psicossociais (NICE, 2002; APA, 2004). Várias alterações fisiológicas relacionadas à idade (débito cardíaco reduzido, ritmo de filtração glomerular reduzido, possível redução no metabolismo hepático e aumento do conteúdo de gordura) alteram a absorção, a distribuição, o metabolismo e a excreção dos medicamentos. Comparados a pacientes mais jovens, os pacientes geriátricos mostram maior variabilidade de resposta e maior sensibilidade aos medicamentos. Embora uma resposta exagerada seja mais comum entre idosos, alguns pacientes manifestam diminuição idiossincrásica e até mesmo efeitos paradoxais em relação aos medicamentos.

Em geral, as doses iniciais recomendadas em pacientes mais idosos são de $25 \%$ a $50 \%$ da dose habitual de início para um adulto jovem (APA, 2004). Pacientes idosos tendem a ser mais sensíveis aos efeitos terapêuticos e tóxicos dos medicamentos antipsicóticos, 
parcialmente por causa das reduções relacionadas à idade na neurotransmissão cerebral da dopamina e da acetilcolina, sensibilidade especialmente elevada em pacientes idosos com anormalidades estruturais do cérebro. Os efeitos colaterais dos medicamentos antipsicóticos que ocorrem mais frequientemente em pacientes idosos são: sedação, hipotensão ortostática, reações anticolinérgicas, sintomas extrapiramidais (acatisia e parkinsonismo, mas não distonia aguda) e discinesia tardia (Jeste, 2000). Pelo fato de quase todos os medicamentos antipsicóticos habitualmente prescritos serem igualmente eficazes para pacientes idosos com esquizofrenia, a seleção do medicamento antipsicótico deve ser baseada principalmente no perfil de efeitos colaterais (ver o item "Comorbidades somáticas") (APA, 2004). Em seis estudos duplo-cegos controlados que incluíram pacientes esquizofrênicos com idade média superior a 45 anos, a taxa média de recaídas para os grupos cujo medicamento antipsicótico havia sido retirado foi 3de 9,9\% ao longo de um período médio de acompanhamento de 6 meses, enquanto a taxa de recaída para os grupos cujo medicamento antipsicótico havia sido mantido foi de 11,4\% (Jeste et al., 1993). Esses estudos podem sugerir a continuidade do medicamento. Especialmente em pessoas idosas, a polifarmacoterapia desnecessária deve ser evitada, e os efeitos colaterais anticolinérgicos das drogas antipsicóticas se tornam mais proeminentes e importantes, o que deve ser levado em conta ao se prescrever um antipsicótico ou um agente adjuvante.

\section{DifERENÇAS ENTRE OS SEXOS}

$\mathrm{Na}$ apresentação clínica e no curso da esquizofrenia, diversas diferenças entre os sexos são percebidas (Goldstein e Tsuang, 1990; Häfner, 2000). A média de idade de início nas mulheres é 3 a 4 anos mais tardia que nos homens, e o pico de início da doença ocorre em dois pontos, com um segundo pico após a menopausa (Häfner, 2000). Provavelmente em razão do início mais tardio, de uma história pré-mórbida melhor e dos potencias efeitos protetores dos estrógenos, as mulheres apresentam um curso favorável da doença, com menos sintomas negativos e mais sintomas afetivos, tendo maior chance de apresentar melhor resposta aos neurolépticos que os pacientes do sexo masculino (Seeman, 1986; Goldstein e Tsuang, 1990; Castle et al., 1993, Häfner, 2000). Outros fatores além dos biologicamente mediados, tais como as expectativas familiares e da sociedade, o menor níveis de abuso de drogas (pré e pós-admissão) e um bom suporte dos membros da família, também podem afetar os resultados de maneira positiva. Além disso, entre as pacientes esquizofrênicas do sexo feminino, as práticas tradicionais de socialização tornam mais aceitáveis a maior dependência da família, permitindo uma boa aceitação do tratamento por parte da família. Ainda, tem sido observado que, mesmo depois de considerado o peso corporal, as mulheres com primeiro episódio de esquizofrenia respondem a doses menores de medica- mentos antipsicóticos que os homens (Szymanski et al., 1995; Leung e Chue, 2000), embora existam evidências de que as mulheres na pós-menopausa possam precisar de doses mais elevadas (Leung e Chue, 2000). As mulheres tendem a desenvolver mais SEP e maiores níveis de prolactina durante o tratamento antipsicótico que os homens (Leung e Chue, 2000). Em decorrência de alterações hormonais, as mulheres podem precisar de redução da dose dos neurolépticos na metade do ciclo menstrual e de aumento da dose durante a menstruação (Castle et al., 1995). As mulheres com esquizofrenia apresentam risco mais elevado de abuso físico e sexual do que as mulheres sadias e os homens. Portanto, uma exploração cuidadosa e a ajuda especial nesse quesito podem ser necessárias (Goodman et al., 1997).

Em resumo, Há evidências limitadas em relação ao fato de as mulheres serem tratadas com doses menores de medicamentos antipsicóticos quando comparadas aos homens (Nível D). Informações adicionais devem ser fornecidas sobre contracepção, proteção contra violência física e sexual e o potencial de risco dos antipsicóticos específicos para o sexo feminino (osteoporose, câncer de mama) (Nível D).

\section{Gravidez e LACTAÇão}

O tratamento antipsicótico de mulheres esquizofrênicas grávidas ou que estejam amamentando deve ponderar, de um lado, os riscos dos vários medicamentos antipsicóticos para o feto, o recém-nascido e o lactente e, de outro, os riscos de que os sintomas psicóticos não tratados acarretem cuidados inadequados nos períodos pré e perinatal (APA, 2004). Estudos controlados com drogas antipsicóticas durante a gravidez não estão disponíveis por razões éticas óbvias. Portanto, o conhecimento dos riscos desses agentes provém de estudos em animais e de exposições não controladas em humanos. Dois períodos de alto risco para o feto ou o recém-nascido são identificáveis: o primeiro trimestre, com o maior potencial teratogênico, e o momento do nascimento, com o maior risco obstétrico (APA, 2004).

A exposição às drogas psicotrópicas no primeiro trimestre está apenas sob total controle do médico e da paciente numa gravidez planejada. Em relação aos APGs, há relativamente poucas evidências de efeitos prejudiciais, especialmente com agentes de alta potência, em razão de seu amplo uso no passado (Cohen e Rosenbaum, 1998; American Academy of Pediatrics, 2000; Gold, 2000). Os relatos do uso de medicamentos psicotrópicos durante a gravide $z$ concentraram-se principalmente na clorpromazina e no haloperidol. Menos informação está disponível em relação à exposição fetal aos ASGs. Numa revisão, casos de abortamento espontâneo, natimortos, prematuridade, anormalidades fetais, reações perinatais indesejadas e complicações gestacionais, incluindo o desenvolvimento de diabetes e pré-eclâmpsia, foram relatados durante o tratamento com olanzapina (Ernst e Goldberg, 2002). 
Com a clozapina, há relatos de interrupções eletivas da gravidez, desenvolvimento de diabetes ou piora do diabetes gestacional, síndrome hipotônica do recém-nascido, convulsões neonatais, doença do refluxo gastroesofágico e morte fetal intra-uterina (Gentile, 2004). Abortamentos eletivos (MacKay et al., 1998) e um caso de agenesia do corpo caloso foram descritos no tratamento com risperidona (Gentile, 2004). Dois relatos do uso de quetiapina na gravidez foram isentos de complicações (Tenyi et al., 2002; Taylor et al., 2003), mas faltam relatos de casos com aripiprazol e ziprasidona, embora possíveis efeitos teratogênicos tenham sido descritos em estudos com animais (Gentile, 2004). Numa revisão sistemática, concluiu-se que a olanzapina e a clozapina não aumentam o risco teratogênico comparado à evolução na população geral saudável. $\mathrm{O}$ conhecimento sobre a quetiapina, a risperidona, o aripiprazol e a ziprasidona é limitado, faltando estudos nesse sentido (Gentile, 2004).

O tratamento com olanzapina e clozapina pode estar associado ao maior risco de hiperglicemia (Gentile, 2004). Além disso, mulheres grávidas com esquizofrenia tomando ASGs se mostram frequientemente obesas e com ingestão inadequada de ácido fólico (relacionado ao risco aumentado de defeitos no tubo neural), sugerindo até mesmo efeitos indiretos em vez de um efeito direto do medicamento (Koren et al., 2002). Ainda, um número de estudos demonstrou que mulheres grávidas com esquizofrenia recebem cuidados pré-natais relativamente mais fracos, têm mais complicações obstétricas, seus filhos têm maior probabilidade de apresentar baixo peso ao nascimento e maior índice de natimortalidade (APA, 2004). Os fatores que contribuem para esses desfechos podem ser, entre outros, baixo nível socioeconômico, altas taxas de tabagismo ou abuso de drogas durante a gravidez.

Comparados aos medicamentos antipsicóticos, os estabilizadores do humor e os benzodiazepínicos estão muito mais associados a malformações fetais e efeitos comportamentais. $\mathrm{O}$ efeito teratogênico do valproato de sódio é especialmente bem conhecido (Ernst e Goldberg, 2002; American Academy of Pediatrics, 2000; Gold, 2000). Portanto, sua relação risco-benefício é diferente, e a necessidade de sua continuação durante a gravidez ou o período de amamentação requer uma forte justificativa clínica.

Com base nos achados e nas considerações relatadas, recomenda-se iniciar precocemente o seguimento obstétrico pré-natal, o que pode ajudar a reduzir os riscos da gravidez, além de possibilitar maior interação entre os especialistas e a ampla discussão dos riscos e benefícios das opções farmacológicas de tratamento. Quando possível, o controle não-farmacológico da esquizofrenia deve ser realizado durante a gravidez (RANZCP, 2003), muito embora, nesses casos, o risco de exacerbação psicótica possa afetar a díade mãe-bebê, podendo acarretar danos gestacionais que eventualmente anulam o beneficio de parar o medicamento em prol do melhor desenvolvimento fetal (Working Group for the Canadian Psychiatric Association 1998). Se o tratamento antipsicótico for necessário, a mínima dose efetiva deve ser usada, e atenção especial deve ser dada quanto à redução da dose durante o mês antes do parto. Idealmente, devese interromper a medicação 5 a 10 dias antes da data prevista para o parto (APA, 1997; Working Group for the Canadian Psychiatric Association, 1998).

Pelo fato de ainda haver mais experiência com os APGs na gravidez, não foi demonstrada nenhuma vantagem dos ASGs nessa condição (Gentile, 2004). Alguns agentes de alta potência parecem ser seguros (como o haloperidol) e devem ser usados preferencialmente, mas tão brevemente quanto possível, com dose baixa o suficiente para evitar SEP e, portanto, a necessidade de medicamentos antiparkinsonianos (APA, 1997; DGPPN, 1998; Working Group for the Canadian Psychiatric Association, 1998). O medicamento antiparkinsoniano deve ser especialmente evitado no primeiro trimestre (APA, 1997), e o tratamento com fenotiazinas não deve ser implementado (DGPPN, 1998). Após o parto, devese considerar o reinício da dose plena do APG ou ASG, pois pode haver risco maior de psicose pós-parto (APA, 1997; Working Group for the Canadian Psychiatric Association, 1998).

A eficácia da ECT durante a gravidez na esquizofrenia é considerada similar à de mulheres não-grávidas, embora faltem evidências a partir de estudos randomizados (UK ECT Group, 2002). A taxa de complicações, com base em mais de 300 relatos de caso, resumidos nas revisões (Miller, 1994; UK ECT Group, 2002), mostrouse baixa (cerca de 1\%), incluindo 4 casos de trabalho de parto prematuro, 5 casos de abortamento, 5 casos de anormalidades congênitas e 3 casos de natimortos ou morte neonatal. Portanto, a ECT é recomendada como uma opção possível de tratamento em diversas diretrizes se o tratamento farmacológico com antipsicóticos não for apropriado (APA, 1997; DGPPN, 1998).

Com base em relatos da literatura, e uma vez que os antipsicóticos se acumulam no leite materno (o que é especialmente observado com a clozapina), a amamentação não pode ser recomendada nas mulheres que fazem uso de drogas antipsicóticas (Gentile, 2004). Há um consenso entre as diferentes diretrizes para evitar o aleitamento durante o tratamento da mãe com psicotrópicos (APA, 1997; DGPPN, 1998; Working Group for the Canadian Psychiatric Association, 1998).

\section{Intervenção precoce na fase inicial prodrômica}

Características psicóticas subliminares combinadas ao início da incapacidade, especialmente se houver histórico familiar, indicam risco muito elevado para desenvolver psicose (McGorry et al., 2003). Em conseqüência, pessoas com alto risco familiar devem ser ativamente envolvidas em avaliações e monitoramento regulares do estado mental e da segurança, o que deve ser reali- 
zado em ambiente domiciliar, com cuidados primários, ou em consultório, se possível, para reduzir o estigma (McGorry et al., 2003). Síndromes simultâneas (como depressão e abuso de substâncias) e problemas como estresse interpessoal, profissional e familiar devem ser apropriadamente controlados. Informações sobre o nível de risco devem ser cuidadosamente fornecidas, imprimindo certo otimismo terapêutico. Deve-se enfatizar que os problemas atuais podem ser aliviados, mas a progressão para a psicose não é inevitável. Então, se a psicose ocorrer, tratamentos eficazes e bem tolerados estarão facilmente disponíveis. O envolvimento no estágio inicial ajudará a reduzir qualquer atraso subseqüente na avaliação do tratamento para o primeiro episódio de psicose. O uso de medicamento antipsicótico durante o período prodrômico ainda é assunto de pesquisa, devendo, no momento, ficar reservado para pacientes que exibem sintomas psicóticos claros (Nível D) (McGorry et al., 2003).

\section{Agradecimentos}

Gostaríamos de agradecer a Jacqueline Klesing, de Munique, Alemanha, pela grande ajuda e pelo apoio editorial no preparo destas diretrizes.

\section{Referências}

Adityanjee, Aderibigbe Y.A.; Mathews, T. - Epidemiology of neuroleptic malignant syndrome. Clin Neuropharmacol 22: 151-158, 1999.

Addington, J.; El-Guebaly, N. - Group treatment for substance-abuse in schizophrenia. Can J Psychiatry 43: 843-845, 1998.

Addington, D.; Addington, J.; Patten, S.; Remington, G.; Moamal, J.; Labelle, A. et al. - Double-blind, placebo-controlled comparison of the efficacy of sertraline as treatment for a major depressive episode in patients with remitted schizophrenia. J Clin Psychopharmacol 22: 20-25, 2002.

Aguilar, E.J.; Keshavan, M.S.; Martinez-Quiles, M.D.; Hernandez, J.; GomezBeneYto, M.; Schooler, N.R. - Predictors of acute dystonia in first-episode psychotic patients. Am J Psychiatry 151: 1819-1821, 1994.

Aizenberg, D.; Zemishlany, Z.; Etrog, P.D.; Weizman, A. - Sexual dysfunction in male schizophrenic patients. J Clin Psychiatry 56: 137-141, 1995.

Akhondzadeh, S.; Nejatisafa, A.A.; Aminı, H.; Mohammadi, M.R.; LariJani, B.; KASHANI, L. et al. - Adjunctive estrogen treatment in women with chronic schizophrenia: A double-blind, randomized, and placebo-controlled trial. Prog Neuropsychopharmacol Biol Psychiatry 27 (6): 1007-1012, 2003.

Albanese, M.J.; Khantzian, E.J.; Murphy, S.L.; Green, A.I. - Decreased substance use in chronically psychotic patients treated with clozapine. Am J Psychiatry 151: 780-781 (letter), 1994.

AlBERS, L.J.; OzDEMIR, V. - Pharmacogenomic-guided rational therapeutic drug monitoring: conceptual framework and application platforms for atypical antipychotics. Curr Med Chem 11 (3): 297-312, 2004.

Al Khatib, S.M.; LaPointe, N.M.; Kramer, J.M.; Califf, R.M. - What clinicians should know about the OT interval. J Am Med Assoc 289: 2120-2127, 2003.

Allan, E.R.; Alpert, M.; Sison, C.E.; Citrome, L.; Laury, G.; Berman, I. - Adjunctive nadolol in the treatment of acutely aggressive schizophrenic patients. $J$ Clin Psychiatry 57: 455-459, 1996.

Aleman, A.; KaHn, R.S. - Effects of the atypical antipsychotic risperidone on hostility and aggression in schizophrenia: A meta-analysis of controlled trials. Eur Neuropsychopharmacol 11: 289-293, 2001.

Aluson, D.B.; Mentore, J.L.; Heo, M.; Chandler, L.P.; Cappelleri, J.C.; Infante, M.C. et al. - Antipsychotic-induced weight gain: a comprehensive research synthesis. Am J Psychiatry 156: 1686-1696, 1999.

AluIson, D.B.; MACKELL, J.A.; McDonneLL, D.D. - The impact of weight gain on quality of life among persons with schizophrenia. Psychiatr Serv 54: 565-567, 2003

Altamura, A.C.; Mauri, M.C.; Mantero, M.; Brunettı, M. - Clonazepam/haloperidol combination therapy in schizophrenia: a double-blind study. Acta Pychiatr Scand 76: 702-706, 1987.

Altamura, A.C.; Sassella, F.; Santini, A.; Montresor, C.; Fumagalli, S.; Mundo, E. - Intramuscular preparations of antipsychotics: uses and relevance in clinical practice. Drugs 63 (5): 493-512, 2003.

Alvarez, E.; Baron, J.; Puigdemont, J.S.D.; Masip, C.; Perez-Sola, V. - Ten years' experience with clozapine in treatment resistant schizophrenic patients: factors indicating the therapeutic response. Eur $P$ sychiatry 12 (suppl. 5): 343-346, 1997.

American Academy of Pediatrics - Use of psychoactive medication during pregnancy and possible effects on the fetus and newborn. Pediatrics 105: 880-887, 2000.

American Diabetes Association; American Psychiatric Association; American AssoCiation of Clinical Endocrinologists; North American Association for the Study OF OBESITY. - Consensus development conference on antipsychotic drugs and obesity and diabetes. J Clin Psychiatry 65 (2): 267-272, 2004.

American Psychiatric Association - Practice guideline for the treatment of patients with schizophrenia. Am J Psychiatry 154 (suppl. 4): 1-63, 1997.

American Psychiatric Association - The practice of electroconvulsive therapy: recommendations for treatment, training, and privileging: a task force report of the American Psychiatric Association. American Psychiatric Association, Washington D.C, 2001.

American Psychiatric Association - Practice guideline for the treatment of patients with schizophrenia. 2.ed. Am J Psychiatry 161 (suppl 2): 1-114, 2004.

ANDREASEN, N.C.; OLSEN, S. - Negative versus positive schizophrenia. Definition and validation. Arch Gen Psychiatry 39 (7): 789-794, 1982.

AngermeYer, M.C. - Schizophrenia and violence. Acta Psychiatr Scand 102 (suppl. 407): 63-67, 2000.

Anil Yagcioglu, A.E.; Kivircik Akdede, B.B.; Turgut, T.l.; TumuKlu, M.; Yazici, M.K.; ALPTEKIN, K. et al. - A double-blind controlled study of adjunctive treatment with risperidone in schizophrenic patients partially responsive to clozapine: Efficacy and safety. J Clin Psychiatry 66 (1): 63-72, 2005.

Arango, C.; Kirkpatrick, B.; Buchanan, R.W. - Fluoxetine as an adjunct to conventional antipsychotic treatment of schizophrenia patients with residual symptoms. J Nerv Ment Dis 188: 50-53, 2000.

Arango, C.; Bobes, J. - Managing acute exacerbations of schizophrenia: Focus on quetiapine. Curr Med Res Opin 20 (5): 619-626, 2004.

Arato, M.; O'Connor, R.; Meltzer, H.Y. - A 1-year, double-blind, placebo-controlled trial of ziprasidone 40,80 and $160 \mathrm{mg} /$ day in chronic schizophrenia: The Ziprasidone Extended Use in Schizophrenia (ZEUS) study. Int Clin Psychopharmacol 17: 207-215, 2002.

Arndt, S.; Tyrrell, G.; Flaum, M.; Andreasen, N.C. - Comorbidity of substance abuse in schizophrenia: the role of pre-morbid adjustment. Psychol Med 22: 279-388, 1992.

Arvanitis, L.A.; Mıller, B.G. (The Seroquel Trial 13 Study Group) - Multiple fixed doses of 'Seroquel' (quetiapine) in patients with acute exacerbation of schizophrenia: A comparison with haloperidol and placebo. Biol Psychiatry 42: 233-246, 1997.

Azorin, J.M.; Spiegel, R.; Remington, G.; Vanelle, J.M.; Péré, J.J.; Giguere, M. et al. - A double-blind comparative study of clozapine and risperidone in the management of severe chronic schizophrenia. Am J Psychiatry 158: 1305-1313, 2001. 
Baker, A.A.; Bird, G.; LaVIn, N.I.; Thorpe, J.G. - ECT in schizophrenia. J Ment Sci 106: 1506-1511, 1960.

Baker, A.; Lewin, T.; Reichler, H.; Clancy, R.; Carr, V.; Garrett, R. et al. - Motivational interviewing among psychiatric in-patients with substance use disorders. Acta Psychiatr Scand 106: 233-240, 2002.

BaLDWIN, D.; BIRTWISTLE, J. - Schizophrenia, antipsychotic drugs and sexual function. Prim Care Psychiatry 3: 117-122, 1997.

Barak, Y.; Mirecki, I.; Knobler, H.Y.; Natan, Z.; Aizenberg, D. - Suicidality and second generation antipsychotics in schizophrenia patients: a casecontrolled retrospective study during a 5-year period. Psychopharmacology (Berlin) 175 (2): 215-219, 2004.

Bark, N.; Revheim, N.; Huo, F.; Khalderov, V.; Ganz, Z.W.; Medalia, A. - The impact of cognitive remediation on psychiatric symptoms of schizophrenia. Schizophr Res 63: 229-235, 2003.

Barnas, C.; Stuppack, C.H.; Miller, C.; Haring, C.; Sperner-Unterweger, B.; FLeISCHHACKER, W.W. - Zotepine in the treatment of schizophrenic patients with prevailingly negative symptoms. A double-blind trial vs. haloperidol. Int Clin Psychopharmacol 7: 23-27, 1992.

Barrowclough, C.; Haddock, G.; Tarrier, N.; Lewis, S.W.; Moring, J.; O'Brien, R. et al. - Randomized controlled trial of motivational interviewing, cognitive behavior therapy, and family intervention for patients with comorbid schizophrenia and substance use disorders. Am J Psychiatry 158: 1706-1713, 2001

Battaglia, J.; Moss, S.; Rush, J.; Kang, J.; Mendoza, R.; Leedom, L. et al. Haloperidol, lorazepam, or both for psychotic agitation? A multicenter, prospective, double-blind, emergency department study. Am J Emerg Med 15 (4): 335-340, 1997.

Beasley, C.M. JR.; Tollefson, G.; Tran, P.; Satterlee, W.; Sanger, T.; Hamilton, S. - Olanzapine versus placebo and haloperidol: acute phase results of the North American double-blind olanzapine trial. Neuropsychopharmacology 14: 111-123, 1996a.

Beasley, C.M. Jr.; Sanger, T.; Satterlee, W.; Tollefson, G.; Tran, P.; Hamilton, S. - Olanzapine versus placebo: results of a double-blind, fixed-dose olanzapine trial. Psychopharmacology (Berlin) 124: 159-167, 1996b.

Beasley, C.M. Jr.; Hamilton, S.H.; Crawford, A.M.; Dellva, M.A.; Tollefson, G.D.; Tran, P.V. et al. - Olanzapine versus haloperidol: Acute phase results of the international double-blind olanzapine trial. Eur Neuropsychopharmacol 7: 125-137, 1997.

Beautrals, A. - Suicides and serious suicide attempts: Two populations or one? Psychol Med 31: 837-845, 2001.

BeIser, M.; Erickson, D.; Fleming, J.A.; IACONo, W.G. - Establishing the onset of psychotic illness. Am J Psychiatry 150: 1349-1354, 1993.

BerK, M.; ICHIM, C.; BRook, S. - Efficacy of mirtazapine add on therapy to haloperidol in the treatment of the negative symptoms of schizophrenia: a double-blind randomized placebo-controlled study. Int Clin Psychopharmaco/ 16 (2): 87-92, 2001.

Berman, I.; Sapers, B.L.; Chang, H.H.; Losonczy, M.F.; Schmildler, J.; Green, A.I. Treatment of obsessive-compulsive symptoms in schizophrenic patients with clomipramine. J Clin Psychopharmacol 15: 206-210, 1995.

Bersani, G.; Orlandi, V.; Kotzalidis, G.D.; Pancheri, P. - Cannabis and schizophrenia: Impact on onset, course, psychopathology and outcomes. Eur Arch Psychiatry Clin Neurosci 252: 86-92, 2002.

Bilder, R.M.; Goldman, R.S.; Volavka, J.; Czobor, P.; Hoptman, M.; Sheitman, B. et al. Neurocognitive effects of clozapine, olanzapine, risperidone, and haloperidol in patients with chronic schizophrenia or schizoaffective disorder. Am J Psychiatry 159: 1018-1028, 2002.

Bieniek, S.A.; Ownby, R.L.; Penalver, A.; Dominguez, R.A. - A double-blind study of lorazepam versus the combination of haloperidol and lorazepam in managing agitation. Pharmacotherapy 18 (1): 57-62, 1998.

BIRCHW00D, M.; SMITH, J.; McMILLAN, J.F. - Predicting relapse in schizophrenia: The development and implementation of an early signs monitoring system using patients and families as observers, a preliminary investigation. Psychol Med 19: 649-656, 1989.

BuIN, 0.; Azorin, J.M.; Bounours, P. - Antipsychotic and anxiolytic properties of risperidone, haloperidol, and methotrimeprazine in schizophrenic patients. J Clin Psychopharmacol 16: 38-44, 1996.

BLUMER, D. - Catatonia and the neuroleptics: Psychobiologic significance of remote and recent findings. Comp Psychiatry 38 (4): 193-201, 1997.
Bobes, J.; Gibert, J.; Ciudad, A.; Alvarez, E.; Canas, F.; Carrasco, J.L. et al. - Safety and effectiveness of olanzapine versus conventional antipsychotics in the acute treatment of first-episode schizophrenic inpatients. Prog Neuropsychopharmacol Biol Psychiatry 27 (3): 473-481, 2003.

Bollini, P.; Pampallona, S.; Orza, M.J.; Adams. M.E.; Chalmers, T.C. - Antipsychotic drugs: is more worse? A meta/analysis of the published randomized control trials. Psychol Med 24: 307-316, 1994.

Bondolfi, G.; Dufour, H.; Patris, M.; MaY, J.P.; Billeter, U.; EAP, C.B. et al. - Risperidone vs. clozapine in treatmentresistant chronic schizophrenia: a randomized double-blind study. The Risperidone Study Group. Am J Psychiatry 155: 499-504, 1998.

BONTA, J.; LAW, M.; HANSON, K. - The prediction of criminal and violent recidivism among mentally disordered offenders: a meta-analysis. Psychol Bull 123: 123-142, 1998.

Borison, R.L.; Arvanitis, L.A.; Mıller, B.G. (US Seroquel Study Group) - ICI 204,636, an atypical antipsychotic: efficacy and safety in a multicenter, placebo-controlled trial in patients with schizophrenia. J Clin Psychopharmacol 16: 158-169, 1996.

Bottlender, R.; Strauss, A.; Möller, H.J. - Impact of duration of symptoms prior to first hospitalisation on acute outcome in 998 schizophrenic patients. Schizophr Res 44: 145-150, 2000.

Bottlender, R.; Sato, T.; Jäger, M.; Groll, C.; Strauss, A.; Möller, H.J. - The impact of duration of untreated psychosis and premorbid functioning on outcome of first inpatient treatment in schizophrenic and schizoaffective patients. Eur Arch Psychiatry Clin Neurosci 252: 226-231, 2002.

Bottlender, R.; Sato, T.; Jäger, M.; Wegener, U.; Wittmann, J.; Strauss, A. et al. - The impact of the duration of untreated psychosis prior to first psychiatric admission on the 15-year outcome in schizophrenia. Schizophr Res 62: 37-44, 2003.

Boyer, P.; Lecrubier, Y.; Puech, A.J.; Dewallly Aubin, F. - Treatment of negative symptoms in schizophrenia with amisulpride. Br J Psychiatry 166: 68-72, 1995.

Bradford, D.W.; Perkins, D.0.; LIeberman, J.A. - Pharmacological management of first-episode schizophrenia and related nonaffective psychoses. Drugs 63 (21): 2265-2283, 2003.

Braude, W.M.; Barnes, T.R.E.; GoRE, S.M. - Clinical characteristics of akathisia: a systematic investigation of acute psychiatric inpatient admissions. Br J Psychiatry 143: 139-150, 1983.

Breier, A.; Buchanan, R.W.; Kirkpatrick, B.; Davis, O.R.; Irish, D.; Summerfelt, A. et al. - Effects of clozapine on positive and negative symptoms in outpatients with schizophrenia. Am J Psychiatry 151: 20-26, 1994.

Breier, A.; Hamilton, S.H. - Comparative efficacy of olanzapine and haloperidol for patients with treatment-resistant schizophrenia. Biol Psychiatry 45: 403-411, 1999.

Breler, A.F.; Malhotra, A.K.; Su, T.P.; Pinals, D.A.; Elman, I.; Adler, C.M. et al. - Clozapine and risperidone in chronic schizophrenia: effects on symptoms,parkinsonian side effects, and neuroendocrine response. Am J Psychiatry 156: 294-298, 1999.

Brenner, H.D.; Dencker, S.J.; Goldstein, M.J.; Hubbard, J.W.; Keegan, D.L.; Kruger, G. et al. - Defining treatment refractoriness in schizophrenia. Schizophr Bull 16: 551-561, 1990

Brown, S.; Inskip, H.; Barraclough, B. - Causes of the excess mortality of schizophrenia. Br J Psychiatry 177: 212-217, 2000.

Brown, E.S.; NeJtek, V.A.; Perantie, D.C. - Neuroleptics and quetiapine in psychiatric illnesses with comorbid stimulant abuse. Abstract/Pôster, CINP; 23-27 Junho, Montreal, Canadá, 2002.

Buchanan, R.W.; Holstein, C.; Breler, A. - The comparative efficacy and long-term effect of clozapine treatment on neuropsychological test performance. Biol Psychiatry 36 (11): 717-725, 1994.

Buchanan, R.W. - Clozapine: efficacy and safety. Schizophr Bull 21 (4): 579-591, 1995.

Buchanan, R.W.; Kirkpatrick, B.; Bryant, N.; Ball, P.; Breler, A. - Fluoxetine augmentation of clozapine treatment in patients with schizophrenia. Am J Psychiatry 153:1625-1627, 1996.

Buchanan, R.W.; Breier, A.; Kirkpatrick, B.; Ball, P.; Carpenter, W.T. Jr. - Positive and negative symptom response to clozapine in schizophrenic patients with and without the deficit syndrome. Am J Psychiatry 155: 751-760, 1998. 
Buchanan, R.W.; Summerfelt, A.; Tek, C.; Gold, J. - An openlabeled trial of adjunctive donepezil for cognitive impairments in patients with schizophrenia. Schizophr Res 59: 29-33, 2003.

Buckley, P.; Thompson, P.A.; Way, L.; Meltzer, H.Y. - Substance use among patients with treatment-resistant schizophrenia: characteristics and implication for clozapine therapy. Am J Psychiatry 151: 385-389, 1994a.

Buckley, P.; Thompson, P.A.; WAY, L.; Meltzer, H.Y. Substance use and clozapine treatment. J Clin Psychiatry 55 (suppl. B): 114-116, 1994b.

Buckley, P.; Noffsinger, S.G.; Smith, D.A.; Hrouda, D.R.; KnolL, J.L. - Treatment of the psychotic patient who is violent. Psychiatr Clin North Am 26: 231272, 2003.

BuRns, M.J. - The pharmacology and toxicology of atypical antipsychotic agents. Clin Toxicol 39 (1): 1-14, 2001

Burt, T.; Lisanby, S.H.; SACKeIm, H.A. - Neuropsychiatric applications of transcranial magnetic stimulation: a meta-analysis. Int J Neuropsychopharmacol 5: 73-103, 2002.

Bush, G.; Fink, M.; Petrides, G.; Dowling, F.; Francis, A. - Catatonia. II: Treatment with lorazepam and electroconvulsive therapy. Acta Psychiatr Scand 93: 137-143, 1996.

Bushe, C.; HoLt, R. - Prevalence of diabetes and impaired glucose tolerance in patients with schizophrenia. Br J Psychiatry 184 (suppl. 47): s67-s71, 2004.

Bushe, C.; LeONARD, B. - Association between atypical antipsychotic agents and type 2 diabetes: Review of prospective clinical data. Br J Psychiatry 184 (suppl. 47): s87-s93, 2004.

Caroff, S.N.; Mann, S.C.; CampbelL, E.C. - Atypical antipsychotics and neuroleptic malignant syndrome. Psychiatr Ann 30: 314-321, 2000.

Carpenter, W.T. JR.; HeinRichs, D.W.; Alphs, L.D. - Treatment of negative symptoms. Schizophr Bull 11: 440-452, 1985.

Carriere, P.; Bonhomme, D.; Lemperiere, T. - Amisulpride has a superior benefit/risk profile to haloperidol in schizophrenia: results of a multicentre double-blind study (the Amisulpride Study Group). Eur Psychiatry 15: 321-329, 2000.

Casey, D.E.; Daniel, D.G.; Wassef, A.A.; Tracy, L.A.; Wozniak, P.; Sommerville, K.W. - Reply effect of divalproex combined with olanzapine or risperidone in patients with an acute exacerbation of schizophrenia. Neuropsychopharmacology 28: 2052-2053, 2003a.

Casey, D.E.; Carson, W.H.; Saha, A.R.; LieBeskind, A.; Al, M.W.; Jody, D. et al. for the Aripiprazole Study Group. - Switching patients to aripiprazole from other antipsychotic agents: a multicenter randomized study. Psychopharmacology (Berlin) 166 (4): 391-399. 2003b.

Caspari, D.; Wobrock, T. - Cannabis psychosis/from a distinct category to comorbidity. Sucht 50 (5): 320-326, 2004.

Caspi, N.; Modal, I.; Barak, P.; Waisbourd, A.; Zbarsky, H.; Hirschmann, S. et al. - Pindolol augmentation in aggressive schizophrenic patients: a double-blind crossover randomized study. Int Clin Psychopharmacol 16: 111-115, 2001

Cassens, G.; Inglis, A.K.; Appelbaum, P.S.; Guthell, T.G. - Neuroleptic effects on neuropsychological function in chronic schizophrenic patients. Schizophr Bull 16: 477-499, 1990.

Castle, D.J.; Wessely, S.; MurRay, R.M. - Sex and schizophrenia: Effects of diagnostic stringency, and associations with and premorbid variables. Br J Psychiatry 162: 658-664, 1993.

Castle, D.J.; Abel, K.; Takel, N.; MurRay, R.M. - Gender differences in schizophrenia: Hormonal effect or subtypes? Schizophr Bull 21 (1): 1-12, 1995.

Cavallaro, C.; Cordoba, C.; Smeraldi, E. - A pilot, open study on the treatment of refractory schizophrenia with risperidone and clozapine. Hum Psychopharmacol 10: 231-234, 1995.

Centre for Outcomes Research and Effectiveness of the British Psychological SocIeTY. - Systematic Review Fluphenazine (Pharmacology Group of the National Institute for Clinical Excellence). In: National Institute for Clinical Excellence. Schizophrenia: core interventions in the treatment and management of schizophrenia in primary and secondary care. 2002.

Centre for Outcomes Research and Effectiveness of the British Psychological SocIETY. - Systematic Review Flupenthixol (Pharmacology Group of the National Institute for Clinical Excellence). In: National Institute for Clinical Excellence. Schizophrenia: core interventions in the treatment and management of schizophrenia in primary and secondary care. 2002.
Centre for Outcomes Research and Effectiveness of the British Psychological SocIETY. - Systematic Review Perphenazine (Pharmacology Group of the National Institute for Clinical Excellence). In: National Institute for Clinical Excellence. Schizophrenia: core interventions in the treatment and management of schizophrenia in primary and secondary care. 2002.

Ceskova, E.; SvestKa, J. - Double-blind comparison of risperidone and haloperidol in schizophrenic and schizoaffective psychoses. Pharmacopsychiatry 26: $121-124,1993$

Chakos, M.; Lieberman, J.; Hoffman, E.; Bradford, D.; Sheitman, B. - Effectiveness of second-generation antipsychotics in patients with treatment-resistant schizophrenia: a review and meta-analysis of randomized trials. Am J Psychiatry 158: 518-526, 2001.

Chanpattana, W.; Chakrabhand, M.L.; Sackeim, H.A.; Kitaroonchai, W.; Kongsakon, R.; Techakasem, P. et al. - Continuation ECT in treatment resistant schizophrenia: a controlled study. J ECT 15: 178-192, 1999.

Chanpattana, W.; Chakrabhand, M.L. - Combined ECT and neuroleptic therapy in treatment-refractory schizophrenia: prediction of outcome. Psychiatr Res 105: 107-115, 2001.

Cheer, S.M.; WagstafF, A.J. - Quetiapine. A review of its use in the management of schizophrenia. CNS Drugs 18 (3): 173-199, 2004.

Cheine, M.; Ahonen, J.; Wahlbeck, K. - Beta-blocker supplementation of standard drug treatment for schizophrenia (Cochrane Review). In: The Cochrane Library, Issue 2. John Wiley \& Sons Ltd., Chichester, 2004.

Chengappa, K.N.; Vasile, J.; Levine, J.; Ulrich, R.; Baker, R.; Gopalani, A. et al. - Clozapine: Its impact on aggressive behavioramong patients in a state psychiatric hospital. Schizophr Res 53: 1-6, 2002.

Chengappa, K.N.; Levine, J.; Ulrich, R.; Parepally, H.; BraR, J.S.; Atzert, R. et al. - Impact of risperidone on seclusion and restraint at a state psychiatric hospital. Can J Psychiatry 45 (9): 827-832, 2000.

Chiu, E.; Burrows, G.; Stevenson, J. - Double-blind comparison of clozapine with chlorpromazine in acute schizophrenic illness. Aust NZJ Psychiatry 10: 343-347, 1976

Chiu, N.Y.; Yang, Y.K.; Chen, P.S.; Chang, C.C.; LeE, I.H.; LeE, J.R. - Olanzapine in Chinese treatment-resistant patients with schizophrenia: an open-label, prospective trial. Psychiatry Clin Neurosci 57: 478-484, 2003.

Chouinard, G.; Jones, B.; Remington, G.; Bloom, D.; Addington, D.; MacEwan, G.W. et al. - A Canadian multicenter placebo-controlled study of fixed doses of risperidone and haloperidol in the treatment of chronic schizophrenic patients. J Clin Psychopharmacol 13: 25-40, 1993.

Citrome, L.; VolavkA, J. - Optimal dosing of atypical antipsychotics in adults: A review of the current evidence. Harv Rev Psychiatr 10 (5): 280-291, 2002.

Citrome, L.; Casey, D.E.; Daniel, D.G.; Wozniak, P.; Kochan, L.D.; Tracy, K.A. - Adjunctive divalproex and hostility among patients with schizophrenia receiving olanzapine or risperidone. Psychiatr Serv 55 (3): 290-294, 2004.

ClaRK, R.E. - Family support and substance use outcome for persons with mental illness and substance use disorders. Schizophr Bull 27: 93-101, 2001.

Claus, A.; Bollen, J.; De Cuyper, H.; Eneman, M.; Malfroid, M.; Peuskens, J. et al. - Risperidone versus haloperidol in the treatment of chronic schizophrenic inpatients: a multic entre double-blind comparative study. Acta Psychiatr Scand 85: 295-305, 1993.

Cohen, L.S.; Rosenbaum, J.F. - Psychotropic drug use during pregnancy: Weighing the risks. J Clin Psychiatry 59 (suppl. 2): 18-28, 1998.

Colonna, L.; Saleem, P.; Dondey-Nouvel, L.; Rein, W.; Amisulpride Study Group. - Long-term safety and efficacy of amisulpride in sub-chronic or chronic schizophrenia. Int J Clin Psychopharmacol 15 (1): 13-22, 2000.

Conley, R.R.; BuCHANAN, R.W. - Evaluation of treatment resistant schizophrenia. Schizophr Bull 23: 663-674, 1997.

Conley, R.R.; Carpenter, W.T.; Tamminga, C.A. - Time to clozapine response in a standardized trial. Am J Psychiatry 154:1243/1247, 1997.

Conley, R.R.; Kelly, D.L.; Gale, E.A. - Olanzapine response in treatmentrefractory schizophrenic patients with a history of substance abuse. Schizophr Res 33: 95-101, 1998.

Conley, R.R.; MAhmoud, R. - A randomized double-blind study of risperidone and olanzapine in the treatment of schizophrenia or schizoaffective disorder. Am J Psychiatry 158: 765-774, 2001.

Cooper, S.J.; Tweed, J.; Raniwalla, J.; Butler, A.; Welch, C. - A placebo-controlled comparison of zotepine versus chlorpromazine in patients 
with acute exacerbation of schizophrenia. Acta Psychiatr Scand 101: 218-225, 2000a.

Cooper, S.J.; Butler, A.; Tweed, J.; Welch, C.; Raniwalla, J. - Zotepine in the prevention of recurrence: a randomised, double-blind, placebo-controlled study for chronic schizophrenia. Psychopharmacology (Berlin) 150: 237-243, 2000b.

Copolov, D.L.; LINK, C.G.; KowalcYK, B. - A multicentre, double-blind, randomized comparison of quetiapine (ICI 204,636, 'Seroquel') and haloperidol in schizophrenia. Psychol Med 30: 95-105, 2000.

Cormac, I.; Jones, C.; CampBell, C. - Cognitive behaviour therapy for schizophrenia. (Cochrane Review). In: The Cochrane Library, Issue 2. John Wiley \& Sons Ltd., Chichester, 2004.

Correll, C.U.; LeUCHT, S.; KANE, J.M. - Lower risk for tardive dyskinesia associated with second-generation antipsychotics: a systematic review of 1-year studies. Am J Psychiatry 161: 414-425, 2004.

Coryell, W.; Miller, D.D.; Perry, P.J. - Haloperidol plasma levels and dose optimization. Am J Psychiatry 155: 48-53, 1998.

CreEse, I.; BuRt, D.R.; SNydeR, S.H. - Dopamine receptor binding predicts clinical and pharmacological potencies of antischizophrenic drugs. Science 192: 481-483, 1976.

CRow, T.J. - The two syndrome concept: origins and current status. Schizophr Bull 11: 471-486, 1985.

CSernansky, J.G.; Riney, S.J.; Lombarozo, L.; Overall, J.E.; Holuister, L.E. - Double-blind comparison of alprazolam, diazepam and placebo for the treatment of negative schizophrenic symptoms. Arch Gen Psychiatry 45: 655-659, 1988

Csernansky, J.G.; Mahmoud, R.; Brenner, R. - A comparison of risperidone and haloperidol for the prevention of relapse in patients with schizophrenia. New Engl J Med 346: 16-22, 2002.

CuRRIER, G.W.; SIMPSON, G.M. - Risperidone liquid concentrate and oral lorazepam versus intramuscular haloperidol and intramuscular lorazepam for treatment of psychotic agitation. J Clin Psychiatry 62 (3): 153-157, 2001.

Cutler, A.J. - Sexual dysfunction and antipsychotic treatment. Psychoneuroendocrinology 28: 69-82, 2003.

DAHL, S.G. - Pharmacokinetics of antipsychotic drugs in man. Acta Psychiatr Scand (suppl.) 358: 37-40, 1990.

Daniel, D.G.; Goldberg, T.E.; Weinberger, D.R.; Kleinman, J.E.; Pickar, D.; Lubick, L.J. et al. - Different side effect profiles of risperidone and clozapine in 20 outpatients with schizophrenia or schizoaffective disorder: a pilot study. Am J Psychiatry 153: 417-419, 1996.

Daniel, D.G.; Zimbroff, D.L.; PotKin, S.G.; Reeves, K.R.; Harrigan, E.P.; LakshmiNaraYanan, M. (Ziprasidone Study Group) Ziprasidone $80 \mathrm{mg} /$ day and 160 $\mathrm{mg} /$ day in the acute exacerbation of schizophrenia and schizoaffective disorder: A 6-week placebo-controlled trial. Neuropsychopharmacology 20: 491-505, 1999.

Daniel, D.G.; PotKin, S.G.; Reeves, K.R.; Swift, R.H.; Harrigan, E.P. - Intramuscular (IM) ziprasidone $20 \mathrm{mg}$ is effective in reducing acute agitation associated with psychosis: a double-blind, randomized trial. Psychopharmacology (Berlin) 155:128/341, 2001.

Danion, J.M.; Rein, W.; Fleurot, 0.; Amisulpride Study Group. - Improvement of schizophrenic patients with primary negative symptoms treated with amisulpride. Am J Psychiatry 156: 610-616, 1999.

DatTo, C.J. - Side effects of electroconvulsive therapy. Depress Anxiety 12: $130-134,2000$

DavidSON, L.; McGlashan, T.H. - The varied outcomes of schizophrenia. Can J Psychiatry 42: 34-43, 1997.

DAvis, J.M. - Overview: Maintenance therapy in psychiatry: I. Schizophrenia. Am J Psychiatry 132: 1237-1245, 1975.

Davis, J.M.; BARTER, J.T.; KAnE, J.M. - Antipsychotic drugs. In: Kaplan, H.I.; Sadock, B.J. (eds.). Comprehensive textbook of psychiatry. 5.ed. Williams \& Wilkins, Baltimore, pp. 1591-1626, 1989.

Davis, J.M.; Chen, N.; GLICK, I.D. - A meta-analysis of the efficacy of secondgeneration antipsychotics. Arch Gen Psychiatry 60: 553-564, 2003.

Davis, J.M.; Chen, N. - Dose response and dose equivalence of antipsychotics. J Clin Psychopharmacol 24 (2): 192-208, 2004.

De Nayer, A.; Windhager, E.; Irmansyah, X. et al. - Efficacy and tolerability of quetiapine in patients with schizophrenia switched from other antipsychotics. Int J Psychiatry Clin Pract 7: 59-70, 2003.
Delcker, A.; Schoon, M.L.; Oczkowski, B.; Gaertner, H.J. - Amisulpride versus haloperidol in treatment of schizophrenic patients*/Results of a doubleblind study. Pharmacopsychiatry 23: 125-130, 1990.

Devanand, D.P.; Dwork, A.J.; Hutchinson, E.R.; Bolwig, T.G.; Sackheim, H.A. - Does ECT alter brain structure? Am J Psychiatry 151: 957-970, 1994

Devinsky, 0.; Honigfeld, G.; Patin, J. - Clozapine-related seizures. Neurology 41:369/371, 1991

Dickson, R.A.; GLazeR, W.M. - Neuroleptic-induced hyperprolactinemia. Schizophr Res 35 (suppl.): s75-s86, 1999.

Dieterle, D.M.; Müller Spahn, F.; Ackenhell, M. - Effectiveness and tolerance of zotepine in a double-blind comparison with perazine in schizophrenic patients. Fortschr Neurol Psychiat 59 (suppl. 1): 18-22, 1991.

Dinan, T.G. - Stress and the genesis of diabetes mellitus in schizophrenia Br J Psychiatry 184 (suppl. 47): s72-s75, 2004.

Dixon, L.; HaAs, G.; Weiden, P.J.; Sweeney, J.; Frances, A.J. - Drug abuse in schizophrenic patients: Clinical correlates and reasons for use. $A m J$ Psychiatry 14: 224-230, 1991

Dixon, L.B.; LeHMAN, A.F.; LEVINE, J. - Conventional antipsychotic medications for schizophrenia. Schizophr Bull 21 (4): 567-577, 1995.

DodWELL, D.; GoLdBerg, D. - A study of factors associated with response to electroconvulsive therapy in patients with schizophrenic symptoms. Br J Psychiatry 154: 635-639, 1989.

Donahue, A.B. - Electroconvulsive therapy and memory loss: a personal journey. J ECT 16: 133-143, 2000.

Dorevitch, A.; KatZ, N.;Zemishlany, Z;; Aizenberg, D.; Weizman, A. - Intramuscular flunitrazepam versus intramuscular haloperidol in the emergency treatment of aggressive psychotic behavior. Am J Psychiatry 156 (1): 142-144, 1999.

Dose, M.; Hellweg, R.; Yassouridis, A.; Theison, M.; EmRich, H.M. - Combined treatment of schizophrenic psychoses with haloperidol and valproate. Pharmacopsychiatry 31: 122-125, 1998.

Dossenbach, M.R.K.; Beuzen, J.N.; Avnon, M.; Belmaker, R.H.; Elizur, A.; Merk, M. et al. The effectiveness of olanzapine in treatment-refractory schizophrenia when patients are nonresponsive to or unable to tolerate clozapine. Clin Ther 22: 1021-1034, 2000.

Drake, R.E.; Mueser, K.T. - Psychosocial approaches to dual diagnosis. Schizophr Bull 26: 105-118, 2000

DruRY, V.; BIRChwood, M.; Cochrane, R. - Cognitive therapy and recovery from acute psychosis: a controlled trial. Br J Psychiatry 177: 8-14, 2000.

Dufresne, R.L.; Valentino, D.; KASS, D.J. - Thioridazine improves affective symptoms in schizophrenic patients. Psychopharmacol Bull 29: 249-255, 1993

Duke, P.J.; Pantelis, C.; McPhilipps, M.A.; Barnes, T.R.E. - Comorbid non-alcohol substance misuse among people with schizophrenia. Br J Psychiatry 179: 509-513, 2001

DURSUn, S.M.; McInTOSH, D.; MıLIKEN, H. - Clozapine plus lamotrigine in treatment-resistant schizophrenia. Arch Gen Psychiatry 56: 950, 1999.

DuRsun, S.M.; DEAKIN, J.F.W. - Augmenting antipsychotic treatment with lamotrigine or topiramate in patients with treatment-resistant schizophrenia: A naturalistic case-series outcome study. J Psychopharmacol 15 (4): 297-301, 2001

Ebrecht, M.; Jody, D.; Kane, J.; Carson, W.; Kujawa, M.; Stringfellow, J. et al. Aripiprazole versus perphenazine in treatment-resistant schizophrenia. Pôster. 12. AEP Congress, Genebra, Suíça, 14 a 18 de abril, 2004.

EmsLeY, R.A. - Risperidone in the treatment of first-episode psychotic patients: A double-blind multicenter study. Risperidone Working Group. Schizophr Bull 25: 721-729, 1999.

Emsley, R.A.; Raniwalla, J.; Balley, P.J.; Jones, A.M. - A comparison of the effects of quetiapine ('seroquel') and haloperidol in schizophrenic patients with a history of and a demonstrated, partial response to conventional antipsychotic treatment. PRIZE Study Group. Int Clin Psychopharmacol 15: 121-131, 2000.

Emsley, R.; Oosthuzen, P.; van RensbuRg, S.J. - Clinical potential of omega-3 fatty acids in the treatment of schizophrenia. CNS Drugs 17 (15): 1081-1091, 2003

ERNST, L.C.; GoldBERG, J.F. - The reproductive safety profile of mood stabilizers, atypical antipsychotics, and broad-spectrum psychotropics. J Clin Psychiatry 63 (suppl. 4): 42-55, 2002.

Essock, S.M.; Hargreaves, W.A.; Dohm, F.A.; Goethe, J.; Carver, L.; Hipshman, L. - Clozapine eligibility among state hospital patients. Schizophr Bull 22: $15-25,1996 \mathrm{a}$. 
Essock, S.M.; Hargreaves, W.A.; Covell, N.H.; Goethe, J. - Clozapine's effectiveness for patients in state hospitals: results from a randomized trial. Psychopharmacol Bull 32: 683-697, 1996b.

Evins, A.E.; Fitzgerald, S.M.; Wine, L.; Rosselu, R.; Goff, D.C. - Placebo-controlled trial of glycine added to clozapine in schizophrenia. Am J Psychiatry 157: 826-828, 2000.

Ewing, J.A.; Meuller, R.A.; Rouse, B.A. et al. - Low levels of dopamine-betahydroxylase and psychosis. Am J Psychiatry 134: 927-928, 1977.

Fabre, L.F. JR.; Arvanitis, L.; Pultz, J.; Jones, V.M.; Malick, J.B.; Slotnick, V.B. - ICl 204,636, a novel, atypical antipsychotic: early indication of safety and efficacy in patients with chronic and subchronic schizophrenia. Clin Ther 17: 366-378, 1995.

Fagerlund, B.; Mackeprang, T.; Gade, A.; Glenthoj, B.Y. - Effects of low-dose risperidone and low-dose zuclopenthixol on cognitive functions in first-episode drug-naive schizophrenic patients. CNS Spectr 9 (5): 364-374, 2004

FaLLoon, I.R.H. - Family interventions for mental disorders: Efficacy and effectiveness. World J Psychiatry 2:20/28, 2003

Farde, L.; Nordstrom, A.L.; Wiesel, F.A.; Pauli, S.; Halldin, C.; Sedvall, G. - Positron emission tomographic analysis of central D1 and D2 dopamine receptor occupancy in patients treated with classical neuroleptics and clozapine. Relation to extrapyramidal side effects. Arch Gen Psychiatry 49: 538-544, 1992

Farren, C.K.; Hameedi, F.A.; Rosen, M.A.; Woods, S.; Jatlow, P.; Kosten, T.R. - Significant interaction between clozapine and cocaine in cocaine addicts. Drug Alcohol Depend 59:153-163, 2000.

Fenton, W.S.; McGlashan, T.H. - Prognostic scale for chronic schizophrenia. Schizophr Bull 13: 277-286, 1987.

FENTON, W.S. - Prevalence of spontaneous dyskinesia in schizophrenia. $J$ Clin Psychiatry 61 (suppl. 4): 10-14, 2000.

Fenton, M.; Coutinho, E.S.F.; Campbell, C. - Zuclopenthixol acetate in the treatment of acute schizophrenia and similar serious mental illnesses (Cochrane Review). In: The Cochrane Library, Issue 2. John Wiley \& Sons Ltd., Chichester, 2004.

Fink, M.; SACKEIM, H.A. - Convulsive therapy in schizophrenia? Schizophr Bull 22: 27-39, 1996.

Fischer-Cornelssen, K.A.; Ferner, U.J. - An example of European multicenter trials: Multispectral analysis of clozapine. Psychopharmacol Bull 12: 34-39, 1976.

Fleischhacker, W.W.; Barnas, C.; Stuppack, C.H.; Unterweger, B.; Mlller, C.; HinterhuBer, H. - Zotepine vs. haloperidol in paranoid schizophrenia: a double-blind trial. Psychopharmacol Bull 25: 97-100, 1989.

FLEISCHHACKER, W.W. - Second generation antipsychotics. Psychopharmacology 162: 90-91, 2002.

Flynn, S.W.; MacEwan, G.W.; Altman, S.; Kopala, L.C.; Fredrikson, D.H.; Smith, G.N. et al. - An open comparison of clozapine and risperidone in treatment-resistant schizophrenia. Pharmacopsychiatry 31: 25-29, 1998.

Folstein, M.; Folstein, S.; McHugh, P.R. - Clinical predictors of im-provement after electroconvulsive therapy of patients withschizophrenia, neurotic reactions, and affective disorders. Biol Psychiatry 7:147/152, 1973.

Fortier, P.; Trudel, G.; MotTaRd, J.P.; PICHE, L. - The influence of schizophrenia and standard or atypical neuroleptics on sexual and sociosexual functioning: a review. Sexuality and Disability 18 (2): 85-104, 2000.

Foster, S.; Kessel, J.; Berman, M.E.; Simpson, G.M. - Efficacy of lorazepam and haloperidol for rapid tranquilization in a psychiatric emergency room setting. Int Clin Psychopharmacol 12 (3): 175-179, 1997.

Fowler, I.L.; CARR, V.J.; CARTER, N.T.; LeWIN, T.J. - Patterns of current and lifetime substance use in schizophrenia. Schizophr Bull 24: 443-455, 1998.

FreEMAN, H.L. - Amisulpride compared with standard neuroleptics in acute exacerbations of schizophrenia: Three efficacy studies. Int Clin Psychopharmacol 12 (suppl. 2): s11-s17, 1997.

FrenCH, K.; EASTWOOD, D. - Response of catatonic schizophrenia to amisulpride: a case report. Can J Psychiatry 48 (8): 570, 2003.

FreudenReich, O.; GoFf, D.C. - Antipsychotic combination therapy in schizophrenia. A review of efficacy and risks of current combinations. Acta Psychiatr Scand 106: 323-330, 2002.

Friedman, J.I.; Adler, D.N.; Howanitz, E.; Harvey, P.D.; Brenner, G.; Temporinı, H. et al. - A double blind placebo controlled trial of donepezil adjunctive treatment to risperidone for the cognitive impairment of schizophrenia. Biol Psychiatry 51: 349-357, 2002.

Gaebel, W.; Frick, U.; KöPcke, W.; Linden, M.; Müller, P.; Müller-Spahn, F. et al. - Early neuroleptic intervention in schizophrenia: Are prodromal symptoms valid predictors of relapse? Br J Psychiatry 163 (suppl. 21): 8-12, 1993.

Gaebel, W.; Baumann, A.E. - Interventions to reduce the stigma associated with severe mental illness: Experiences from the Open the doors Program in Germany. Can J Psychiatry 48: 657-662, 2003.

Gaszner, P.; Makkos, Z. - Clozapine maintenance therapy in schizophrenia. Prog Neuropsychopharmacol Biol Psychiatry 28 (3): 465-469, 2004.

GawiN, F.H. - Neuroleptic reduction of cocaine-induced paranoia but not euphoria? Psychopharmacology 90: 142-143, 1986.

Geddes, J.; Freemantle, N.; Harrison, P.; Bebilngton, P. - Atypical antipsychotics in the treatment of schizophrenia: Systematic overview and meta-regression analysis. Br Med J 321 (7273): 1371-1376, 2000.

Gelenberg, A.J.; Doller, J.C. - Clozapine versus chlorpromazine for the treatment of schizophrenia: Preliminary results from a double-blind study. $J$ Clin Psychiatry 40: 238-240, 1979.

Glassman, A.H.; BIGgER, J.T. Jr. - Antipsychotic drugs: prolonged QTc interval, torsade de pointes, and sudden death. Am J Psychiatry 158: 1774-1782, 2001.

GLAZER, W.M. - Review of incidence studies of tardive dyskinesia associated with typical antipsychotics. J Clin Psychiatry 61 (suppl. 4): 15-20, 2000.

Goetz, C.G.; Klawans, H.L. - Drug-induced extrapyramidal disorders: a neuropsychiatric interface. J Clin Psychopharmacol 1: 297-303, 1981.

Goff, D.C.; Midha, K.K.; Sarid-Segal, 0.; Hubbard, J.W.; Amico, E. - A placebo-controlled trial of fluoxetine added to neuroleptic in patients with schizophrenia. Psychopharmacology (Berlin) 117: 417-423, 1995.

Goff, D.C.; Posever, T.; Herz, L.; Simmons, J.; Kletti, N.; Lapierre, K. et al. - An exploratory haloperidol-controlled dose-finding study of ziprasidone in hospitalized patients with schizophrenia or schizoaffective disorder. $J$ Clin Psychopharmacol 18: 296-304, 1998.

Goff, D.C.; Henderson, D.C.; Evins, A.E.; Amico, E. - A placebocontrolled crossover trial of $d$-cycloserine added to clozapine in patients with schizophrenia. Biol Psychiatry 45: 512-514, 1999.

GoLD, L.H. - Use of psychotropic medication during pregnancy: Risk management guidelines. Psychiatr Ann 30: 421-432, 2000.

Goldstein, J.M.; TSAung, M.T. - Gender and schizophrenia: an introduction and synthesis of findings. Schizophr Bull 16: 179-183, 1990.

Goodman, L.A.; Rosenberg, S.D.; Mueser, K.T.; Drake, R.E. - Physical and sexual assault history in women with serious mental illness: Prevalence, correlates, treatment, and future research directions. Schizophr Bull 23 (4): 685-696, 1997.

GREBB, J.A. - Medication induced movement disorders. In: Kaplan, H.I.; Sadock, B.J. (eds.). Comprehensive textbook of psychiatry. Williams \& Wilkins, Nova York, 1995

GreEN, M.F. - What are the functional consequences of neurocognitive deficits in chizophrenia? Am J Psychiatry 153: 321-330, 1996.

Green, M.F.; Marshall, B.D. Jr.; Wirshing, W.C.; Ames, D.; Marder, S.R.; McGurk, S. et al. - Does risperidone improve verbal working memory in treatmentresistant schizophrenia? Am J Psychiatry 154: 799-804, 1997.

Green, M.F.; Marder, S.R.; Glynn, S.M.; McGurk, S.R.; WirShIng, W.C.; WiRSHING, D.A. et al. - The neurocognitive effects of low-dose haloperidol: A twoyear comparison with risperidone. Biol Psychiatry 51: 972-978, 2002.

Green, A.I.; Burgess, E.S.; Dawson, R.; Zimmet, S.V.; Strous, R.D. - Alcohol and cannabis use in schizophrenia: Effects of clozapine vs. risperidone. Schizophr Res 60 (1): 81-85, 2003.

Growe, G.A.; Crayton, J.W.; Klass, D.B.; Evans, H.; Strizich, M. - Lithium in chronic schizophrenia. Am J Psychiatry 136: 454-455, 1979.

GuEST, J.F.; Cookson, R.F. - Costs of schizophrenia to UK Society. An incidencebased cost-of-illness model for the first 5 years following diagnosis. Pharmaeconomics 15: 597-610, 1999.

Guirguis, E.; Voineskos, G.; Gray, J.; Schlieman, E. - Clozapine (Leponex) versus chlorpromazine (Largactil) in acute schizophrenia (a double-blind controlled study). Curr Ther Res 21: 707-719, 1977.

Gupta, S.; Sonnenberg, S.J.; Frank, B. - Olanzapine augmentation of clozapine. Ann Clin Psychiatry 10: 113-115, 1998. 
GUPTA, N.; BASU, D. - Does risperidon reduce concomitant substance abuse in cases of schizophrenia? Can J Psychiatry 46: 862-863, 2001.

HADDAD, P.M.; ANDERSON, I.M. - Antipsychotic-related QTC prolongation, torsade de pointes and sudden death. Drugs 62: 1649-1671, 2002.

HADDAD, P.M. - Antipsychotics and diabetes: Review of nonprospective data. Br J Psychiatry 184 (suppl. 47): 80-86, 2004.

HäFNER, H. - Gender differences in schizophrenia. In: Frank, B. (ed.). Gender and its effects on psychopathology. American Psychiatric Press, Washington DC, pp. 187-228, 2000.

HÄFNER, H.; AN DER HEIDEN, W. - Course and outcome of schizophrenia. In: Hirsch, S.R.; Weinberger, D.R. (eds.). Schizophrenia. Blackwell Science, Oxford, Victoria, Berlin, pp. 101-141, 2003.

HäFNER, H.; MAURER, K.; LöfFLER, W.; RIECHER-RössleR, A. - The influence of age and sex on the onset and early course of schizophrenia. Br J Psychiatry 162: 80-86, 1993.

Hamilton, S.H.; Revicki, D.A.; Genduso, L.A.; Beasley, C.M. JR. - Olanzapine versus placebo and haloperidol: Quality of life and efficacy results of the North American double-blind trial. Neuropsychopharmacology 18:41/49, 1998.

Hanlon, T.E.; OtA, K.Y.; BuRLand, A.A. - Comparative effects of fluphenazine, fluphenazine-chlordiazepoxide, and fluophenazine-imipramine. Dis Nerv Syst 31: 171-177, 1970.

Harada, T.; Otsuki, S.; FuJiwara, Y. - Effectiveness of zotepine in therapyrefractory psychoses. An open, multicenter study ineight psychiatric clinics. Fortschr Neurol Psychiatr 59 (suppl. 1): 41-44, 1991.

Harvey, P.D.; KeEfe, R.S. - Studies of cognitive change in patients with schizophrenia following novel antipsychotic treatment. Am J Psychiatry 158 (2): 176-184, 2001

Harvey, P.D.; Siu, C.0.; Romano, S. - Randomized, controlled, double-blind, multicenter comparison of the cognitive effects of ziprasidone versus olanzapine in acutely ill inpatients with schizophrenia or schizoaffective disorder. Psychopharmacology (Berlin) 172 (3): 324-332, 2004.

HaWkins, J.M.; Archer, K.J.; StraKowski, S.M.; KecK, P.E. - Somatic treatment of catatonia. Int J Psychiatry Med 25 (4): 345-369, 1995

Hegarty, J.D.; Baldessarinı, R.J.; Tohen, M.; Waternaux, C.; Oepen, G. - One hundred years of schizophrenia: A meta-analysis of the outcome literature. Am J Psychiatry 151: 1409-1416, 1994.

Heinrich, K.; Klieser, E.; Lehmann, E.; Kinzler, E.; Hruschia, H. - Risperidone versus clozapine in the treatment of schizophrenic patients with acute symptoms: A double-blind, randomized trial. Prog Neuropsychopharmacol Biol Psychiatry 18: 129-137, 1994.

HELGASON, L. - Twenty years' follow-up of first psychiatric presentation for schizophrenia: What could have been prevented? Acta Psychiatr Scand 81: 231-235, 1990

Hellerstein, D.J.; Rosenthal, R.N.; Miner, C.R. - A prospective study of integrated outpatient treatment for substance- abusing schizophrenic patients. Am J Addict 4: 33-42, 1995.

HendeRson, D.C.; Goff, D.C. - Risperidone as an adjunct to clozapine therapy in chronic schizophrenics. J Clin Psychiatry 57: 395-397, 1996.

Henderson, D.C.; Nasrallah, R.A.; Goff, D.C. - Switching from clozapine to olanzapine in treatment-refractory schizophrenia: Safety, clinical efficacy, and predictors of response. J Clin Psychiatry 59: 585-588, 1998.

Hesslinger, B.; Normann, C.; Langosch, J.M.; Klose, P.; Berger, M.; Walden, J. Effects of carbamazepine and valproate on haloperidol plasma levels and on psychopathologic outcome in schizophrenic patients. J Clin Psychopharmacol 19: 310-315, 1999.

Hesslinger, B.; Walden, J.; Normann, C. - Acute and long-term treatment of catatonia with risperidone. Pharmacopsychiatry 34 (1): 25-26, 2001.

HIROSE, S.; AshBY, C.R.; MILLs, M.J. - Effectiveness of ECT combined with risperidone against aggression in schizophrenia. J ECT 17 (1): 22-26, 2001.

Hirsch, S.R.; Kissuing, W.; Bauml, J.; Power, A.; O'Connor, R. - A 28-week comparison of ziprasidone and haloperidol in outpatients with stable schizophrenia. J Clin Psychiatry 63:516/523, 2002.

Hoff, A.L.; SAKuma, M.; Wieneke, M.; Horon, R.; Kushner, M.; DeLISI, L.E. - Longitudinal neuropsychological follow-up study of patients with first-episode schizophrenia. Am J Psychiatry 156: 1336-1341, 1999.

Hoffman, R.E.; Hawkins, K.A.; Gueorguieva, R.; Boutros, N.N.; Rachid, F.; Carroll, K. et al. - Transcranial magnetic stimulation of left temporoparietal cortex and medication-resistant auditory hallucinations. Arch Gen Psychiatry 60: 49-56, 2003.

Hoffman, R.E.; Boutros, N.N.; Hu, S.; Berman, R.M.; Krystal, J.H.; Charney, D.S. - Transcranial magnetic stimulation and auditory hallucinations in schizophrenia. Lancet 355: 1073-1075, 2000.

Holden, J.M.; ITL, T.M.; Keskiner, A.; FinK, M. - Thioridazine and chlordiazepoxide, alone and combined, in the treatment of chronic schizophrenia Compr Psychiatry 9: 633-643, 1968.

Hong, C.J.; Chen, J.Y.; Chiu, H.J.; Sim, C.B. - A double-blind comparative study of clozapine versus chlorpromazine on Chinese patients with treatmentrefractory schizophrenia. Int Clin Psychopharmacol 12: 123-130, 1997.

Honigfeld, G.; Patin, J.; Singer, J. - Clozapine antipsychotic activity in treatment-resistant schizophrenics. Adv Ther 1: 77-97, 1984.

Horl, M.; SuzukI, T.; SaSaki, M.; ShIRaISHI, H.; KoIzUMI, J. - Convulsive seizures in schizophrenic patients induced by zotepine administration. Jpn J Psychiatry Neurol 46: 161-167, 1992.

Hoyberg, 0.J.; FensBo, C.; Remvig, J.; Lingjaerde, 0.; Sloth-Nielsen, M.; Salvesen, I. Risperidone versus perphenazine in the treatment of chronic schizophrenic patients with acute exacerbations. Acta Psychiatr Scand 88: 395-402, 1993.

Hunt, G.E.; Bergen, J.; Bashir, M. - Medication compliance and comorbid substance abuse in schizophrenia: Impact on community survival 4 years after a relapse. Schizophr Res 54: 253-264, 2002.

Huo, Z.U.; RIS-GBR-32 Investigators. - A trial of low doses of risperidone in the treatment of patients with first-episode schizophrenia, schizophreniform disorder, or schizoaffective disorder. J Clin Psychopharmacol 24 (2): 220-224, 2004.

Huttunen, M.; Piepponen, T.; Rantanen, H.; Larmo, I.; Nyholm, R.; Raitasuo, V. - Risperidone versus zuclopenthixol in the treatment of acute schizophrenic episodes: a double-blind parallel group trial. Acta Psychiatr Scand 91: 271-277, 1995.

HWANG, T.J.; LIN, S.K.; LIN, H.N. - Efficacy and safety of zotepine for the treatment of Taiwanese schizophrenic patients: a double-blind comparison with haloperidol. J Formos Med Assoc 100: 811-816, 2001.

Hwang, T.J.; LeE, S.M.; Sun, H.J.; LIN, H.N.; TsAl, S.J.; LeE, Y.C. et al. - Amisulpride versus risperidone in the treatment of schizophrenic patients: A doubleblind pilot study in Taiwan. J Formos Med Assoc 102: 30-36, 2003.

ISHIGOOKA, J.; INADA, T.; MIURA, S. - Olanzapine versus haloperidol in the treatment of patients with chronic schizophrenia: Results of the Japan multicenter, double-blind olanzapine trial. Psychiatry Clin Neurosci 55: 403-414, 2001.

Jablensky, A.; Sartorius, N.; Ernberg, G.; Anker, M.; Korten, A.; Cooper, J.E. et al. - Schizophrenia: manifestations, incidence, and course in different cultures. A World Health Organization ten-country study. Psychol Med Monogr Supp/ 20: 1-97, 1992.

Janicak, P.; Davis, J.; Preskorn, S.; Ayd, F. - Principles and practice of psychopharmacotherapy. Williams \& Wilkins, Baltimore, 1993.

Javitt, D.C.; Silipo, G.; Cienfuegos, A.; Shelley, A.M.; Bark, N.; Park, M. et al. - Adjunctive highdose glycine in the treatment of schizophrenia. Int $J$ Neuropsychopharmacol 4: 385-391, 2001.

Jeste, D.V.; Lacro, J.P.; Gllbert, P.L.; Kline, J.; Kline, N. - Treatment of late-life schizophrenia with neuroleptics. Schizophr Bull 19 (4): 817-830, 1993.

Jeste, D.V.; Glads.Jo, J.A.; LindameR, L.A.; LACRO, J.P. - Medical comorbidity in schizophrenia. Schizophr Bull 22: 413-430, 1996.

JESTE, D.V. - Tardive dyskinesia in older patients. J Clin Psychiatry 61 (suppl. 4): 27-32, 2000

Johnstone, E.C.; Crow, T.J.; Johnson, A.L.; MacMillan, J.F. - The Northwick Park Study of first episodes of schizophrenia, I: Presentation of the illness and problems relating to admission. Br J Psychiatry 148: 115-120, 1986.

Johnstone, E.C.; Conelly, J.; Frith, C.D.; Lambert, M.T.; Owens, D.G. - The nature of transient and partial psychoses: Findings from the Northwick Park Study Functional Psychosis Study. Psychol Med 26: 361-369, 1996.

Josiassen, R.C.; Joseph, A.; Kohegyı, E.; Stokes, S.; Dadvand, M.; Paing, W.W. et al. - Clozapine augmented with risperidone in the treatment of schizophrenia: A randomized, double-blind, placebo-controlled trial. Am J Psychiatry 162 (1): 130-136, 2005.

Joy, C.B.; Adams, C.E.; LaWRIE, S.M. - Haloperidol versus placebo for schizophrenia (Cochrane Review). In: The Cochrane Library, Issue 2. John Wiley \& Sons Ltd.,Chichester, 2004. 
Kalinowsky, L.B.; WoRTHING, H.J. - Results with electroconvulsive therapy in 200 cases of schizophrenia. Psychiatr Q 17: 144-153, 1943.

KaLINoWSKY, L.B. - Electric convulsive therapy, with emphasis on importance of adequate treatment. Arch Neurol Psychiatry 50: 652-660, 1943.

Kane, J.; Honigfeld, G.; Singer, J.; Meltzer, H. - Clozapine for the treatmentresistant schizophrenic: A double-blind comparison with chlorpromazine. Arch Gen Psychiatry 45: 789-796, 1988.

KANE, J.M.; MARDER, S.R. - Psychopharmacologic treatment of schizophrenia. Schizophr Bull 19 (2): 287-302, 1993.

KANE, J.M. - The use of higher-dose antipsychotic medication. Br J Psychiatry 164: 431-432, 1994.

Kane, J.M.; Marder, S.R.; Schooler, N.R.; Wirshing, W.C.; Umbricht, D.; Baker, R.W. et al. - Clozapine and haloperidol in moderately refractory schizophrenia: a 6-month randomized and double-blind comparison. Arch Gen Psychiatry 58: 965-972, 2001.

Kane, J.M.; Carson, W.H.; Saha, A.R.; McQuade, R.D.; Ingenito, G.G.; Zimbroff, D.L. - Efficacy and safety of aripiprazole and haloperidol versus placebo in patients with schizophrenia and schizoaffective disorder. J Clin Psychiatry 63: 763-771, 2002.

Kane, J.M.; Leucht, S.; Carpenter, D.; Docherty, J.P. - The Expert Consensus Guideline Series. Optimizing Pharmacologic Treatment of Psychotic Disorders. J Clin Psychiatry 63 (suppl. 12): 1-100, 2003.

Karagianis, J.L.; LeDrew, K.K.; WalKer, D.J. - Switching treatment-resistant patients with schizophrenia or schizoaffective disorder to olanzapine: a one-year open-label study with fiveyear follow-up. Curr Med Res Opin 19: 473-480, 2003.

Kasckow, J.W.; Mohamed, S.; Thallasinos, A.; Carroll, B.; Zisook, S.; Jeste, D.V. - Citalopram augmentation of antipsychotic treatment in older schizophrenia patients. Int J Geriatr Psychiatry 16: 1163-1167, 2001.

Kasper, S.; Lerman, M.N.; McQuade, R.D.; Saha, A.; Carson, W.H.; Al, M. et al. - Efficacy and safety of aripiprazole vs. haloperidol for longterm maintenance treatment following acute relapse of schizophrenia. Int J Neuropsychopharmacol 6: 325-337, 2003.

Kaye, N.S. - Ziprasidone augmentation of clozapine in 11 patients. J Clin Psychiatry 64: 215-216, 2003.

Keck, P.E. Jr.; Buffenstein, A.; Ferguson, J.; Feighner, J.; Jaffe, W.; Harkigan, E.P. et al. - Ziprasidone 40 and $120 \mathrm{mg} /$ day in the acute exacerbation of schizophrenia and schizoaffective disorder: A 4-week placebo-controlled trial. Psychopharmacology (Berlin) 140: 173-184, 1998.

Keck, P.E. JR.; Strakowski, S.M.; McElroy, S.L. - The efficacy of atypical antipsychotics in the treatment of depressive symptoms, hostility, and suicidality in patients with schizophrenia. J Clin Psychiatry 61: 4-9, 2000.

Kee, K.S.; Kern. R.S.; Marshall, B.D.; Green, M.F. - Risperidone versus haloperidol for perception of emotion in treatmentresistant schizophrenia: prelimimary findings. Schizophr Res 31: 159-165, 1998.

Keefe, R.S.; Silva, S.G.; Perkins, D.0.; Lieberman, J.A. - The effects of atypical antipsychotic drugs on neurocognitive impairment in schizophrenia: $A$ review and meta-analysis. Schizophr Bull 25 (2): 201-222, 1999.

Keefe, R.S.; Seidman, L.J.; Christensen, B.K.; Hamer, R.M.; Sharma, T.; SitskoORN, M.M. et al. - Comparative effect of atypical and conventional antipsychotic drugs on neurocognition in first-episode psychosis: A randomized, double-blind trial of olanzapine versus low doses of haloperidol. Am J Psychiatry 161 (6): 985-995, 2004.

Kelly, D.L.; Gale, E.A.; Conley, R.R. - Clozapine treatment in patients with prior substance abuse. Can J Psychiatry 48: 111-114, 2003.

Killian, J.G.; Kerr, K.; Lawrence, C.; Celermajer, D.S. - Myocarditis and cardiomyopathy associated with clozapine. Lancet 354: 1841-1845, 1999.

Kinon, B.; Kane, J.; Johns, C.; Perovich, R.; Ismi, M.; Koreen, A. et al. - Treatment of neuroleptic-resistant schizophrenic relapse. Psychopharmacol Bull 29: 309-314, 1993.

KINON, B.J.; LIEBERMAN, J.A. - Mechanisms of action of atypical antipsychotic drugs: A critical analysis. Psychopharmacology (Berlin) 124: 2-34, 1996.

Kinon, B.J.; AhL, J.; Stauffer, V.L.; HiLL, A.L.; BuckLey, P.F. - Dose response and atypical antipsychotics in schizophrenia. CNS Drugs 18 (9): 597616, 2004.

KIRLI, S.; CALISKAN, M. - A comparative study of sertraline versus imipramine in postpsychotic depressive disorder of schizophrenia. Schizophr Res 33: 103-111, 1998.
KIssuInG, W. (ed.). - Guidelines for neuroleptic relapse prevention in schizophrenia. Springer Verlag, Berlin, 1991.

Klein, E.; Kolsky, Y.; Puyerovsky, M.; Konen, D.; Chistyakov, A.; Feinsod, M. - Right prefrontal slow repetitive transcranial magnetic stimulation in schizophrenia: A double-blind shamcontrolled pilot study. Biol Psychiatry 46: 1451-1454, 1999.

Kleinberg, D.L.; Davis, J.M.; de Coster, R.; Van Baelen, B.; Brecher, M. - Prolactin levels and adverse events in patients treated with risperidone. J Clin Psychopharmacol 19: 57-61, 1999.

Klieser, E.; Lehmann, E. - Experimental comparison of the effectivity of individually adapted and standardized dosages of haloperidol. Pharmacopsychiatry 18: 122-126, 1987.

Klieser, E.; Strauss, W.H.; Lemmer, W. - The tolerability and efficacy of the atypical neuroleptic remoxipride compared with clozapine and haloperidol in acute schizophrenia. Acta Psychiatr Scand 89 (suppl. 380): 68-73, 1994.

Klieser, E.; Lehmann, E.; Kinzler, E.; Wurthmann, C.; HeinRich, K.J. - Randomized, double-blind, controlled trial of risperidone versus clozapine in patients with chronic schizophrenia. Clin Psychopharmacol 15 (1 suppl. 1): 45S-51S, 1995.

Klimke, A.; Klieser, E.; Lehmann, E.; Miele, L. - Initial improvement as a criterion for drug choice in acute schizophrenia. Pharmacopsychiatry 26: 25-29, 1993.

Kofoed, L.; Kania, J.; Walsh, T.; Atkinson, R.M. - Outpatient treatment of patients with substance abuse and coexisting psychiatric disorders. Am J Psychiatry 143: 867-872, 1986.

Knapp, M. - Costs of schizophrenia. Br J Psychiatry 171: 509-518, 1997.

Kolivakis, T.T.; Beauclair, L.; Margolese, H.C.; Chouinard, G. - Long-term lamotrigine adjunctive to antipsychotic monotherapy in schizophrenia: Further evidence. Can J Psychiatry 49 (4): 280, 2004.

KöNIG, P.; GlatTer-Gotz, U. - Combined electroconvulsive and neuroleptic therapy in schizophrenia refractory to neuroleptics. Schizophr Res 3: 351-354, 1990.

Konrad, C.; Schormair, C.; Ophaus, P.; Knickelbein, U.; Eikelmann, B. - Risperidon und Clozapin in der Behandlung therapieresistenter Schizophrenien. Krankenhauspsychiatrie 11: 89-93, 2000.

KOPALA, L.C.; Good, K.P.; Honer, W.G. - Extrapyramidal signs and clinical symptoms in first-episode schizophrenia: Response to low-dose risperidone. $J$ Clin Psychopharmacol 17 (4): 308-313, 1997.

KopalA, L.C.; CAUDLE, C. - Acute and longer-term effects of risperidone in a case of first-episode catatonic schizophrenia. J Psychopharmacol 12 (3): 314-317, 1998

Koren, G.; Cohn, T.; Chitayat, D.; Kapur, B.; Remington, G.; Reid, D.M. et al. - Use of atypical antipsychotics during pregnancy and the risk of neural tube defects in infants. Am J Psychiatry 159: 136-137, 2002.

Koreen, A.R.; Siris, S.G.; Chakos, M.; Alvir, J.; Mayerhoff, D.; Lieberman, J. - Depression in first-episode schizophrenia. Am J Psychiatry 150: 1643$1648,1993$.

Koro, C.E.; Fedder, D.0.; L'Italien, G.J.; Weiss, S.S.; Magder, L.S.; Kreyenbuhl, J.; RevickI, D.A.; Buchanan, R.W. - Assessment of independent effect of olanzapine and risperidone on risk of diabetes among patients with schizophrenia: Population based nested case-control study. Br Med J 325 (7358): 243, 2002a.

Koro, C.E.; Fedder, D.O.; L'Italien, G.J.; Weiss, S.; Magder, L.S.; Kreyenbuhl, J.; REVICKI, D.; BuCHANAN, R.W. - An assessment of the independent effects of olanzapine and risperidone exposure on the risk of hyperlipidemia in schizophrenic patients. Arch Gen Psychiatry 59 (11): 1021-1026, 2002b.

Kossen, M.; Selten, J.P.; Kahn, R.S. - Elevated clozapine plasma level with lamotrigine. Am J Psychiatry 158 (11): 1930, 2001.

Kosten, T.R.; KLeBER, H.D. - Rapid death during cocain abuse: Variant of the neuroleptic malignant syndrome? Am J Drug Alcohol Abuse 14: 335-346, 1988.

Kotler, M.; Strous, R.D.; Reznik, I.; Shwartz, S.; Weizman, A.; Spivak, B. - Sulpiride augmentation of olanzapine in the management of treatment-resistant chronic schizophrenia: evidence for improvement of mood symptomatology. Int Clin Psychopharmacol 19: 23-26, 2004.

Kovasznay, B.; Fleischer, J.; Tanenberg-Karant, M.; Jandorf, L.; Mıller, A.D.; Bromet, E. - Substance use disorder and the early course of illness 
in schizophrenia and affective psychosis. Schizophr Bull 23: 195-201, 1997.

Krakowski, M.; Czobor, P.; Volavka, J. - Effect of neuroleptic treatment on depressive symptoms in acute schizophrenic episodes. Psychiatry Res 71: 19-26, 1997.

Kremer, I.; Vass, A.; Gorelik, I.; Bar, G.; Blanaru, M.; Javitt, D.C.; Heresco-Levy, U. - Placebo-controlled trial of lamotrigine added to conventional and atypical antipsychotics in schizophrenia. Biol Psychiatry 56: 441-446, 2004.

Krystal, J.H.; D'Souza, D.C.; Madonick, S.; Petrakis, I.L. - Toward a rational pharmacotherapy of comorbid substance abuse in schizophrenic patients. Schizophr Res 35: S35-S49, 1999.

Kumra, S.; Frazier, J.A.; Jacobsen, L.K.; McKenna, K.; Gordon, C.T.; Lenane, M.C. et al. - Childhood-onset schizophrenia: a double-blind clozapine-haloperidol comparison. Arch Gen Psychiatry 53: 1090-1097, 1996.

Kupchik, M.; Spivak, B.; Mester, R.; Reznik, I.; Gonen, N.; Weizman, A. et al. - Combined electroconvulsive-clozapine therapy. Clin Neuropharmacol 23 (1): 14-16, 2000.

LACRO, J.P.; Dunn, L.B.; Dolder, C.R.; LeCKBAnd, S.G.; JeSTE, D.V. - Prevalence of and risk factors for medication nonadherence in patients with schizophrenia: A comprehensive review of recent literature. J Clin Psychiatry 63: 892-909, 2002.

La Grenade, L.; Graham, D.; Trontell, A. - Myocarditis and cardiomyopathy associated with clozapine use in the United States. New Engl J Med 345: 224-225, 2001.

Landmark, J.; Joseph, L.; Merskey, H. - Characteristics of schizophrenic patients and the outcome of fluphenazine and of electroconvulsive treatments. Can J Psychiatry 32: 425-428, 1987.

Lausberg, H.; Hellweg, R. - Catatonic dilemma. Therapy with lorazepam and clozapine. Nervenarzt 69 (9): 818-822, 1998.

Lee, M.L.; Dickson, R.A.; Campbell, M.; Oliphant, J.; Gretton, H.; Dalby, J.T. - Clozapine and substance abuse in patients with schizophrenia. Can J Psychiatry 43: 855-856 (letter), 1998.

LEE, M.S.; KIM, Y.K.; LeE, S.K.; SuH, K.Y. - A double-blind study of adjunctive sertraline in haloperidol-stabilized patients with chronic schizophrenia. J Clin Psychopharmacol 18: 399-403, 1998.

LeE, J.W.; Schwartz, D.L.; Hallmayer, J. - Catatonia in a psychiatric intensive care facility: Incidence and response to benzodiazepines. Ann Clin Psychiatry 12: 89-96, 2000.

Lehmann, A.F.; Steinwachs, D.M.; PORT Co-Investigators. - Translating research into practice: The Schizophrenia Patient Outcomes Research Team (PORT) treatment recommendations. Schizophr Bull 24: 1-10, 1998.

Lehman, A.F; Lieberman, J.A.; Dixon, L.B.; McGlashan, T.H.; Miller, A.L.; Perkins, D.0. et al. - Practice guideline for the treatment of patients with schizophrenia, 2. ed. Am J Psychiatry 161: 1-56, 2004.

Lerner, V.; Chudakova, B.; Kravets, S.; Polyakova, I. - Combined use of risperidone and olanzapine in the treatment of patients with resistant schizophrenia: A preliminary case series report. Clin Neuropharmacol 23: 284-286, 2000.

LeUcht, S.; HARTung, B. - Benperidol for schizophrenia (Cochrane Review). In: The Cochrane Library, Issue 2. John Wiley \& Sons Ltd., Chichester, 2004a.

Leucht, S.; HaRtung, B. - Perazine for schizophrenia (Cochrane Review). In: The Cochrane Library, Issue 2. John Wiley \& Sons Ltd., Chichester, 2004b.

Leucht, S.; Pitschel-Walz, G.; Abraham, D.; Kissling, W. - Efficacy and extrapyramidal side-effects of the new antipsychotics olanzapine, quetiapine, risperidone, and sertindole compared to conventional antipsychotics and placebo: A metaanalysis of randomized controlled trials. Schizophr Res 35: 51-68, 1999.

Leucht, S.; PItschel-WALz, G.; EngeL, R.R.; KIssLing, W. - Amisulpride, an unusual 'atypical' antipsychotic: A metaanalysis of randomized controlled trials. Am J Psychiatry 159 (2): 180-190, 2002.

Leucht, S.; Wahlbeck, K.; Hamann, J.; Kissling, W. - New generation antipsychotics versus low-potency conventional antipsychotics: A systematic review and meta-analysis. Lancet 361 (9369): 1581-1589, 2003a.

Leucht, S.; Barnes, T.R.; Kissuing, W.; Engel, R.R.; Correll, C.; Kane, J.M. - Relapse prevention in schizophrenia with new-generation antipsychotics: A systematic review and exploratory metaanalysis of randomized, controlled trials. Am J Psychiatry 160: 1209-1222, 2003b.
Leucht, S.; KIssling, W.; McGrath, J. - Lithium for schizophrenia revisited: A systematic review and meta-analysis of randomized controlled trials. $J$ Clin Psychiatry 65: 177-186, 2004.

Leung, A.; ChuE, P. - Sex differences in schizophrenia: A review of the literature. Acta Psychiatr Scand (suppl.) 401: 3-38, 2000.

Levin, R.F.; Evans, S.M.; Coomaraswammy, S.; Coluins, E.D.; Regent, N.; Kleber, H.D. - Flupentixol treatment for cocaine abusers with schizophrenia: A pilot study. Am J Drug Alcohol Abuse 24: 343-360, 1998.

Levinson, D.F.; Umapathy, C.; MusthaQ, M. - Treatment of schizoaffective disorder and schizophrenia with mood symptoms. Am J Psychiatry 156: 1138-1148, 1999.

Lewis, S.; Tarrier, N.; Haddock, G.; Bentall, R.; Kinderman, P.; Kingdon, D. et al. - Randomised controlled trial of cognitive-behavioral therapy in early schizophrenia: Acutephase outcomes. Br J Psychiatry (suppl.) 43: S91-S97, 2002.

Lieberman, J.A.; Safferman, A.Z.; Pollack, S.; Szymanski, S.; Johns, S.; Howard, A. et al. - Clinical effects of clozapine in chronic schizophrenia: Response to treatment and predictors of outcome. Am J Psychiatry 151: $1744-1752$.

Lieberman, J.A.; Koreen, A.R.; Chakos, M.; Sheitman, B.; Woerner, M.; Alvir, J.M. et al. - Factors influencing treatment response and outcome of first-episode schizophrenia: Implications for understanding the pathophysiology of schizophrenia. J Clin Psychiatry 57 (suppl. 9): 5-9, 1996.

Lieberman, J.A.; Phillips, M.; Gu, H.; Stroup, S.; Zhang, P.; Kong, L. - Atypical and conventional antipsychotic drugs in treatment-naive first-episode schizophrenia: A 52-week randomized trial of clozapine vs chlorpromazine. Neuropsychopharmacology 28: 995-1003, 2003a.

Lieberman, J.A.; Tollefson, G.; Tohen, M.; Green, A.I.; Gur, R.E.; Kahn, R. et al. - Comparative efficacy and safety of atypical and conventional antipsychotic drugs in first-episode psychosis: A randomized, double-blind trial of olanzapine versus haloperidol. Am J Psychiatry 160: 1396-1404, 2003b.

Lindenmayer, J.P.; Grochowski, S.; Mabugat, L. - Clozapine effects on positive and negative symptoms: a six-month trial in treatment-refractory schizophrenics. J Clin Psychopharmacol 14: 201-204, 1994.

Lindenmayer, J.P.; Iskander, A.; Park, M.; Apergi, F.S.; Czobor, P.; Smith, R. et al. - Clinical and neurocognitive effects of clozapine and risperidone in treatment-refractory schizophrenic patients: A prospective study. $J$ Clin Psychiatry 59: 521-527, 1998.

Lindenmayer, J.P.; Volavka, J.; Lieberman, J.; Sheitman, B.; Citrome, L.; Chakos, M. et al. - Olanzapine for schizophrenia refractory to typical and atypical antipsychotics: An open-label, prospective trial. J Clin Psychopharmacol 21: 448-453, 2001.

Lindenmayer, J.P.; CZobor, P.; Volavka, J.; Lieberman, J.A.; Citrome, L.; Sheitman, B. et al. - Olanzapine in refractory schizophrenia after failure of typical or atypical antipsychotic treatment: An open-label switch study. J Clin Psychiatry 63: 931-935, 2002.

Linguaerde, 0.; Engstrand, E.; Ellingsen, P.; Stylo, D.A.; Robak, O.H. - Antipsychotic effect of diazepam when given in additino to neuroleptics in chronic psychotic patients: A double-blind clinical trial. Curr Ther Res 26: 505-512, 1979.

Linszen, D.H.; Dingemans, P.M.; LenIor, M.E. - Cannabis abuse and course of recent-onset schizophrenic disorders. Arch Gen Psychiatry 51:273/279, 1994.

Littrell, K.H.; Petty, R.G.; Hilligoss, N.M.; Peabody, C.D.; Johnson, C.G. - Olanzapine treatment for patients with schizophrenia and substance abuse. $J$ Subst Abuse Treat 21: 217-221, 2001.

Loebel, A.D.; Lieberman, J.A.; Alvir, J.M.; Mayerhoff, D.I.; Geisler, S.H.; Szymanski, S.R. - Duration of psychosis and outcome in first episode schizophrenia. Am J Psychiatry 149: 1183-1188, 1992.

Loo, H.; Poirier-LitTre, M.F.; Theron, M.; Rein, W.; Fleurot, O. - Amisulpride versus placebo in the medium-term treatment of the negative symptoms of schizophrenia. Br J Psychiatry 170: 18-22, 1997.

Louza, M.R.; Marques, A.P.; Elkis, H.; Bassitt, D.; Diegoli, M.; Gattaz, W.F. - Conjugated estrogens as adjuvant therapy in the treatment of acute schizophrenia: A double-blind study. Schizophr Res 66 (2-3): 97-100, 2004.

Luchins, D. - Carbamazepine in violent non-epileptic schizophrenics. Psychopharmacol Bull 20: 569-571, 1987. 
Luchins, D.; Klass, D.; Hanrahan, P.; Malan, R.; Harris, J. - Alteration in the recommended dosing schedule for risperidone. Am J Psychiatry 155 (3): 365-366, 1998.

MacKay, F.J.; Wilton, G.L.; Pearce, S.N.; Freemantle, S.N.; Mann, R.D. - The safety of risperidone: A post-marketing study on 7684 patients. Hum Psychopharmacol Clin Exp 13: 413-418, 1998.

Major, L.F.; Lerner, P.; Ballenger, J.C.; Brown, G.L.; Goodwin, F.K.; Lovenberg, W. - Dopamine-b-hydroxylase in the cerebrospinal fluid: Relationship to disulfiram-induced psychosis. Biol Psychiatry 14: 337-343, 1978.

Marcus, P.; SNyder, R. - Reduction of comorbid substance abuse with clozapine. Am J Psychiatry 152: 959 (letter), 1995.

MARDER, S.R.; MeIBACH, R.C. - Risperidone in the treatment of schizophrenia. Am J Psychiatry 151: 825-835, 1994.

Marder, S.R.; Essock, S.M.; Miller, A.L.; Buchanan, R.W.; Davis, J.M.; Kane, J.M. et al. - The Mount Sinai conference on the pharmacotherapy of schizophrenia. Schizophr Bull 28 (1): 5-16, 2002.

Marder, S.R.; McQuade, R.D.; Stock, E.; Kaplita, S.; Marcus, R.; Safferman, A.Z. et al. - Aripiprazole in the treatment of schizophrenia: Safety and tolerability in short-term, placebo-controlled trials. Schizophr Res 61: 123-136, 2003.

Marder, S.R.; Essock, S.M.; Miller, A.L.; Buchanan, R.W.; Casey, D.E.; Davis, J.M. et al. - Physical health monitoring of patients with schizophrenia. Am J Psychiatry 161 (8): 1334-1349, 2004.

Marenco, S.; Weinberger, D.R. - The neurodevelopmental hypothesis of schizophrenia: Following a trail of evidence from cradle to grave. Dev Psychopathol 12: 501-527, 2000.

Maroues, L.0.; LimA, M.S.; SoAReS, B.G.0. - Trifluoperazine for schizophrenia (Cochrane Review). In: The Cochrane Library, Issue 2. John Wiley \& Sons Ltd., Chichester, 2004.

Maxwell, S.; SHinderman, M.S. - Use of naltrexone in the treatment of alcohol use disorders in patients with concomitant major mental illness. $J$ Addict Dis 19: 61-69, 2000.

McCarthy, R.H.; Terkelsen, K.G. - Risperidone augmentation of clozapine. Phamacopsychiatry 28: 61-63, 1995.

McEvoy, J.; Freudenreich, 0.; McGee, M.; Van der Zwaag, C.; Levin, E.; Rose, J. - Clozapine decreases smoking in patients with chronic schizophrenia. Biol Psychiatry 37 (8): 550-552, 1995.

McGlashan, T.H.; Fenton, W.S. - Subtype progression and pathophysiologic deterioriation in early schizophrenia. Schizophr Bull 19: 71-84, 1993.

McGlashan, T.H.; Johannessen, J.O. - Early detection and intervention with schizophrenia: Rationale. Schizophr Bull 22: 201-222, 1996.

McGorry, P.; KILlackey, E.; Elkins, K.; Lambert, M.; Lambert, T. for the RANZCP Clinical Practice Guideline Team for the treatment of schizophrenia. Summary Australian and New Zealand clinical practice guideline for the treatment of schizophrenia. Australasian Psychiatry 11 (2): 136-147, 2003.

Meltzer, H.Y.; ОKaYLI, G. - Reduction of suicidality during clozapine treatment of neuroleptic-resistant schizophrenia: Impact on risk-benefit assessment. Am J Psychiatry 152: 183-190, 1995.

Meltzer, H.Y.; McGurk, S.R. - The effects of clozapine, risperidone, and olanzapine on cognitive function in schizophrenia. Schizophr Bull 25 (2): 233-255, 1999.

Mettzer, H.Y. - Suicidality in schizophrenia: A review of the evidence for risk factors and treatment options. Curr Psychiatry Rep 4: 279-283, 2002.

Meltzer, H.Y.; Alphs, L.; Green, A.I.; Altamura, A.C.; Anand, R.; Bertoldi, A. et al. - Clozapine treatment for suicidality in schizophrenia: International Suicide Prevention Trial (InterSePT). Arch Gen Psychiatry60: 82-91, 2003.

Merlo, M.C.; Hofer, H.; Gekle, W.; Berger, G.; Ventura, J.; Panhuber, I. et al. Risperidone, $2 \mathrm{mg} /$ day vs. $4 \mathrm{mg} /$ day, in first-episode, acutely psychotic patients: Treatment efficacy and effects on fine motor functioning. $J$ Clin Psychiatry 63: 885-891, 2002.

Meyer-Lindenberg, A.; Gruppe, H.; Bauer, U.; Lis, S.; Krieger, S.; Gallhofer, B. Improvement of cognitive function in schizophrenic patients receiving clozapine or zotepine: Results from a double-blind study. Pharmacopsychiatry 30: 35-42, 1997.

MıLLER, L.J. - Use of electroconvulsive therapy during pregnancy. Hosp Com Psychiatry 45 (5): 444-450, 1994.

Miller, A.L.; Chiles, J.A.; Chiles, J.K.; Crismon, M.L.; Rush, A.J.; Shon, S.P. - The Texas Medication Algorithm Project (TMAP) schizophrenia algorithms. J Clin Psychiatry 60 (10): 649-657, 1999.
Mılek, D.D. - Review and management of clozapine side effects. J Clin Psychiatry 61 (suppl. 8): 14-17, 2000.

MöLleR, H.J. - Treatment of schizophrenia: State of the art. Eur Arch Psychiatry Clin Neurosci 246: 229-234, 1996.

MöLleR, H.J. - Definition, psychopharmacological basis and clinical evaluation of novel/atypical neuroleptics: Methodological issues and clinical consequences. World J Biol Psychiatry 1: 75-91, 2000a.

MölleR, H.J. - State of the art of drug treatment of schizophrenia and the future position of the novel/atypical antipsychotics. World J Biol Psychiatry 1: 204-214, 2000b.

Möllek, H.J.; Bottlender, R.; Gross, A.; Hoff, P.; Wittmann, J.; Wegner, U. et al. - The Kraepelinian dichotomy: Preliminary results of a 15-year follow-up study on functional psychoses: Focus on negative symptoms. Schizophr Res 56: 87-94, 2002.

MöLLER, H.J. - Management of the negative symptoms of schizophrenia. New treatment options. CNS Drugs 17 (11): 793-823, 2003.

MöLleR, H.J. - Novel antipsychotics in the long-term treatment of schizophrenia. World J Biol Pschiatry 5: 9-19, 2004a.

MöLLER, H.J. - Non-neuroleptic approaches to treating negative symptoms in schizophrenia. Eur Arch Psychiatry Clin Neurosci 254: 108-116, 2004b.

MölleR, H.J. - Antidepressive effects of traditional and second generation antipsychotics: A review of the clinical data. Eur Arch Psychiatry Clin Neurosci 255: 83-96, 2005a.

MöLleR, H.J. - Occurrence and treatment of depressive comorbidity/cosyndromality in schizophrenic psychoses. World J Biol Psychiatry (no prelo), 2005b.

Möller, H.J.; Müller, H.; Borison, R.L.; Schooler, N.R.; Chouinard, G. - A pathanalytical approach to differentiate between direct and indirect drug effects on negative symptoms in schizophrenic patients. A re-evaluation of the North American risperidone study. Eur Arch Psychiatry Clin Neurosci 245: 45-49, 1995.

MölleR, H.J.; BoYeR, P.; FleURot, 0.; ReIn, W. - Improvement of acute exacerbations of schizophrenia with amisulpride: A comparison with haloperidol. Psychopharmacology 132: 396-401, 1997.

MölleR, H.J.; Riedel, M.; Müller, N.; Fischer, W.; Kohnen, R. - Zotepine versus placebo in the treatment of schizophrenic patients with stable primary negative symptoms: A randomized double-blind multic enter trial. Pharmacopsychiatry 37: 270-278, 2004.

Morera, A.L.; Barrelro, P.; Cano-Munoz, J.L. - Risperidone and clozapine combination for the treatment of refractory schizophrenia. Acta Psychiatr Scand 99: 305-306, 1999.

Morgenstern, H.; Glazer, W.M. - Identifying risk factors for tardive dyskinesia among long-term outpatients maintained with neuroleptic medication. Results of the Yale Tardive Dyskinesia Study. Arch Gen Psychiatry 50: 723-733, 1993.

Morinigo, A.; Martin, J.; Gonzalez, S.; Mateo, I. - Treatment of resistant schizophrenia with valproate and neuroleptic drugs. Hillside J Clin Psychiatry 11: 199-207, 1989

Morris, S.; Bagnall, A.; Cooper, S.J.; DeSilva, P.; Fenton, M.; Gammelin, G.O. et al. - Zotepine for schizophrenia (Cochrane Review). In: The Cochrane Library, Issue 2. John Wiley \& Sons Ltd., Chichester, 2004.

Mortimer, A.; Martin, S.; Loo, H.; Peuskens, J.; SOlianOl Study Group. - A double-blind, randomized comparative trial of amisulpride versus olanzapine for 6 months in the treatment of schizophrenia. Int Clin Psychopharmacol 19: 63-69, 2004.

Mota Neto, J.I.S.; Lima, M.S.; SoARES, B.G.O. - Amisulpride for schizophrenia (Cochrane Review). In: The Cochrane Library, Issue 2. Update Software, Oxford, 2003.

Mulholland, C.; Cooper, S. - The symptom of depression and its management. Adv Psychiatr Treatment 6: 169-177, 2000.

Mueser, K.T.; Yarnold, P.R.; Levinson, D.R.; Singh, H.; Bellack, A.S.; Kee, K. et al. - Prevalence of substance abuse in schizophrenia: Demographic and clinical correlates. Schizophr Bull 16: 31-56, 1990.

Mueser, K.T.; Noordsy, D.L.; Fox, L.; WolfE, R. - Disulfiram treatment for alcoholism in severe mental illness. Am J Addict 12 (3): 242-252, 2003.

Murray, C.J.; Lopez, A.D. - Global mortality, disability and the contribution of risk factors: Global Burden of Disease Study. Lancet 17 (349): 14361442, 1997. 
Myers, D.H.; Campbell, P.L.; Cocks, N.M.; Flowerdew, J.A.; Muir, A. - A trial of propranolol in chronic schizophrenia. Br J Psychiatry 139: 118-121, 1981.

National Institutes of Health Psychopharmacology Service Center Collaborative Study Group - Phenothiazine treatment in acut e schizophrenia. Arch Gen Psychiatry 10: 246-261, 1964.

National Institute for Clinical Excellence - Core Interventions in the Treatment of Schizophrenia. NICE, Londres (www.nice.org.uk), 2003.

National Institute for Clinical Excellence - Guidance on the use of newer (atypical) antipsychotic drugs for the treatment of schizophrenia. Technology Appraisal Guidance 43, Londres (www.nice.org.uk), 2002.

Noorbala, A.A.; Akhondzadeh, S.; Davari-Ashtiani, R.; Amini-Nooshabadi, H. - Piracetam in the treatment of schizophrenia: Implications for the glutamate hypothesis of schizophrenia. J Clin Pharm Ther 24 (5): 369-374, 1999.

NooRDSY, D.L.; O'KEEFE, C. - Effectiveness of combining atypical antipsychotics and psychosocial rehabilitation in a community mental health center setting. J Clin Psychiatry 60 (suppl. 19): 47-51, 1999.

Noordsy, D.L.; O'KeEFE, C.; MUeSeR, K.T.; XIE, H. - Six-month outcomes for patients who switched to olanzapine treatment. Psychiatr Serv 52: 501-507, 2001.

NoordSY, D.L.; GreEN, A.I. - Pharmacotherapy for schizophrenia and co-occuring substance use disorders. Curr Psychiatry Rep 5: 340-346, 2003.

Nordentoft, M.; Jeppesen, P.; Abel, M.; Kassow, P.; Petersen, L.; Thorup, A. et al. - OPUS study: Suicidal behaviour, suicidal ideation and hopelessness among patients with first-episode psychosis. One-year follow-up of a randomised controlled trial. Br J Psychiatry Suppl 43: s98-106, 2002.

Nuechterlein, K.H.; Dawson, M.E.; Ventura, J.; Gituln, M.; Subotnik, K.L.; Snyder, K.S. etal. - The vulnerability/stress model of schizophrenic relapse. Acta Psychiatr Scand Supp/382: 58-64, 1994.

Окимa, T.; Yamashita, I.; ТАKahashI, R.; ІтоH, H. - A doubleblind study of adjunctive carbamazepine versus placebo on excited states of schizophrenic and schizoaffective disorders. Acta Psychiatr Scand 80 (3): 250-259, 1989.

Olivera, A.A.; KIefer, M.W.; Manley, N.K. - Tardive dyskinesia in psychiatric patients with substance abuse. Am J Alcohol Abuse 16: 57-66, 1990.

Oosthuizen, P.; Emsley, R.A.; Turner, J.; Keyter, N. - Determining the optimal dose of haloperidol in first-episode psychosis. J Psychopharmacol 15 (4): 251-255, 2001

Oosthuizen, P.; Emsley, R.A.; Roberts, M.C.; Turner, J.; Keyter, L.; Keyter, N. et al. - Depressive symptoms at baseline predict fewer negative symptoms at follow-up in patients with first-episode schizophrenia. Schizophr Res 58: 247-252, 2002.

Oosthuizen, P.; Emsley, R.A.; Maritz, J.S.; Turner, J.A.; Keyter, N. - Incidence of tardive dyskinesia in first-episode psychosis patients treated with low-dose haloperidol. J Clin Psychiatry 64 (9): 1075-1080, 2003.

Oosthuizen, P.; Emsley, R.; Jadri Turner, H.; Keyter, N. - A randomized, controlled comparison of the efficacy and tolerability of low and high doses of haloperidol in the treatment of first-episode psychosis. Int J Neuropsychopharmaco/7 (2): 125-131, 2004.

Osser, D.N.; Sigadel, R. - Short-term inpatient pharmacotherapy of schizophrenia. Harv Rev Psychiatry 9: 89-104, 2001.

Pailliere-Martinot, M.L.; Lecrubier, Y.; Martinot, J.L.; Aubin, F. - Improvement of some schizophrenic deficit symptoms with low doses of amisulpride. Am J Psychiatry 152: 130-133, 1995.

Pato, C.N.; Wolkowitz, O.M.; Rapaport, M.; Schulz, S.C.; Pickar, D. - Benzodiazepine augmentation of neuroleptic treatment in patients with schizophrenia. Psychopharmacol Bull 25: 263-266, 1989.

Pelonero, A.L.; Levenson, J.L.; Pandurangi, A.K. - Neuroleptic malignant syndrome: a review. Psychiatr Serv 49: 1163-1172, 1998.

Perkins, D., Lieberman, J.; Gu, H.; Tohen, M.; McEvor, J.; Green, A. et al.; HGDH Research Group. - Predictors of antipsychotic treatment response in patients with first-episode schizophrenia, schizoaffective and schizophreniform disorders. Br J Psychiatry 185:18-24, 2004.

Petit, M.; Raniwalla, J.; Tweed, J.; Leutenegger, E.; Dollfus, S.; Kelly, F. - A comparison of an atypical and typical antipsychotic, zotepine versus haloperidol in patients with acute exacerbation of schizophrenia: A parallel-group double-blind trial. Psychopharmacol Bull 32: 81-87, 1996.
Petrides, G.; Divadeenam, K.M.; Bush, G.; Francis, A. - Synergism of lorazepam and electroconvulsive therapy in the treatment of catatonia. Biol Psychiatry 42: 375-381, 1997.

Peuskens, J.; Risperidone Study Group. - Risperidone in the treatment of patients with chronic schizophrenia: A multinational, multi-centre, double-blind, parallel-group study versus haloperidol. Br J Psychiatry 166: 712-726, 1995.

Peuskens, J.; LINK, C.G. - A comparison of quetiapine and chlorpromazine in the treatment of schizophrenia. Acta Psychiatr Scand 96: 265-273, 1997.

Peuskens, J.; Bech, P.; Möller, H.J.; Bale, R.; Fleurot, 0.; Rein, W. the Amisulpride Study Group. - Amisulpride versus risperidone in the treatment of acute exacerbations of schizophrenia. Psychiatr Res 88: 107-117, 1999.

Peuskens, J.; van Baelen, B.; de Smedt, C.; Lemmens, P. - Effects of risperidone on affective symptoms in patients with schizophrenia. Int Clin Psychopharmacol 15: 343-349, 2000.

Рiснот, P.; Boyer, P. - Controlled double-blind multi-centre trial of low dose amisulpride versus fluphenazine in the treatment of the negative syndrome of chronic schizophrenia. Ann Psychiatr 3 (3 bis): 312-320, 1988.

Pigott, T.A.; Carson, W.H.; Saha, A.R.; Torbeyns, A.F.; Stock, E.G.; Ingenito, G.G. -Aripiprazole for the prevention of relapse in stabilized patients with chronic schizophrenia: A placebocontrolled 26-week study. J Clin Psychiatry 64: 1048-1056, 2003.

Potkin, S.G.; Jin, Y.; Bunney, B.G.; Costa, J.; Gulasekaram, B. - Effect of clozapine and adjunctive high-dose glycine in treatment-resistant schizophrenia. Am J Psychiatry 156 (1): 145-147, 1999.

Potkin, S.G.; Saha, A.R.; Kujawa, M.J.; Carson, W.H.; Alı, M.; Stock, E. et al. - Aripiprazole, an antipsychotic with a novel mechanism of action, and risperidone vs placebo in patients with schizophrenia and schizoaffective disorder. Arch Gen Psychiatry 60: 681-690, 2003.

Potvin, S.; StIP, E.; Roy, J.Y. - Clozapine, quetiapine and olanzapine among addicted schizophrenic patients: Towards testable hypotheses. Int Clin Psychopharmacol 18: 121-132, 2003.

Poyurousky, M.; Bergman, J.; Weizman, A. - Risperidone in the treatment of catatonia in a schizophrenic patient. Isr J Psychiatry Relat Sci 34 (4): 323-324, 1997.

PrIOR, T.I.; BAKER, G.B. - Interactions between the cytochrome P450 system and the second-generation antipsychotics. J Psychiatry Neurosci 28: 99-112, 2003.

Procyshyn, R.M.; IhsAn, N.; Thompson, D. - A comparison of smoking behaviours between patients treated with clozapine and depot neuroleptics. Int Clin Psychopharmacol 16 (5): 291-294, 2001.

Procyshyn, R.M.; Tse, G.; Sin, 0.; Flynn, S. - Concomitant clozapine reduces smoking in patients treated with risperidone. Eur Neuropsychopharmacol 12 (1): 77-80, 2002.

Prudic, J.; Peyser, S.; SACKeim, H.A. - Subjective memory complaints: A review of patient self-assessment of memory after electroconvulsive therapy. J ECT 16: 121-132, 2000.

Puech, A.; Fleurot, 0.; Rein, W.; Amisulpride Study Group. - Amisulpride, an atypical antipsychotic, in the treatment of acute episodes of schizophrenia: A dose-ranging study versus haloperidol. Acta Psychiatr Scand 98: 65-72, 1998

Pugh, C.R.; Steinert, J.; Priest, R.G. - Propranolol in schizophrenia: A doubleblind, placebo-controlled trial of propranolol as an adjunct to neuroleptic medication. Br J Psychiatry 143: 151-155, 1983.

Purdon, S.E.; Jones, B.D.; Stip, E.; Labelle, A.; Addington, D.; David, S.R. et al. (Canadian Collaborative Group for Research in Schizophrenia). - Neuropsychological change in early phase schizophrenia during 12 months of treatment with olanzapine, risperidone, or haloperidol. Arch Gen Psychiatry 57: 249-258, 2000.

Purdon, S.E.; Malla, A.; Labelle, A.; Lit, W. - Neuropsychological change in patients with schizophrenia after treatment with quetiapine or haloperidol. J Psychiatry Neurosci 26: 137-149, 2001.

Rabinowitz, T.; Frankenburg, F.R.; Centorrino, F; Kando, J. - The effect of clozapine on saliva flow rate: a pilot study. Biol Psychiatry 40: 1132-1134, 1996.

Rabinowitz, J.; Hornik, T.; Davidson, M. - Rapid onset of therapeutic effect of risperidone versus haloperidol in a doubleblind randomized trial. J Clin Psychiatry 62: 343-346, 2001. 
Raggl, M.A.; Mandrioli, R.; Sabbioni, C.; Puccl, V. - Atypical antipsychotics: Pharmacokinetics, therapeutic drug monitoring and pharmacological interactions. Curr Med Chem 11: 279-296, 2004.

RASKIN, S.; DuRST, R.; KATZ, G.; ZISLIN, J. - Olanzapine and sulpiride: A preliminary study of combination/augmentation in patients with treatmentresistant schizophrenia. J Clin Psychopharmacol 20: 500-503, 2000.

Raskin, S.; Katz, G.; Zislin, Z.; Knobler, H.Y.; DuRSt, R. - Clozapine and risperidone: Combination/augmentation treatment of refractory schizophrenia: A preliminary observation. Acta Psychiatr Scand 101: 334-336, 2000.

Regier, D.A.; Farmer, M.E.; Rae, D.S.; Locke, B.Z.; Keith, S.J.; Judd, L.L. et al. - Comorbidity of mental disorders with alcohol and other drug abuse: Results form the Epidemiologic Catchment Area (ECA) Study. J Am Med Assoc 264: 2511-2518, 1990.

Remington, G.; Kapur, S.; Zipursky, B. - Pharmacotherapy of first-episode schizophrenia. Br J Psychiatry 172 (suppl. 33): 66-70, 1998.

Rey, J.M.; Walter, G. - Half a century of ECT use in young people. Am J Psychiatry 154 (5): 595-602, 1997.

REZNIK, I.; SIROTA, P. - An open study of fluvoxamine augmentation of neuroleptics in schizophrenia with obsessive and compulsive symptoms. Clin Neuropharmacol 23: 157-160, 2000.

Rice, E.H.; Sombrotto, L.B.; Markowitz, J.C.; Leon, A.C. - Cardiovascular morbidity in high-risk patients during ECT. Am J Psychiatry 151: 1637$1641,1994$.

Risch, S.C.; McGurk. S.; Horner, M.D.; Nahas, Z.; OWens, S.D.; Molloy, M. et al. - A double-blind placebo-controlled case study of the use of donepezil to improve cognition in a schizoaffective disorder patient: Functional MRI correlates. Neurocase 7: 105-110, 2001.

Robinson, D.G.; Woerner, M.G.; Alvir, J.M.; Geisler, S.; Koreen, A.; Sheitman, B. et al. - Predictors of treatment response from a first episode of schizophrenia or schizoaffective disorder. Am J Psychiatry 156: 544-549, 199a.

Robinson, D.G.; Woerner, M.G.; Alvir, J.M.; Bilder, R.; Goldman, R.; Geisler, S. et al. - Predictors of relapse following response from a first episode of schizophrenia or schizoaffective disorder. Arch Gen Psychiatry 56: 241-247, 1999b.

Rodriguez-Perez, V.; Lopez, A.; Blanco, C.; Pena C.; Lopez, A.; Abel, A. et al. - Olanzapine for the treatment of chronic refractory schizophrenia: $A$ 12-month follow-up naturalistic study. Prog Neuropsychopharmacol Biol Psychiatry 26: 1055-1062, 2002.

Rollnik, J.D.; Huber, T.J.; Mogk, H.; Siggelkow, S.; Kropp, S.; Dengler, R. et al. - High frequency repetitive transcranial magnetic stimulation (rTMS) of the dorsolateral prefrontal cortex in schizophrenic patients. Neuroreport 11: 4013-4015, 2000.

Rosebush, P.I.; Hildebrand, A.M.; Furlong, B.G.; Mazurek, M.F. - Catatonic syndrome in a general psychiatric inpatient population: Frequency, clinical presentation, and response to lorazepam. J Clin Psychiatry 51: 357-362, 1990.

Rosenheck, R.; Cramer, J.; Xu, W.; Thomas, J.; Henderson, W.; Frisman, L. et al. (Department of Veterans Affairs Cooperative Study Group on Clozapine in Refractory Schizophrenia). 1997. A comparison of clozapine and haloperidol in hospitalized patients with refractory schizophrenia. New Engl J Med 337: 809-815, 2000.

Rosenheck, R.; Evans, D.; Herz, L.; Cramer, J.; Xu, W.; Thomas, J. et al. - How long to wait for a response to clozapine: A comparison of time course of response to clozapine and conventional antipsychotic medication in refractory schizophrenia. Schizophr Bull 25: 709-719, 1999.

Royal Australian and New Zealand College of Psychiatrists (RANZCP) - Australian and New Zealand clinical practice guideline for the treatment of schizophrenia. Draft only, 2003.

Rüther, E.; Blanke, J. In: Helmchen, H.; Hippius, H.; Tölle, R. (eds.). Therapie mit Neuroleptika/Perazin. Thieme Verlag, Stuttgart, New York, pp. 65-70, 1998.

Rummel, C.; Hamann, J.; Kissung, W.; Leucht, S. - New generation antipsychotics for first-episode schizophrenia (Cochrane Review). In: The Cochrane Library, Issue 4, 2003.

Rupniak, N.M.; JenNeR, P.; MARSDEN, C.D. - Acute dystonia induced by neuroleptic drugs. Psychopharmacology (Berlin) 88: 403-419, 1986.

Rupp, A.; KeITH, S.J. - The costs of schizophrenia: Assessing the burden. Psychiatr Clin North Am 16: 413-423, 1993.
Rupprecht, R.; Soyka, M.; Grohmann, R.; Rüther, E.; Möller, H.J. - Considerations in the combination of clozapine and benzodiazepines. Nervenarzt 75: 857-860, 2004.

Ruskin, P.; Averbukh, I.; Belmaker, R.H.; Dasberg, H. - Benzodiazepines in chronic schizophrenia. Biol Psychiatry 14: 557-558, 1979.

Ryan, M.C.; Collins, P.; Thakore, J.H. - Impaired fasting glucose tolerance in first-episode, drug-naive patients with schizophrenia. Am J Psychiatry 160 (2): 284-289, 2003.

Saba, G.; Dumortier, G.; Kalalou, K.; Benadhira, R.; Degrassat, K.; Glikman, J. et al. - Lamotrigine-clozapine combination in refractory schizophrenia: Three cases. J Neuropsychiatry Clin Neurosci 14 (1): 86, 2002.

Sajatovic, M.; Meltzer, H.Y. - The effect of short-term electroconvulsive treatment plus neuroleptics in treatmentresistant schizophrenia and schizoaffective disorder. Convuls Ther 9: 167-175, 1993.

Salokangas, R.K.; Saarijarvi, S.; Taiminen, T.; Kallioniemi, H.; Lehto, H.; Niemi, H. et al. - Citalopram as an adjuvant in chronic schizophrenia: A double-blind placebo-controlled study. Acta Psychiatr Scand 94: 175-180, 1996.

Salzman, C.; Solomon, D.; Miyawaki, E.; Glassman, R.; Rood, L.; Flowers, E. Parenteral lorazepam versus parenteral haloperidol for the control of psychotic disruptive behavior. J Clin Psychiatry 52: 177-180, 1991.

Sanger, T.M.; Lieberman. J.A.; Tohen, M.; Grundy, S.; Beasley, C.; Tollefson, G.D. - Olanzapine versus haloperidol treatment in first-episode psychosis. Am J Psychiatry 156: 79-87, 1999.

Sartorius, N.; Fleischhacker, W.; Guerris, A.; Kern, U.; Knapp, M.; Leonhard, B.E. et al. - The usefulness and use of second-generation antipsychotic medications/an update: Curr Opin Psychiatry 15 (suppl. 1): S1-51, 2002.

SCheller-Gilkey, G.; Woolwine, B.J.; Cooper, I.; Olumuyiwa, G.; Moynes, K.A.; MILleR, A.H. - Relationship of clinical symptoms and substance use in schizophrenia patients on conventional versus atypical antipsychotics. Am J Drug Alcohol Abuse 29: 553-566, 2003.

Schilkrut, R.; Cabrera, J.; Morales, E.; Herrera, L. - Neuroleptics in the treatment of drug dependence in schizophrenics. A study with flupenthixol decanoate. Psychopharmacology 96 (suppl): 342 (abstract No. 33.01.50), 1988.

Schmidt, L.G.; Schüssler, G.; Kappes, C.V.; Müller-Oerlinghausen, B. - Vergleich einer höher dosierten Haloperidol-Therapie mit einer Perazin-Standard-Therapie bei akut schizophrenen Patienten. Nervenarzt 53 (9): 530-536, 1982.

Schmidt, A.W.; LeBeL, L.A.; Howard, H.R. JR.; Zorn, S.H. - Ziprasidone: A novel antipsychotic agent with a unique human receptor binding profile. Eur J Pharmacol 425: 197-201, 2001.

SCHUTZ, G.; BeRK, M. - Reboxetine add on therapy to haloperidol in the treatment of schizophrenia: A preliminary double-blind randomized placebocontrolled study. Int Clin Psychopharmacol 16 (5): 275-278, 2001.

Scottish Intercollegiate Gudelines Network - Psychosocial Interventions in the Management of Schizophrenia. Scottish Intercollegiate Gudelines Network (SIGN). SIGN Publication 30, 1998.

Sechter, D.; Peuskens, J.; Fleurot, 0.; Rein, W.; Lecrubier, Y. - Amisulpride vs. risperidone in chronic schizophrenia: Results of a 6-month double-blind study. Neuropsychopharmacology 27: 1071-1081, 2002.

Sedvall, G.; Farde, L. - Chemical brain anatomy in schizophrenia. Lancet 346 (8977): 743-749, 1995.

SeEman, MV. - Current outcome in schizophrenia: Women vs men. Acta Psychiatr Scand 73: 609-617, 1986.

Sharma, T. - Cognitive effects of conventional and atypical antipsychotic in schizophrenia. Br J Psychiatry 174 (suppl. 38): 44-51, 1999.

SheKelle, P.G.; Woolf, S.H.; Eccles, M.; GrimshaW, J. - Developing guidelines. Br Med J 318: 593-596, 1999.

Shiloh, R.; Zemishlany, Z.; Aizenberg, D.; Radwan, M.; Schwartz, B.; DorfmanEtrog, P. et al. - Sulpiride augmentation in people with schizophrenia partially responsive to clozapine. A double-blind, placebo-controlled study. British Journal of Psychiatry 171: 569-573, 1997.

Shopsin, B.; Klein, H.; Aaronsom, M.; Collora, M. - Clozapine, chlorpromazine, and placebo in newly hospitalized, acutely schizophrenic patients: A controlled, double-blind comparison. Arch Gen Psychiatry 36 (6): 657-664, 1979.

Simhandl, C.; Meszaros, K.; Denk, E.; Thau, K.; Topitz, A. - Adjunctive carbamazepine or lithium carbonate in therapyresistant chronic schizophrenia. Can J Psychiatry 41 (5): 317, 1996. 
Silver, H.; NASSAR, A. - Fluvoxamine improves negative symptoms in treated chronic schizophrenia: An add-on double-blind, placebo-controlled study. Biol Psychiatry 31: 698-704, 1992.

Silver, H.; Shmuglakov, N. - Augmentation with fluvoxamine but not maprotiline improves negative symptoms in treated schizophrenia: Evidence for a specific serotonergic effect from a double-blind study. J Clin Psychopharmacol 18: 208-211, 1998.

Silver, H.; Barash, I.; Aharon, N.; Kaplan, A.; Poyurovsky, M. - Fluvoxamine augmentation of antipsychotics improves negative symptoms in psychotic chronic schizophrenic patients: A placebo-controlled study. Int Clin Psychopharmacol 15: 257-261, 2000.

Silver, H.; Nassar, A.; Aharon, N.; Kaplan, A. - The onset and time course of response of negative symptoms to add-on fluvoxamine treatment. Int Clin Psychopharmacol 18:87/92, 2003.

SILver, H. - Selective serotonin reuptake inhibitor augmentation in the treatment of negative symptoms of schizophrenia. Int Clin Psychopharmacol 18: 305-313, 2003.

SIRIS, S.G. - Pharmacological treatment of substance-abusing schizophrenic patients. Schizophr Bull 16: 111-122, 1990.

Siris, S.G.; Bermanzohn, P.C.; Mason, S.E.; Shuwall, M.A. - Antidepressant for substance-abusing schizophrenic patients: A minireview. Prog Neuropsychopharmacol Biol Psychiat 15: 1-13, 1991.

Siris, S.G.; Mason, S.E.; Bermanzohn, P.C.; Shuwall, M.A.; Aseniero, M.A. - Dual diagnosis/psychiatric comorbidity of drug dependence: Epidemiology and treatment. Adjunctive imipramine in substance-abusing dysphoric schizophrenic patients. Psychopharmacol Bull 29: 127-133, 1993.

Siris, S.G.; Bermanzohn, P.C.; Mason, S.E.; Shuwall, M.A. - Maintenance imipramine therapy for secondary depression in schizophrenia: $A$ controlled trial. Arch Gen Psychiatry 51: 109-115, 1994.

SIRIS, S.G. - Depression in schizophrenia: perspective in the era of 'atypical' antipsychotic agents. Am J Psychiatry 157: 1379-1389, 2000.

Siris, S.; Pollack, S.; Bermanzohn, P.; Stronger, R. - Adjunctive imipramine for a broader group of post-psychotic depressions in schizophrenia. Schizophr Res 44: 187-192, 2000.

SIRIS, S.G. - Suicide and schizophrenia. J Psychopharmacol 15 (2): 127-135, 2001.

Small, J.G.; Kellams, J.J.; Milstein, V.; Moore, J. - A placebo controlled study of lithium combined with neuroleptics in chronic schizophrenic patients. Am J Psychiatry 132: 1315-1317, 1975.

Small, J.G.; Hirsch, S.R.; Arvanitis, L.A.; Miller, B.G.; Link, C.G. (Seroquel Study Group). Quetiapine in patients with schizophrenia: A high- and low-dose double-blind comparison with placebo. Arch Gen Psychiatry 54: 549-557, 1997.

Smelson, D.A.; Losonczy, M.F.; Davis, C.W.; Kaune, M.; Willams, J.; Ziedonis, D. - Risperidone decreases craving and relapses in individuals with schizophrenia and cocain dependence. Can J Psychiatry 47: 671-675, 2002.

Smith, R.C.; Infante, M.; Singh, A.; Khandat, A. - The effects of olanzapine on neurocognitive functioning in medication-refractory schizophrenia. Int J Neuropsychopharmacol 4: 239-250, 2001.

Soares, B.G.0.; Fenton, M.; Chue, P. - Sulpiride for schizophrenia (Cochrane Review). In: The Cochrane Library, Issue 2. John Wiley \& Sons Ltd., Chichester, 2004.

SoNI, S.D.; BAmRAH, J.S.; KRSKA, J. - Effects of alcohol on serum fluphenazine levels in stable chronic schizophrenics. Hum Psychopharmacol 6: 301306, 1991.

Soyka, M.; Albus, M.; Kathmann, N.; Finelli, A.; Hofstetter, S.; Holzbach, R. et al. - Prevalence of alcohol and drug abuse in schizophrenia inpatients. Eur Arch Psychiatry Clin Neurosci 242: 362-372, 1993.

SoYKA, M.; SAND, P. - Successful treatment with flupenthixol decanoate of a patient with both schizophrenia and alcoholism. Pharmacopsychiatry 28: 64-65, 1995.

Soyka, M. - Dual diagnosis in patients with schizophrenia. Issues in pharmacological treatment. CNS Drugs 5: 414-425, 1996.

Soyka, M.; Aichmüller, C.; von Bardeleben, U.; Beneke, M.; Glaser, T.; Hornung-Knobel, S. et al. on behalf of the study group. - Flupenthixol in relapse prevention in schizophrenics withcomorbid alcoholism: Results from an open clinical study. Eur Addict Res 9: 65-72, 2003.
Speller, J.C.; Barnes, T.R.E.; Curson, D.A.; Pantelis, C.; Alberts, J.L. - One-year, low-dose neuroleptic study of in-patients with chronic schizophrenia characterised by persistent negative symptoms: Amisulpride v. haloperidol. Br J Psychiatry 171: 564-568, 1997.

Spina, E.; De Domenico, P.; Ruello, C.; Longobardo, N.; Gitto, C.; Ancione, M. et al. - Adjunctive fluoxetine in the treatment of negative symptoms in chronic schizophrenic patients. Int Clin Psychopharmaco/ 9 (4): 281-285, 1994.

Spina, E.; Avenoso, A.; Facciola, G.; Scordo, M.G.; Ancione, M.; Madia, A.G. et al. - Relationship between plasma concentrations of clozapine and norclozapine and therapeutic response in patients with schizophrenia resistant to conventional neuroleptics. Psychopharmacology 148: 83-89, 2000.

Spina, E.; Scordo, M.G.; D'Arrigo, C. - Metabolic drug interactions with new psychotropic agents. Fund Clin Pharmacol 17: 517-538, 2003.

Steinert, T. - Prediction of inpatient violence. Acta Psychiatr Scand (Suppl) 104: 133-141, 2002.

Still, D.J.; Dorson, P.G.; Crismon, M.L.; Pousson, C. - Effects of switching inpatients with treatment-resistant schizophrenia from clozapine to risperidone. Psychiatr Serv 47: 1382-1384, 1996.

Stone, C.K.; Garve, D.L.; Griffith, J.; Hirschowitz, J.; Bennett, J. - Further evidence of a dose-response threshold for haloperidol in psychosis. Am J Psychiatry 152: 1210-1212, 1995.

Sultana, A.; McMonagle, T. - Pimozide for schizophrenia or related psychoses (Cochrane Review). In: The Cochrane Library, Issue 2. John Wiley \& Sons Ltd., Chichester, 2004.

Sultana, A.; Reilly, J.; Fenton, M. - Thioridazine for schizophrenia (Cochrane Review). In: The Cochrane Library, Issue 2. John Wiley \& Sons Ltd., Chichester, 2004

Suzuki, K.; Awata, S.; Matsuoka, H. - Short-term effect of ECT in middleaged and elderly patients with intractable catatonic schizophrenia. $J$ ECT 19: 73-80, 2003.

Taylor, C.G.; Flynn, S.W.; Altman, S.; Ehmann, T.; MacEwan, G.W.; Honer, W.G. - An open trial of risperidone augmentation of partial response to clozapine. Schizophr Res 48: 155-158, 2001.

Taylor, T.M.; O'Toole, M.S.; Ohlsen, R.I.; Walters, J.; Pilowsky, L.S. - Safety of quetiapine during pregnancy (letter). Am J Psychiatry 160: 588-589, 2003.

Tenyi, T.; Trixler, M.; Kereszetes, Z. - Quetiapine and pregnancy (letter). Am J Psychiatry 159: 674, 2002.

Tharyan, P.; Adams, C.E. - Electroconvulsive therapy for schizophrenia (Cochrane Review). In: The Cochrane Library, Issue 2. John Wiley \& Sons Ltd., Chichester, 2004.

The Scottish First Episode Schizophrenia Study. II. - Treatment: Pimozide versus flupenthixol. The Scottish Schizophrenia Research Group. Br J Psychiatry 150: 334-338, 1987.

Thornley, B.; Rathbone, J.; Adams, C.E.; Awad, G. - Chlorpromazine versus placebo for schizophrenia (Cochrane Review). In: The Cochrane Library, Issue 2. John Wiley \& Sons Ltd., Chichester, 2004.

Tiihonen, J.; Hallikainen, T.; Ryynänen, O.P.; Repo-Tiihonen, E.; Kotilainen, I.; Eronen, M. et al. - Lamotrigine in treatment-resistant schizophrenia: a randomized placebo-controled crossover trial. Biol Psychiatry 54: 1241-1248, 2003.

Tollefson, G.D.; Beasley CM Jr, Tran PV, Street JS, Krueger JA, Tamura RN et al. - Olanzapine versus haloperidol in the treatment of schizophrenia and schizoaffective and schizophreniform disorders: Results of an international collaborative trial. Am J Psychiatry 154: 457-465, 1997.

Tollefson, G.D.; Sanger, T.M. - Negative symptoms: A path analytic approach to a double-blind, placebo- and haloperidolcontrolled clinical trial with olanzapine. Am J Psychiatry 154: 466-474, 1997.

Tollefson, G.D.; Sanger, T.M.; Lu, Y.; Thieme, M.E. - Depressive signs and symptoms in schizophrenia: A prospective blinded trial of olanzapine and haloperidol. Arch Gen Psychiatry 55: 250-258, 1998.

Tollefson, G.D.; Birkett, M.A.; Kiesler, G.M.; Wood, A.J. - Doubleblind comparison of olanzapine versus clozapine in schizophrenic patients clinically eligible for treatment with clozapine. Biol Psychiatry 49: 52-63, 2001.

Tondo, L.; Ghiani, C.; Albert, M. - Pharmacologic interventions in suicide prevention. J Clin Psychiatry 62: 51-55, 2001. 
Tran, P.V.; Hamilton, S.H.; Kuntz, A.J.; Potvin, J.H.; Andersen, S.W.; Beasley, C. Jr. et al- Double-blind comparison of olanzapine versus risperidone in the treatment of schizophrenia and other psychotic disorders. Clin Psychopharmacol 17 (5): 407-418, 1997.

Tsai, G.; Yang, P.; Chung, L.C.; Lange, N.; Coyle, J.T. - D-Serine added to antipsychotics for the treatment of schizophrenia. Biol Psychiatry 44: 1081-1089, 1998.

Tsai, G.; Yang, P.; Chung, L.C.; Tsai, I.C.; Tsai, C.W.; Coyle, J.T. - D-Serine added to clozapine for the treatment of schizophrenia. Am J Psychiatry 156: 1822-1825, 1999.

Tsuang, J.; Eckman, T.E.; Shaner, A.; Marder, S.R. - Clozapine for substance-abusing schizophrenic patients. Am J Psychiatry 156: 1119-1120 (letter), 1999.

Tsuang, J.; Marder, S.R.; Han, A.; Hsieh, W. - Olanzapine treatment for patients with schizophrenia and cocaine abuse. J Clin Psychiatry 63: 1180-1181 (letter), 2002.

Tyson, S.C.; Devane, C.L.; Risch, S.C. - Pharmacokinetic interaction between risperidone and clozapine. Am J Psychiatry 152: 1401-1402, 1995.

Ungvari, G.S.; Leung, H.C.; Lee, T.S. - Benzodiazepines and the psychopathology of catatonia. Pharmacopsychiatry 27 (6): 242-245, 1994.

Ungvari, G.S.; Chiu, H.F.; Chow, L.Y.; Lau, B.S.; Tang, W.K. - Lorazepam for chronic catatonia: a randomized, double-blind, placebo-controlled cross-over study. Psychopharmacology (Berlin) 142 (4): 393-398, 1999.

Valevski, A.; Loebl, T.; Keren, T.; Bodinger, L.; Weizman, A. - Response of catatonia to risperidone: Two case reports. Clin Neuropharmacol 24 (4): 228-231, 2001.

Van Bruggen, J.; Tijssen, J.; Dingemans, P.; Gersons, B.; Linszen, D. Symptom response and side-effects of olanzapine and risperidone in young adults with recent onset schizophrenia. Int Clin Psychopharmacol 18: 341-346, 2003.

VanderZwaag, C.; McGee, M.; McEvoy, J.P.; Freudenreich, 0.; Wilson, W.H.; Cooper, T.B. - Response of patients with treatmentrefractory schizophrenia to clozapine within three serum level ranges. Am J Psychiatry 153: 1579-1584, 1996.

Van Putten, T.; Marder, S.R.; Mintz, J. - A controlled dose comparison of haloperidol in newly admitted schizophrenic patients. Arch Gen Psychiatry 47 (8): 754-758, 1990.

Van Putten, T.; Aravagiri, M.; Marder, S.R.; Wirshing, W.C.; Mintz, J.; Chabert, $\mathrm{N}$. - Plasma fluphenazine levels and clinical response in newly admitted schizophrenic patients. Psychopharmacol Bull 27 (2): 91-96, 1991.

Vartiainen, H.; Tiihonen, J.; Putkonen, A.; Koponen, H.; Virkkunen, M.; Hakola, P. et al. - Citalopram, a selective serotonin re-uptake inhibitor, in the treatment of aggression in schizophrenia. Acta Psychiatr Scand 91: 348-351, 1995.

Velligan, D.I.; Newcomer, J.; Pultz, J.; Csernansky, J.; Hoff, A.L.; Mahurin, R. et al. - Does cognitive function improve with quetiapine in comparison to haloperidol? Schizophr Res 53: 239-248, 2002.

Volavka, J.; Cooper, T.B.; Czobor, P.; Meisner, M. - Effect of varying haloperidol plasma levels on negative symptoms in schizophrenia and schizoaffective disorder. Psychopharmacol Bull 32: 75-79, 1996.

Volavka, J.; Cooper, T.B.; Czobor, P.; Lindenmayer, J.P.; Citrome, L.L.; Mohr, P.; Bark, N. - High-dose treatment with haloperidol: The effect of dose reduction. J Clin Psychopharmacol 20: 252-256, 2000.

Volavka, J.; Czobor, P.; Sheitman, B.; Lindenmayer, J.P.; Citrome, L.; McEvoy, J.P. et al. - Clozapine, olanzapine, risperidone, and haloperidol in the treatment of patients with chronic schizophrenia and schizoaffective disorder. Am J Psychiatry 159: 255-262, 2000.

Waehrens, J.; Gerlach, J. - Antidepressant drugs in anergic schizophrenia. Acta Psychiatr Scand 61: 438-444, 1980.

Wagstaff, A.; Perry, C. - Clozapine: In prevention of suicide in patients with schizophrenia or schizoaffective disorder. CNS Drugs 17: 273-280, 2003.

Wahlbeck, K.; Cheine, M.; Essali, A.; Adams, C. - Evidence of clozapine's effectiveness in schizophrenia: A systematic review and meta-analysis of randomized trials. Am J PSychiatry 156: 990-999, 1999.

Wahlbeck, K.; Cheine, M.; Tuisku, K.; AhokAs, A.; Joffe, G.; Rimon, R. - Risperidone versus clozapine in treatment-resistant schizophrenia: $A$ randomized pilot study. Prog Neuropsychopharmacol Biol Psychiatry 24: 911-922.
Walter, G.; Rey, J.M.; MitchelL, P.B. - Practitioner review: Electroconvulsive therapy in adolescents. J Child Psychol Psychiatry 40 (3): 325-334, 1999.

Waraich, P.S.; Adams, C.E.; Roque, M.; Hamill, K.M.; MartI, J. - Haloperidol dose for the acute phase of schizophrenia (Cochrane Review). In: The Cochrane Library, Issue 2. John Wiley \& Sons Ltd., Chichester, 2004.

Warner, B.; Alphs, L.; Schaedelin, J.; Koestler, T. - Clozapine and sudden death (letter). Lancet 355: 842, 2000.

Wassef, A.; Dott, S.G.; Harris, A.; Brown, A.; O’Boyle, M.; Meyer, W.J. $3^{\text {rd }}$. et al. - Randomized, placebo-controlled pilot study of divalproex sodium in the treatment of acute exacerbations of chronic schizophrenia. J Clin Psychopharmacol 20: 357-361, 2000.

WASSEF, A.; BAKER, J.; KoCHAN, L.D. - GABA and schizophrenia: A review of basis science and clinical studies. J Clin Psychopharmacol 23: 601-640, 2003b.

Weiden, P.J.; Simpson, G.M.; Potkin. G.; 0'Sulivan, R.L. - Effectiveness of switching to ziprasidone for stable but symptomatic outpatients with schizophrenia. J Clin Psychiatry 64: 580-588, 2003a.

WEISMAN, R.L. - Quetiapine in the successful treatment of schizophrenia with comorbid alcohol and drug dependence: A case report. Int J Psychiatry Med 33 (1): 85-89, 2003.

WeISS, E.M.; BILDER, R.M.; FLEISCHHACKER, W.W. - The effects of second-generation antipsychotics on cognitive functioning and psychosocial outcome in schizophrenia. Psychopharmacology (Berlin) 162 (1): 11-17, 2002.

Wetzel, H.; von Bardeleben, U.; Holsboer, F.; Benkert, 0. - Zotepine versus perazine in patients with paranoid schizophrenia: A double-blind controlled trial of its effectiveness. Fortschr Neurol Psychiat 59 (suppl. 1): 23-29, 1991.

Wetzel, H.; Gründer, G.; Hillert, A.; Philipp, M.; Gattaz, W.F.; Sauer, H. et al. and the Amisulpride Study Group. - Amisulpride versus flupentixol in schizophrenia with predominantly positive symptomatology/double-blind study comparing a selective D2-like antagonist to a mixed D1-/D2-like antagonist. Psychopharmacology 137: 223-232, 1998.

Whitehead, C.; Moss, S.; Cardno, A.; LeWIs, G. - Antidepressants for people with both schizophrenia and depression (Cochrane Review). In: The Cochrane Library, Issue 2. John Wiley \& Sons Ltd., Chichester, 2004.

Wiedemann, G.; KLingBerg, S. - Psychotherapie produktiver Symptomatik bei Patienten mit schizophrener Psychose. Nervenarzt 74: 76-84, 2003.

Wiesbeck, G.A.; WeiJers, H.G.; Lesch, O.M.; Glaser, T.; Toennes, P.J.; Boening, J. - Flupenthixol decanoate and relapse prevention in alcoholics: Results from a placebo-controlled study. Alcoho/36 (4): 329-334, 2001.

WILKINS, J.N. - Pharmacotherapy of schizophrenia patients with comorbid substance abuse. Schizophr Bull 23: 215-228, 1997.

Wirshing, D.A.; Marshall, B.D. JR.; Green, M.F.; Mintz, J.; Marder, S.R.; WiRSHING, W.C. - Risperidone in treatment-refractory schizophrenia. Am J Psychiatry 156: 1374-1379, 1999.

Wirshing, D.A.; Boyd, J.A.; Meng, L.R.; Ballon, J.S.; Marder, S.R.; Wirshing, W.C. - The effects of novel antipsychotics on glucose and lipid levels. $J$ Clin Psychiatry 63 (10): 856-865, 2002.

Wobrock, T.; FalKal, P.; PAJonk, F.G. - Acute treatment of schizophrenia. Fortschr Neurol Psychiatr 72: 705-726, 2004.

WoLKowITz, 0.M.; PICKAR, D. - Benzodiazepines in the treatment of schizophrenia: A review and reappraisal. Am J Psychiatry 148: 714-726, 1991.

Wolkowitz, O.M.; Turetsky, N.; Reus, V.I.; Hargreaves, W.A. - Benzodiazepine augmentation of neuroleptics in treatment resistant schizophrenia. Psychopharmacol Bull 28: 291-295, 1992.

Woods, S.W.; Stolar, M.; Sernyak, M.J.; Charney, D.S. - Consistency of atypical antipsychotic superiority to placebo in recent clinical trials. Biol Psychiatry 49 (1): 64-70, 2001.

World Health Organization - WhO Guide to Mental Health in Primary Care. London (www.royscomed.ac.uk), 2000.

Wright, P.; Birkett, M.; David, S.R.; Meehan, K.; Ferchland, I.; Alaka, K.J. et al. - Double-blind, placebo-controlled comparison of intramuscular olanzapine and intramuscular haloperidol in the treatment of acute agitation in schizophrenia. Am J Psychiatry 158 (7): 1149-1151, 2001.

Yap, H.L.; Mahendran, R.; Lim, D.; Liow, P.H.; Lee, A.; Phang, S. et al. - Risperidone in the treatment of first episode psychosis. Singapore Med J 42 (4): 170-173, 2001. 
Yorkston, N.J.; Gruzeller, J.H.; Zaki, S.A.; Hollander, D.; Pitcher, D.R.; Sergeant, H.G. Propranolol as an adjunct to the treatment of schizophrenia. Lancet ii: 575-578, 1977.

YoveLL, Y.; OpLER, L.A. - Clozapine reverses cocaine craving in a treatmentresistant mentally ill chemical abuser: A case report and a hypothesis. J Nerv Ment Dis 182: 591-592 (letter), 1994.

Zemlan, F.P.; Hirschowitz, J.; Sautter, F.; Garver, D.L. - Relationship of psychotic symptom clusters in schizophrenia to neuroleptic treatment and growth hormone response to apomorphine. Psychiatry Res 18 (3): 239-255, 1986.

Zhang, X.Y.; Zhou, D.F.; Cao, L.Y.; Zhang, P.Y.; Wu, G.Y.; Shen, Y.C. - Risperidone versus haloperidol in the treatment of acute exacerbations of chronic inpatients with schizophrenia: A randomized double-blind study. Int Clin Psychopharmacol 16: 325-330, 2001.

Ziedonis, D.M.; Richardoson, T.; Lee, E.; Petrakis, l.; Kosten, T.R. - Adjunctive desipramine in the treatment of cocaine abusing schizophrenics. Psychopharmacol Bull 28: 309-314,1992.

Zimmet, S.; Strous, R.D.; Burgess, E.; Kohnstamm, S.; Green, A.I. - Effects of clozapine on substance use in patients with schizophrenia and schizoaffective disorder. J Clin Psychopharmacol 20: 94-98, 2000.

Zoccali, R.; Muscatello, M.R.; Cedro, C.; Neri, P.; La Torre, D.; Spina, E. et al. - The effect of mirtazapine augmentation of clozapine in the treatment of negative symptoms of schizophrenia: A double-blind, placebo-controlled study. Int Clin Psychopharmacol 19: 71-76, 2004. 